\title{
Regulation of rat Liver Glucokinase Gene Expression by \\ Sterol Regulatory Element Binding Protein-1a and Forkhead box Class 01 Transcription factors
}

\section{Dissertation}

Zur Erlangung des Doktorgrades

der Mathematisch-Naturwissenschaftlichen Fakultäten der Georg-August-Universität zu Göttingen

Vorgelegt von

Goutham Kumar Ganjam

aus Uppugundur, Indien

Göttingen 2007 
D 7

Referent:

Prof. Dr. R. Hardeland

Korreferent:

Prof. Dr. D. Doenecke

Tag der mündlichen Prüfung: 
to my sister 
INDEX

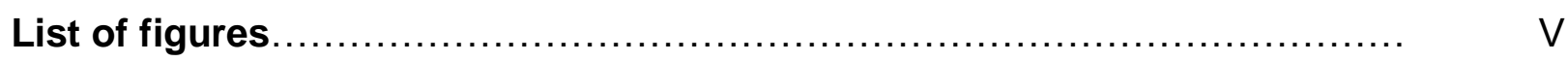

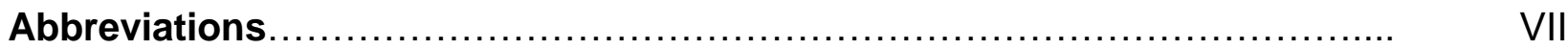

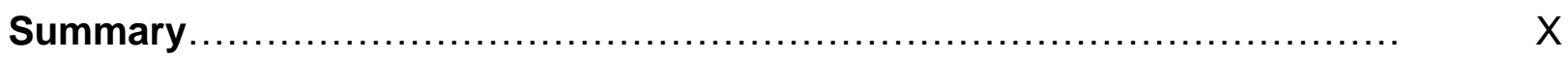

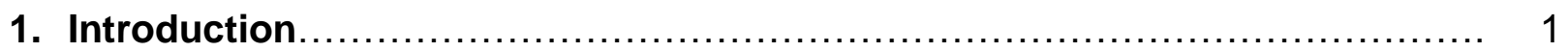

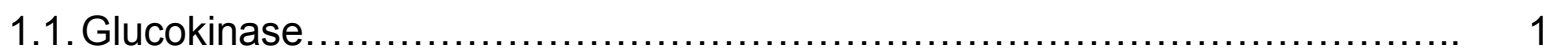

1.1.1. Glucose homeostasis............................................ 1

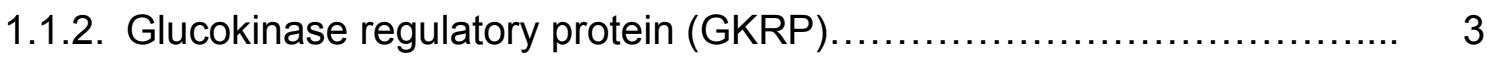

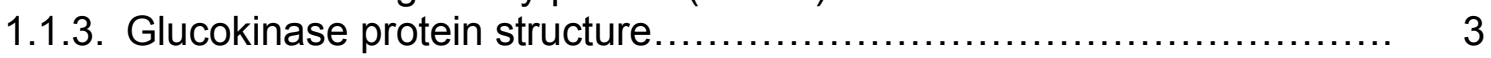

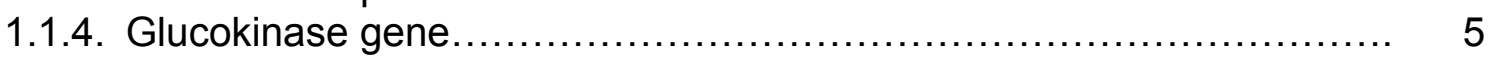

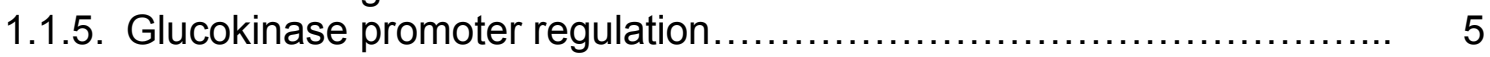

1.2. Sterol regulatory element binding proteins (SREBPs) $\ldots \ldots \ldots \ldots \ldots \ldots \ldots \ldots \ldots \ldots \ldots \ldots \ldots \ldots \ldots \ldots$

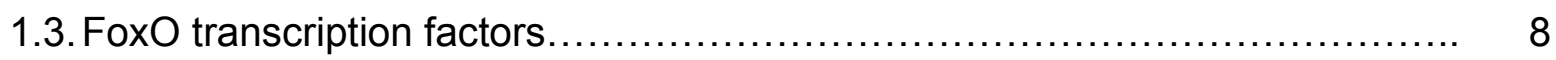

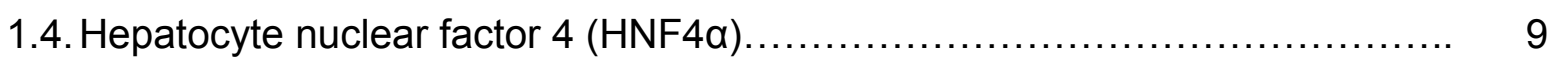

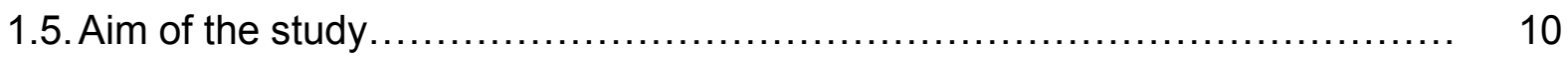

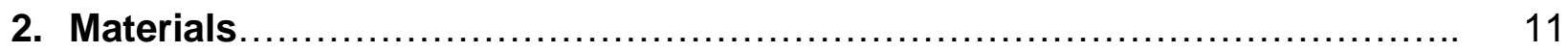

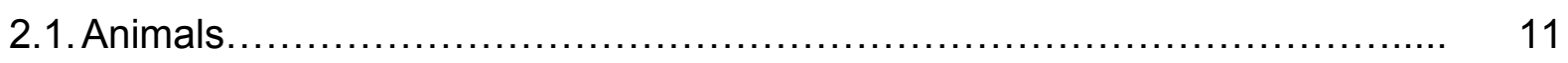

2.2. Bacterial strains, vectors and plasmid constructs........................ 11

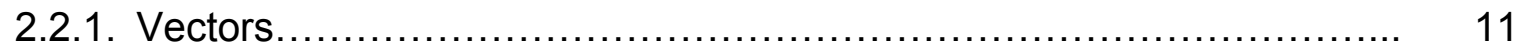

2.2.1.1. pBluescript-KS II vector.................................... 11

2.2.1.2. $\mathrm{pTZ57R/T}$ (T/A cloning vector to clone PCR fragments)........... 11

2.2.1.3. pGL3-Basic and pGL3-Promoter vectors....................... 13

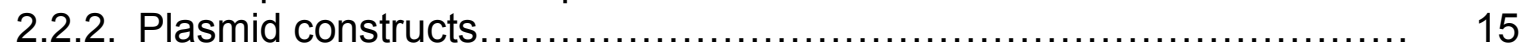

2.2.2.1. Reporter gene plasmid constructs............................ 15

2.2.2.1.1. Glucokinase promoter pGL3-Basic constructs.............. 15

2.2.2.1.2. pGL3-Promoter constructs........................... 18

2.2.2.2. Expression Plasmids..................................... 19

2.3. Oligonucleotides................................................... 20

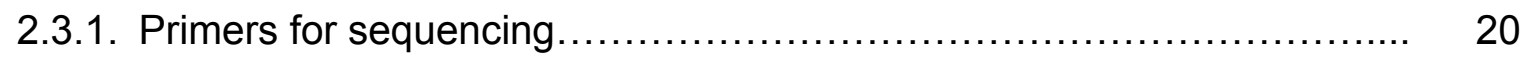

2.3.2. Oligonucleotides for PCR reaction.................................... 20

2.3.3. Primers used for site directed mutagenesis.......................... 21

2.3.4. Oligonucleotides used for $p G L 3-S R E$ and SRE/SP construction.......... 22

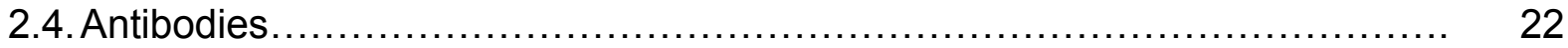




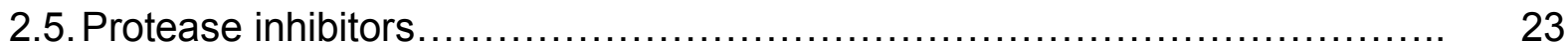

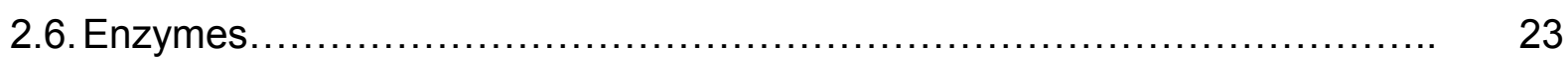

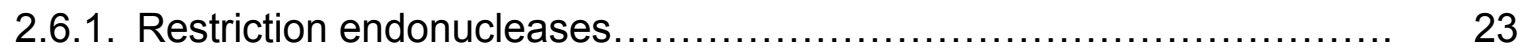

2.6.2. DNA and RNA modifying enzymes.................................... 23

2.6.3. Enzymes used in glucokinase enzyme activity assays.................. 23

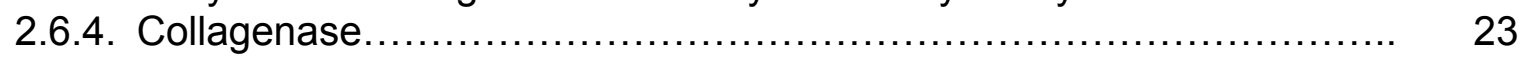

2.6.5. Lysozyme..................................................... 24

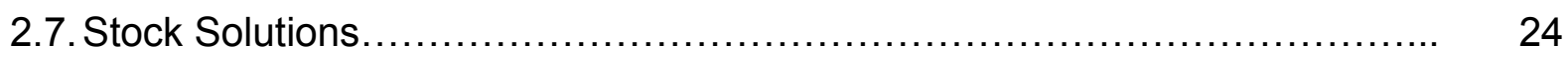

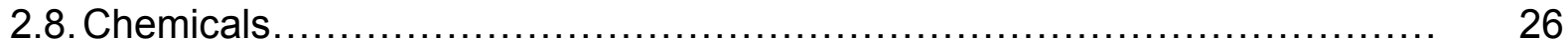

2.9. Detection, purification and synthesis kits............................. 29

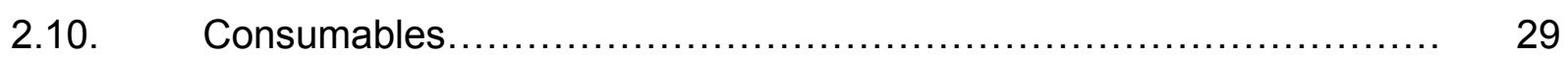

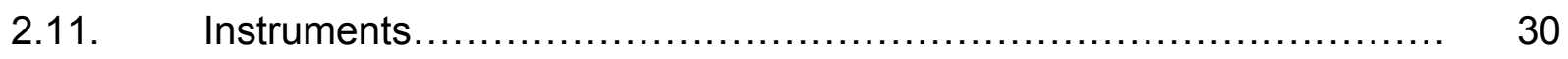

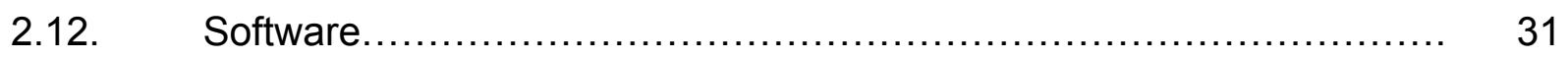

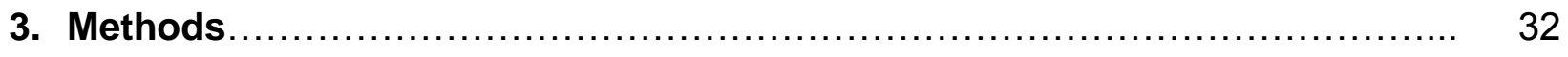

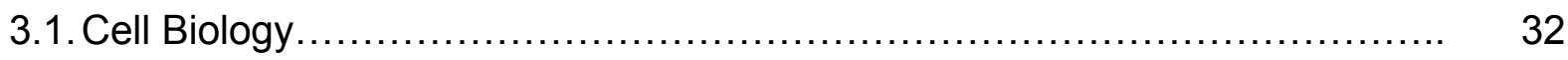

3.1.1. Isolation of primary rat hepatocytes............................. 32

3.1.1.1. Liver perfusion............................................. 32

3.1.1.2. Preparation of the hepatocyte suspension.................... 34

3.1.1.3. Culture of primary rat hepatocytes............................. 34

3.1.1.4. Hormone and antibiotic stock solutions........................ 35

3.1.2. Transfection of hepatocytes, HepG2 and HEK293-T cells.............. 35

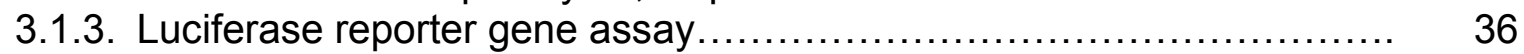

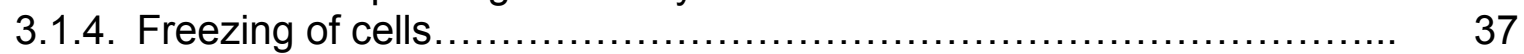

3.1.5. Treatment of hepatocytes with different compounds ..................... 38

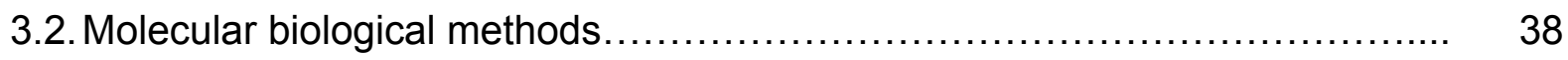

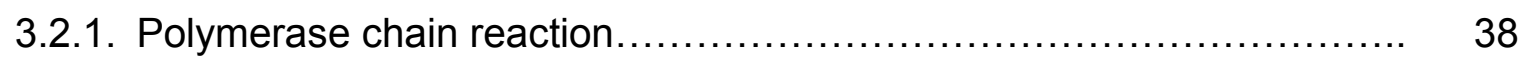

3.2.1.1. Purification of PCR products................................. 39

3.2.1.2. Cloning of PCR fragments into (pTZ57R/T) the T/A cloning Vector.

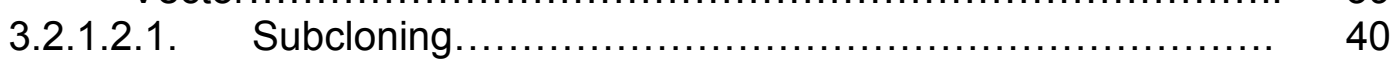

3.2.1.2.2. Dephosphorylation of linearized vector.................. 40

3.2.2. In vitro site-specific mutagenesis....................................... 40

3.2.3. Synthetic double stranded oligonucleotide cloning into pGL3 promoter

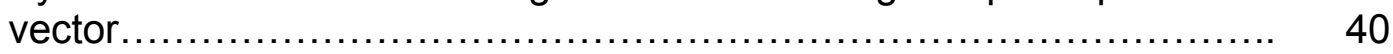

3.2.4. E.coli competent cell preparation .................................... 43 
3.2.5. Transformation of competent E.coli cells.............................. 43

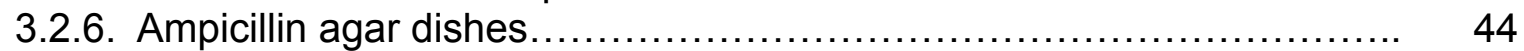

3.2.7. Isolation of plasmid DNA (mini preparation) ........................ 44

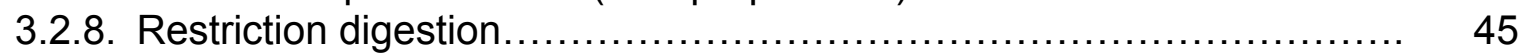

3.2.9. Isolation of plasmid DNA in large scale (Maxipreparation) .............. 46

3.2.10. Estimation of nucleic acid concentration........................ 46

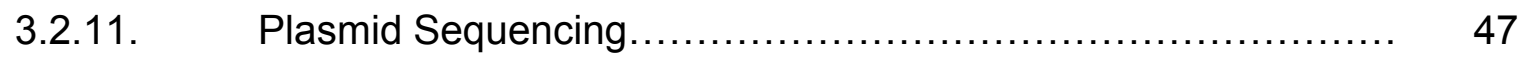

3.2.12. Preparation of digoxigenin-labeled RNA probes................. 48

3.2.13. Isolation of RNA from primary rat hepatocytes.................. 49

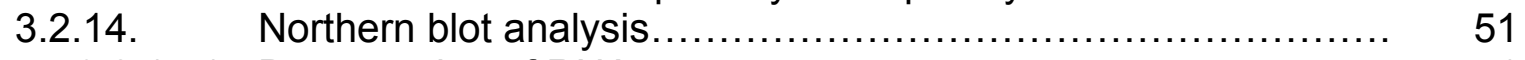

3.2.14.1. Denaturation of RNA .................................... 51

3.2.14.2. Denaturing agarose gel electrophoresis of RNA ............... 52

3.2.14.3. RNA blotting onto nylon membrane......................... 53

3.2.14.4. Hybridization of RNA with digoxigenin-labeled RNA probes..... 53

3.2.14.5. Detection and quantification................................ 54

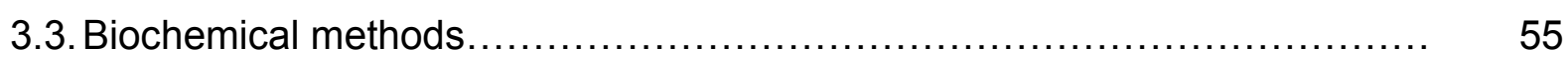

3.3.1. Total protein isolation from the cultured cells...................... 55

3.3.2. Estimation of protein concentration................................ 56

3.3.3. Western blot analysis (Immunoblotting).......................... 56

$\begin{array}{ll}\text { 3.3.3.1. } & \text { SDS-polyacrylamide gel electrophoresis of protein } \\ & \text { (SDS-PAGE) } \ldots \ldots \ldots \ldots \ldots \ldots \ldots \ldots \ldots \ldots \ldots \ldots \ldots \ldots \ldots \ldots \ldots \ldots \ldots \ldots \ldots \ldots \ldots \ldots \ldots \ldots \ldots \ldots \ldots \ldots \ldots \ldots \ldots \ldots\end{array}$

3.3.3.2. Electroblotting of immobilized proteins...................... 57

3.3.3.3. Immunological detection of proteins with specific antibodies.. 58

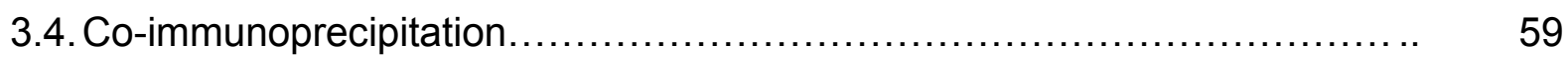

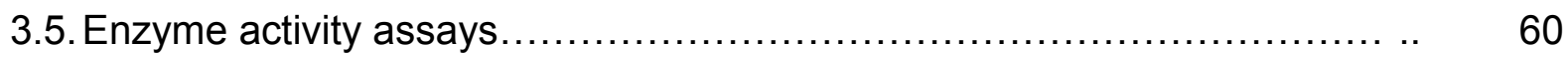

4. Results.

4.1. Regulation of glucokinase gene expression by sterol regulatory element binding protein-1 (SREBP-1).

4.1.1. Regulation of rat GK promoter deletion constructs by SREBP-1a.... 63

4.1.2. Mutation in the putative SRE-2 site abrogates the rat GK promoter activity

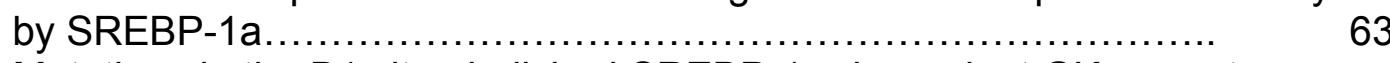

4.1.3. Mutations in the B1 site abolished SREBP-1a-dependent GK promoter

4.1.4. Reduction of SREBP-1a-dependent GK promoter activity by mutation of the HRE and HNF4 binding element.

4.1.5. Induction of the FAS SRE enhancer Luc gene constructs by SREBP-1a

4.1.6. Regulation of rat glucokinase gene expression by insulin, the LXR ligand TO-901317 and by overexpression of SREBP-1a in primary rat Hepatocytes. 
Factors

4.2.1. Loss of FoxO1-mediated suppression of GK promoter activity by mutating the FBE $b$ site.

4.2.2. Mutation in the HNF4 binding site leads to loss of FoxO1-mediated repression activity of GK promoter.

4.2.3. Regulation of glucokinase mRNA levels by insulin, glucagon and CAMP...

4.2.4. Modulation of rat liver glucokinase promoter by resveratrol.............

4.2.5. In-vivo binding of FoxO1 with HNF4 in HEK293T cells.

4.2.6. Modulation of FoxO1-mediated repression of the GK promoter by insulin.

4.2.7. Resveratrol inhibits insulin-induced glucokinase mRNA and protein levels.

4.2.8. Down regulation of glucokinase gene expression by FoxO1 and SIRT1 overexpression.

4.2.9. Resveratrol deacetylated p300-dependent acetylated FoxO1........ 79

4.2.10. Repression of glucokinase enzyme activity by resveratrol and FoxO1 in primary rat hepatocytes.

5. Discussion

5.1. Regulation of glucokinase expression by insulin and SREBP-1a.

5.2. Regulation of glucokinase promoter activity by SREBP-1a.

5.2.1. The B site in the GK promoter is important for the SREBP-1a-mediated Induction.

5.2.2. The SRE2 and SRE3 elements are important for the SREBP-1a-mediated induction of the GK promoter.

5.2.3. Co-operativity of HNF-4 and SREBP-1a is important for the regulation of the GK promoter.

5.3. Down regulation of glucokinase gene expression by the transcription

factor FoxO1....

5.3.1. Expression of glucokinase during fasting and refeeding

5.3.2. Effects of resveratrol on glucokinase gene expression.

5.3.3. Deacetylation of FoxO1 by resveratrol.

5.3.4. Modulation of glucokinase enzyme activity by resveratrol and FoxO1

6. References.

7. Acknowledgements.

8. Publications and Conferences

9. Biography 


\section{List of Figures}

Figure 1. Role of glucokinase in glucose homeostastis and the interplay between pancreatic $\beta$-cells and hepatocytes.

Figure 2. Model of the two glucokinase reaction cycles

Figure 3. Insulin signalling and SREBP activation pathways

Figure 4. Activation and inactivation of FoxO mediated gene expression

Figure 5. The vector pBluescript vector (pBS-KS II)

Figure $6 . \quad$ The $\mathrm{pTZ57R/T}$ vector

Figure 7. Structure of the pGL3-Basic vector

Figure 8. Structure of the pGL3-Promoter vector

Figure 9. Rat glucokinase promoter deletion constructs

Figure 10. Rat glucokinase promoter mutation constructs

Figure 11. Rat glucokinase promoter mutation constructs

Figure 12. Luciferase gene constructs with oligonucleotides carrying SREBP1 and SP1 responsive elements from fatty acid synthase promoter as enhancers

Figure 13. Activation of serially deleted GK promoter-Luc constructs by SREBP-1a in HepG2 cells and primary rat hepatocytes

Figure 14. Activation of SRE mutated GK promoter-Luc constructs by SREBP-1a

Figure 15. Regulation of Footprint B and E-box mutated GK promoter-Luc constructs by SREBP-1a

Figure 16. Regulation of HNF4 and HRE mutated GK promoter-Luc constructs by SREBP$1 \mathrm{a}$

Figure 17. Activation of FAS SRE enhancer Luc gene constructs by SREBP-1a

Figure 18. Regulation of GK and SREBP mRNA expression levels by insulin and TO-901317 or by overexpression of SREBP in primary rat hepatocytes

Figure 19. Mutations in the putative FoxO binding elements lead to loss of FoxO1-mediated repression of GK promoter Luc constructs

Figure 20. Mutation of the HNF4 binding element leads to loss of FoxO-1-mediated repression of GK promoter Luc constructs

Figure 21. Insulin and glucagon/CAMP act antagonistic on GK and PEPCK transcription and regulation of GK during fasting and refeeding

Figure 22. Mutations in the FoxO binding elements lead to loss of resveratrol mediated repression of GK promoter Luc constructs 
Figure 23. Interaction of FoxO1 with HNF4 in HEK293T cells

Figure 24. Insulin abolished the FoxO1-mediated repression of GK promoter Luc constructs

Figure 25. Regulation of GK and PEPCK gene expression by insulin and resveratrol in primary rat hepatocytes

Figure 26. Regulation of GK and PEPCK gene expression by FoxO1 and SIRT1 in primary rat hepatocytes

Figure 27. Resveratrol deacetylates p300 acetylated FoxO1

Figure 28. Regulation of glucokinase enzyme activity by resveratrol and FoxO1 in primary rat hepatocytes

Figure 29. Insulin-dependent SREBP-1a-mediated regulation of glucokinase gene expression

Figure 30. Regulation of glucokinase and PEPCK gene expression by FoxO1 


\begin{tabular}{|c|c|}
\hline AA & $\operatorname{aminoacid}(\mathrm{s})$ \\
\hline acetyl-CoA & acetyle-CoenzymeA \\
\hline ADP & Adenosine diphosphate \\
\hline Akt & PKB, homologue of v-Akt \\
\hline Amp & Ampicillin \\
\hline $\begin{array}{l}\text { Ampr } \\
\text { approx. }\end{array}$ & $\begin{array}{l}\text { Ampicillin resistance } \\
\text { approximately }\end{array}$ \\
\hline APS & Ammonium persulfate \\
\hline ATP & Adenosine triphosphate \\
\hline$\beta-G a l$ & $\beta$-galactosidase \\
\hline$\beta-M E$ & $\beta$-mercaptoethanol \\
\hline $\mathrm{bHLH}$ & Basic helix-loop-helix \\
\hline bHLH-zip & basic helix-loop-helix leucine-zipper \\
\hline $\mathrm{bp}$ & basepairs \\
\hline BSA & Bovine serum albumin \\
\hline $\mathrm{Ca}^{2+}$ & Calcium \\
\hline cAMP & Cyclic adenosine monophosphate \\
\hline cDNA & complementary DNA \\
\hline CK1 & casein kinase 1 \\
\hline CREB & cAMP-response element-binding protein \\
\hline CSPD & $\begin{array}{l}\text { Dinatrium 3-(4-methoxyspiro }\left\{1,2 \text {-dioxetane-3, } 2-\left(5^{\prime} \text {-chloro }\right) \text { tricycle }\right. \\
[3.3 .1 .13,7] \text { decan }\}-4-y l) \text {-phenylphosphate }\end{array}$ \\
\hline C-terminus & Carboxyl-terminus \\
\hline DEPC & Diethylpyrocarbonate \\
\hline DIG & Digoxigenin \\
\hline DMSO & Dimethylsulfoxide \\
\hline DNA & Deoxyribonucleic acid \\
\hline DNase & Deoxyribonuclease \\
\hline dNTPs & Deoxynucleotide-5'-triphosphates \\
\hline dsDNA & Double-stranded DNA \\
\hline DTT & Dithiothreitol \\
\hline DUSP12 & Dual specific phosphatase \\
\hline E. coli & Escherichia coli \\
\hline $\mathrm{ECL}^{+}$ & Enhanced Chemiluminescence ${ }^{\mathrm{TM}}+$ kit \\
\hline EDTA & Ethylenediaminotetraacetate \\
\hline EMSA & Electrophoretic Mobility Shift Assay \\
\hline ERK & Extracellular signal-regulated kinase \\
\hline $\mathrm{EtBr}$ & Ethidium bromide \\
\hline $\mathrm{EtOH}$ & Ethanol \\
\hline FAS & Fatty acid synthase \\
\hline FBE & FoxO binding element \\
\hline FCS & Fetal calf serum \\
\hline FoxO & Forkhead transcription factor \\
\hline G6P & Glucose-6-phosphate \\
\hline
\end{tabular}




\begin{tabular}{|c|c|}
\hline G6PDH & glucose 6-phosphate dehydrogenase \\
\hline 6PDGH & 6-phosphogluconate dehydrogenase \\
\hline GK & Glucokinase \\
\hline GKRP & Glucokinase regulatory protein \\
\hline GLUT & Glucose transporter \\
\hline GTP & Guanosine-5'-triphosphate \\
\hline $\mathrm{HC}$ & Hepatocytes \\
\hline HEK & Human Embryonic Kidney cell line \\
\hline Hepes & N-[2-hydroxyethyl]-piperazine-N'-[2-ethanesulfonic acid] \\
\hline HIF-1 & Hypoxia-inducible factor-1 \\
\hline HNF-4 & Hepatocyte nuclear factor- 4 \\
\hline HRE & Hypoxia responsive element \\
\hline HRP & Horseradish peroxidase \\
\hline Ins & Insulin \\
\hline Kan & Kanamycine \\
\hline $\mathrm{Kan}^{\mathrm{r}}$ & Kanamycine resistance \\
\hline $\mathrm{K}_{\mathrm{M}}$ & Michaelis Menten constant \\
\hline lacZ & $\beta$-galactosidase gene \\
\hline $\mathrm{LiCl}$ & Lithium Chloride \\
\hline LB & Luria-Bertani medium \\
\hline Luc & Luciferase \\
\hline LZ & Leucine zipper \\
\hline NES & Nuclear export signal \\
\hline MAPK & Mitogen-activated protein kinase \\
\hline MCS & Multiple cloning site \\
\hline MODY-1 & maturity-onset diabetes of the young type- 1 \\
\hline MOPS & 3-[N-morpholino]-propansulfonic acid \\
\hline mRNA & messenger ribonucleic acid \\
\hline MW & molecular weight \\
\hline NAD & Nicotinamide Adenine Dinucleotide \\
\hline $\mathrm{NADP}^{+}$ & nicotinamide adenine dinucleotide phosphate, oxidized form \\
\hline NADPH & nicotinamide adenine dinucleotide phosphate \\
\hline NOS & Nitric oxide synthase \\
\hline N-terminus & Amino-terminus \\
\hline OD & Optical density \\
\hline $\mathrm{o} / \mathrm{n}$ & overnight \\
\hline PCR & Polymerase chain reaction \\
\hline PCV & Packed cell volume \\
\hline PEG & Polyethyleneglycol \\
\hline PEPCK & Phosphoenolpyruvate kinase \\
\hline $\mathrm{PI}(3) \mathrm{K}$ & Phosphatidylinositol-3-kinase \\
\hline $\mathrm{PI}(4,5) \mathrm{P} 2$ & Phosphatidyl-inositol-4,5-biphosphate \\
\hline PKB & Protein kinase $B$ \\
\hline PMSF & Phenylmethylsulfonylfluoride \\
\hline
\end{tabular}




\begin{tabular}{ll} 
polyA & Polyadenylation signal \\
PVDF & Polyvinylendifluoride \\
RNA & Ribonucleic acid \\
RNase A & Ribonuclease A \\
rpm & rotations per minute \\
RT & Room temperature \\
S1P & site-1 serine protease \\
S2P & site-2 metallo protease \\
SAP & Shrimp alkaline phosphatase \\
SCAP & SREBP cleavage activating protein \\
SDS & Sodium dodecylsulfate \\
SDS-PAGE & Denaturing SDS-polyacrylamide electrophoresis \\
SEM & Standard error of the mean \\
SGK & serum and glucocorticoid-regulated kinase \\
SIRT1 & Sirtuin1 \\
SREBP-1a & Sterol regulatory element binding protein-1a \\
SRE & SREBP responsive element \\
SSC & Standard saline citrate buffer \\
SSDNA & Single-stranded DNA \\
TAD & Transactivation domain \\
TAE & Tris-acetate-EDTA buffer \\
Tann & Annealing temperature \\
Taq & Thermophylus aquaticus \\
TBE & Tris-borate-EDTA buffer \\
TdT & deoxynucleotidyl transferase \\
TEMED & N,N,N',N'-tetramethylethylenediamine \\
T4-PNK & T4 polynucleotide kinase \\
Tris & Tris-(hydroxymethyl)-aminomethane \\
U & Unit (enzyme activity) \\
USF & Upstream stimulatory factor \\
5 '-UTR & 5'-untranslated region \\
UV & Ultraviolet light \\
V max & maximal velocity \\
Vol & volume \\
\% (v/v) & volume \% (volume-per-volume) \\
wt & Wild-type \\
\% (w/v) & \\
& Weight (weight-per-volume) \\
\hline ST &
\end{tabular}




\section{Summary}

Glucokinase (GK) also known as hexokinase IV catalyzes phosphorylation of glucose to glucose-6-phosphate. In contrast to other hexokinases, GK has a low affinity for glucose, is not inhibited by its reaction product and, although existing as monomer, displays sigmoidal kinetics. Defects in the GK gene lead to maturity-onset diabetes of the young type 2 (non-insulindependent [MODY-2]). Thus, GK plays an important role for maintenance of glucose homeostasis. GK is predominantly expressed in hepatocytes of the liver, pancreatic $\beta$-cells and some neuroendocrine cells of the gastrointestinal tract and the brain. Insulin and glucagon are the major hormones regulating expression of GK in hepatocytes. Thereby, insulin acts mainly via the PI3K/PKB pathway and modulates the activity of several transcription factors such as sterol regulatory element binding protein-1 (SREBP-1) and FoxO/forkhead transcription factors (FoxO). Recent reports from cell culture experiments and transgenic mice indicated that both SREBP-1 and FoxO1 may act in an antagonistic fashion on GK expression and thus on hepatic glucose/lipid metabolism. However, the complete details of the SREBP-1 and FoxO1 regulated GK gene expression are not yet known.

Therefore, it was the aim of this study to investigate, the insulin-dependent SREBP-1- and FoxO1-mediated GK gene expression at the molecular level in primary rat hepatocytes and HepG2 hepatoma cells. Stimulation of primary hepatocytes with insulin induced GK and SREBP1 expression. Similarly SREBP could be induced by treatment with the LXR agonist TO901317 which in turn induced GK mRNA levels. Likewise, overexpression of SREBP-1 in hepatocytes induced GK mRNA levels. Computer analysis of the liver-specific GK promoter revealed three putative SREBP-1 binding sites (SREs). Transfection experiments in hepatocytes and HepG2 cells with luciferase gene constructs driven by serially deleted GK promoter fragments indicated that a sequence known as the footprint $B$ site is critically involved in SREBP-1-dependent regulation. Further analysis of the footprint $B$ site which could be divided in part 1 and part 2 showed that part 2 rather than part 1 is necessary for the SREBP-1 effect. In addition, two other sequences termed SRE2 and SRE3 were identified by mutation analyses of GK promoter. Interestingly, transfection data in primary hepatocytes and HepG2 cells implicated that these elements are utilized in a cell-specific manner. While both SRE2 and SRE3 are important for the SREBP-1-mediated GK promoter activity in primary hepatocytes, only SRE2 contributed to the SREBP-1 effect in HepG2 cells. Moreover, the SREBP-1-mediated activation of the GK promoter was lost upon mutation of the HNF-4 binding element indicating that full induction of GK gene expression by SREBP-1 requires interaction of these transcription factors. 
Insulin has a dynamic effect on FoxO transcription factors which are mediated by PKBdependent phosphorylation which lead to inactive FoxO by nuclear exclusion. Hepatocytes transfected with FoxO1 expression vectors down regulated GK mRNA and GK promoter activity and the repression was lost when hepatocytes were stimulated with insulin. When rats were fasted for $48 \mathrm{~h}$ the GK protein levels were nearly undetectable, whereas FoxO1 protein levels were induced. In addition to insulin, transcriptional activity of FoxO proteins is known to be regulated by $\mathrm{NAD}^{+}$-dependent SIRT1 deacetylases. Resveratrol down regulated GK mRNA and protein levels and reversed the inducing effects of insulin. Similar results were observed with the GK enzyme activity. Computational analysis of the GK promoter predicted two FoxO1 binding elements (FBEa and FBEb). Overexpression of FoxO1 suppressed GK promoter activity in primary hepatocytes and HepG2 cells. Mutations in the FoxO1 binding element FBEb abolished the FoxO1-mediated repression of GK promoter. Further, treatment of hepatocytes with the SIRT1 activator resveratrol deacetylated and activated FoxO1. Resveratrol also down regulated GK promoter activity in transfected hepatocytes; it was unable to repress promoter activity when FBEb was mutated. Interestingly, the FoxO1 effect was also lost when the HNF-4 binding site was mutated. This suggested that FoxO1 interacts physically with HNF-4 to mediate its action. Indeed, coimmunoprecipitation assays revealed that FoxO1 physically interacts with HNF-4.

Together, the present study showed that SREBP-1 could activate GK gene expression via the footprint B2 site, SRE2 and interaction with HNF-4. Although interaction with HNF-4 is also important for the FoxO1-dependent GK promoter regulation, two additional binding sites were identified. The FoxO1 activity was shown for the first time to be regulated by resveratrol and SIRT1, and the resveratrol-mediated down regulation of GK expression was due to either binding of FoxO1 to the binding elements or via interaction with HNF-4. 


\section{Introduction}

\subsection{Glucokinase}

In mammals glucose can be utilized by all cells to produce ATP and additionally in hepatocytes, myocytes and cardiomyocytes to form glycogen which serves as an energy store. Glucose enters into the cells through glucose transporters (GLUT) from which at least 5 have been identified. The first step of glucose utilization is phosphorylation of glucose to glucose-6phosphate. This can be done by four different hexokinases I-IV from which hexokinases I-III have relatively high affinities for different hexose substrates and their molecular mass is about $100 \mathrm{kDa}$. The hexokinases I-III are inhibited by physiological concentrations of their reaction product glucose-6-phosphate (G6-P). In contrast, hexokinase IV (EC 2.7.1.2), also known as glucokinase (GK) with a mass of about $52 \mathrm{kDa}$ exhibits and displays sigmoidal kinetics with a Hill coefficient of $\sim 1.5-1.7$ and is not inhibited by its reaction product glucose 6 -phosphate. Even though glucose is the preferred substrate of the enzyme, GK can also convert mannose to 2deoxyglucose and fructose (Lenzen et al., 1987). However, GK is inhibited by glucosamine and its derivatives, by mannoheptulose, alloxan, and in vitro by palmitoyl-CoA and other long chain acyl-CoA esters.

\subsubsection{Glucose homeostasis}

GK was first discovered in the liver (Grossbard and Schimke, 1966) and a few years later GK activity was also assigned to pancreatic cells (Matschinsky et al., 1968). Later it was shown that GK expression is not only restricted to hepatocytes and pancreatic $\beta$-cells, but is also present in some neuroendocrine cells of the gastrointestinal tract and the brain (Jetton et al., 1994). The hepatic GK exerts a very strong influence on glucose homeostasis by glucose utilization and glycogen synthesis. Small variations of GK levels in transgenic mice modulated blood glucose concentration (Hariharan et al., 1997). In addition, overexpression of GK in primary hepatocytes led to elevations in glucose 6-phosphate (O'Doherty et al., 1996), which as a central metabolite triggers increased rates of glycolysis and glycogen synthesis (Aiston et al., 1999). The importance of GK was underlined by the findings that homozygous knockout mice died a few days after birth and heterozygous knockout mice appeared normal at birth but died within 4 days due to a defect in insulin secretion in response to glucose and hyperglycaemia (Bali et al., 1995). In addition, $\beta$-cell-specific knockout mice were similar to global GK knockout mice showing hepatic steatosis, a depleted hepatic glycogen content and an $\sim 70 \%$ decrease in plasma insulin concentrations suggesting the role of GK as glucose sensor in $\beta$-cells. In contrast, liver specific loss of hepatic GK was not lethal and had relatively small effects on 
plasma glucose concentration. These results indicate a cooperative mode of both $\beta$-cell GK and hepatocyte GK in the regulation of glucose homeostasis.

In pancreatic $\beta$-cells, GK was considered to be the 'glucose sensor' (Garfinkel et al., 1984), as the phosphorylation of glucose within $\beta$-cells is tightly coupled to insulin secretion. When glucose enters the $\beta$-cell by type 2 glucose transporters it is phosphorylated by GK and converted to glucose-6-phosphate, which effectively traps glucose inside the cell. As glucose metabolism proceeds, ATP is produced in the mitochondria. This increase in the ATP:ADP ratio shuts ATPgated potassium channels in the $\beta$-cell membrane, thus keeping positively charged potassium ions inside the $\beta$-cell. This decrease in $\mathrm{K}^{+}$-efflux depolarizes the $\beta$-cell, resulting in opening of voltage-gated calcium-channels, which in turn flood $\mathrm{Ca}^{2+}$ ions into the $\beta$-cell. The increase in $\mathrm{Ca}^{2+}$ ion concentration then triggers the secretion of insulin via exocytosis (Gilon et al., 2002). Thus, even small changes in GK activity can be physiologically significant, as they directly affect the threshold for glucose-stimulated insulin secretion (Fig 1).

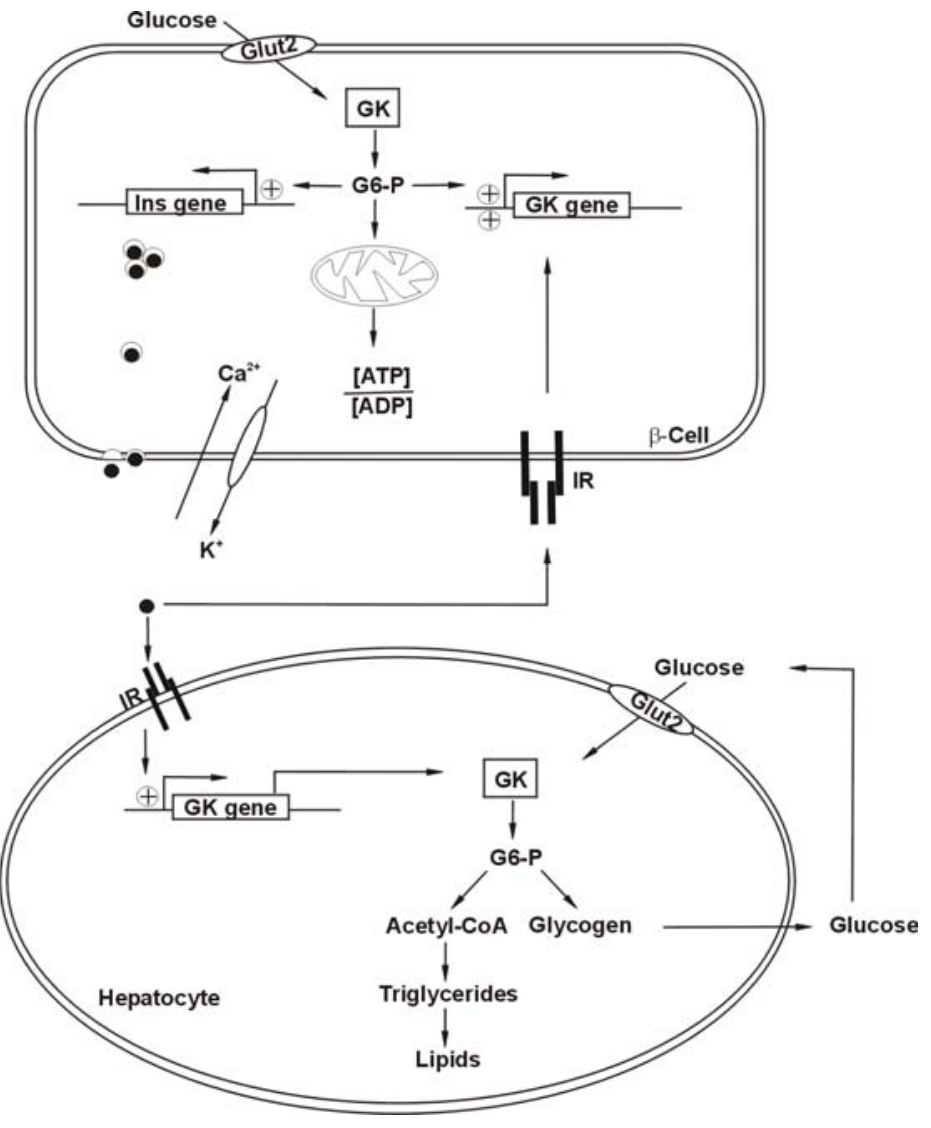

Figure 1. Role of glucokinase in glucose homeostasis and the interplay between pancreatic $\beta$-cells and hepatocytes In pancreatic $\beta$-cells, glucose is transported into the cells via glucose transporter Glut2, and phosphorylated by GK to yield glucose-6phosphate (G6-P). Subsequently, glycolysis and mitochondrial metabolism increase the ATP:ADP ratio, thus leading to inactivation of the Kir6.2 potassium channel, and following a depolarisation of the membrane, to an influx of $\mathrm{Ca}^{2+}$ which triggers insulin secretion. Glucose per se or a glucose metabolite, such as G6-P, can activate GK expression either transcriptionally, translationally or posttranslationally. Insulin can also activate GK expression via a transcriptional mechanism. In hepatocytes, insulin acts as the primary activator of GK transcription, the prerequisite for production of G6-P by GK and the storage of glucose as glycogen, which is stimulated by insulin. Conversion of glucose to G6-P with subsequent glycolysis also leads to acetyl-CoA formation which can be used for lipid synthesis. 


\subsubsection{Glucokinase regulatory protein (GKRP)}

In the liver, GK activity and subcellular localization is regulated by a $68 \mathrm{kDa}$ GK regulatory protein (GKRP) in conjugation with fructose 6-phosphate (F6-P) (Vandercammen and Van, 1990). GKRP inhibits GK, with respect to glucose, by forming a protein-protein complex which is sequestered in the nucleus. This effect can be reversed by high glucose or fructose 1-phosphate (F1-P) (Veiga-da-Cunha and van Schaftingen, 2002). Surprisingly, GK lacks a nuclear localization sequence and entry into the nucleus depends on GKRP by a piggy-back mechanism. By contrast, GK has a nuclear export signal (NES) sequence (300 ELVRLVLLKLV 310) near to its carboxy terminus that is masked upon binding of GKRP, thus ensuring that the GK-GKRP complex remains in the nucleus (Shiota et al., 1999). When blood glucose levels rise after feeding, GKRP is released from GK and allows export from the nucleus to the cytoplasm via an active process. Within the cytoplasm GK is catalytically active and converts glucose to glucose 6-phosphate. However, as the blood glucose levels begin to fall, GKRP binds cytoplasmic GK and moves it back into the nucleus.

GKRP 'knockout' experiments showed that homozygous GKRP ${ }^{-/-}$mice have a $\sim 40 \%$ reduction in liver GK protein levels and enzymatic activity. These deficient mice show an impaired glucose tolerance to a bolus of injected glucose, which is due to the inability to recruit GK from a nuclear reserve. These results strongly suggest the physiological role of the regulatory protein which may aid to provide a functional reserve of GK that can be quickly released after a meal.

However, it is questioned whether GKRP as such is present in the pancreatic $\beta$-cell. Alternatively, although splice variants of GKRP have been described, it appears that other GKbinding partners exist, including long chain fatty acyl-CoA, propionyl-CoA carboxylase $\beta$-subunit precursor, insulin-containing granules and nitric oxide synthase (NOS), dual specific phosphatase (DUSP12), the bifunctional enzyme 6-phosphofructo-2-kinase/fructose-2-6bisphosphatase (PFK-2/FBPase-2) and $\beta$-cell matrix proteins (Baltrusch et al., 2001).

\subsubsection{Glucokinase protein structure}

The resolved GK crystal structure allowed an easier elucidation of its unique kinetic properties. The crystal structure of GK unveiled a palm shaped structure with a small and large domain separated by an interdomain cleft. The connecting region, Asn204 and Asp205, in conjunction with Glu256 and Glu290 of the large domain and Thr168 along with Lys169 of the small domain, are involved in glucose binding. In addition, an allosteric site was identified at the interface between the two domains and is surrounded by connecting region-I, the large domain ( $\beta 1$ strand and $\alpha 5$ helix) and the small domain ( $\alpha 13$ helix) (Kamata et al., 2004). 
The GK can be found in two confirmations along with an intermediate confirmation. Without glucose, GK exists in its thermodynamically favorable wide-open inactive confirmation. Once bound to glucose, GK undergoes a conformational change and switches from the inactive wideopen to an intermediate active open confirmation and then to the very active closed form. Upon conversion of glucose, G6-P and ADP will be released and GK returns via the open confirmation to the wide-open form. As both forms slowly equilibrate and the conformational change from the closed to the open form is faster than from wide-open to open and vice versa, it appears that a large portion of GK exists in the open form for some time (Fig 2). These conformational changes indicate that GK operates in two cycles: a fast cycle and a slow cycle. If glucose binds to the intermediate open form, GK immediately enters into the catalytic cycle; if not (e.g., low glucose concentration) GK returns to the wide-open form and uses the slow cycle. This shift between catalytic cycles explains the mnemonic mechanism and the sigmoidal saturation curve for glucose of GK, as well as its ability to regulate blood glucose levels in vivo.

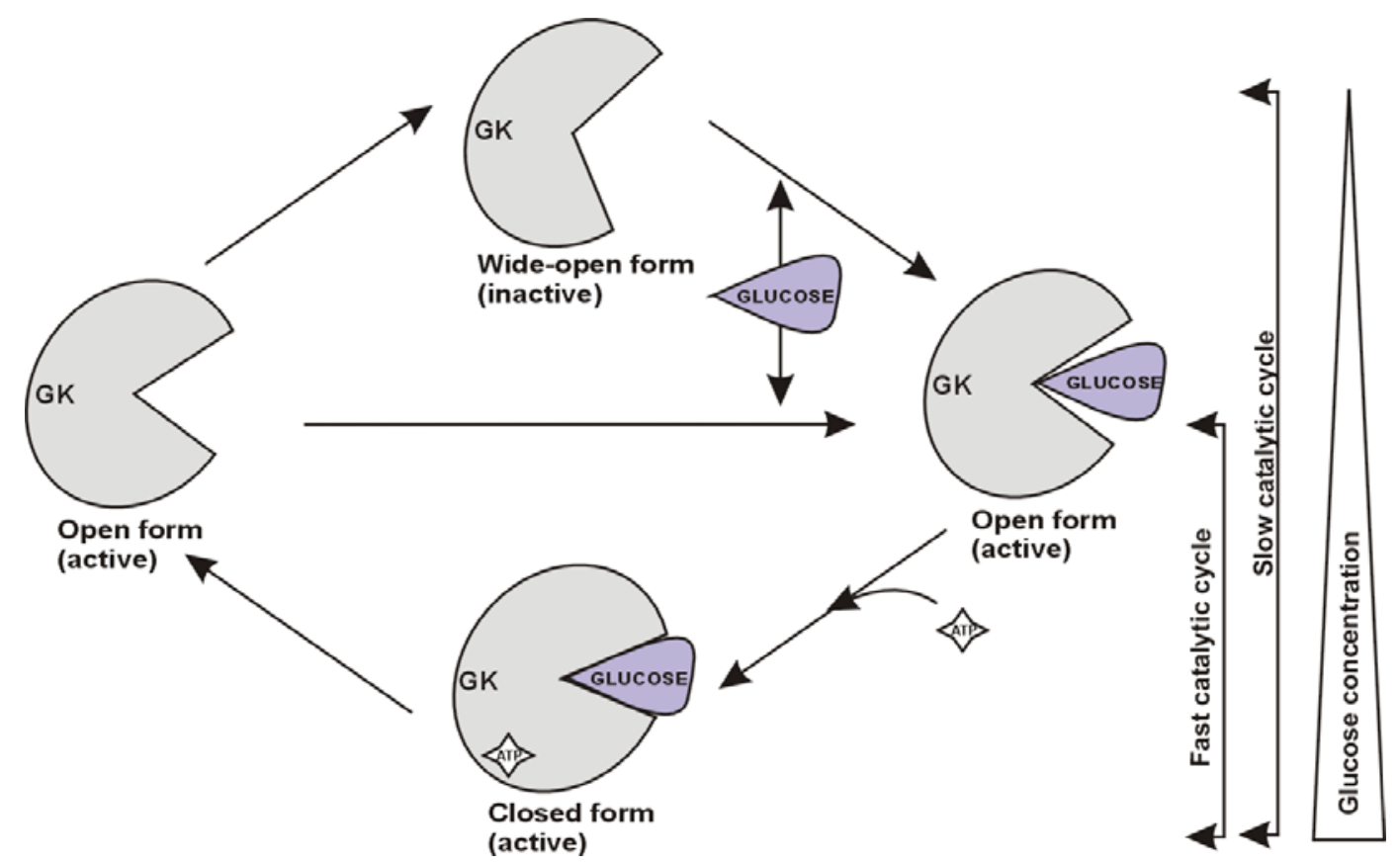

\section{Figure 2. Model of the two glucokinase reaction cycles}

The glucose-unbound glucokinase (GK) exists in a wide-open confirmation. When glucose binds to it, GK undergoes confirmational changes from the wide-open to the close active confirmation via the intermediate open but active conformation. After conversion of glucose, GK returns to the open form, thereby releasing glucose 6-phosphate (G6-P) and ADP. At this stage, the enzyme may aquire a new glucose molecule and may undergo an immediate new reaction (fast cycle) or, as under low glucose concentrations, return to the wide-open inactive conformation. 


\subsubsection{Glucokinase gene}

Glucokinase is encoded by a single gene in humans, rats and mice. The human GK gene is located on chromosome 7p13, whereas the mouse gene is located on chromosome 11. The gene consists of 10 exons and has two widely separated and functionally distinct cell-typespecific promoters. Cloning and characterization of an $83 \mathrm{~kb}$ clone (P1-305) having both promoters and all coding sequences of the mouse GK revealed that the 11 exons of total gene span $49 \mathrm{~kb}$, with exons $1 \beta$ (upstream promoter) and $1 \mathrm{~L}$ (downstream promoter) being separated by $\sim 35 \mathrm{~kb}$ (Postic et al., 1995). These alternate promoters in conjunction with the use of different first exons lead to tissue-specific GK expression. The $\beta$-cell GK mRNA is a product of exon 1a and 2-10, whereas the liver expresses GK from exons $1 \mathrm{~b}$ and 2-10 and $1 \mathrm{~b}, 1 \mathrm{c}$ and 2-10 due to alternate splicing.

The upstream ( $\beta$-cell promoter) GK promoter is expressed specifically in several different cell types including pancreatic $\beta$-cells, neural/neuroendocrine cells of the gastrointestinal tract and corticotropes of the pituitary (Liang et al., 1991). However, the downstream GK promoter is mainly responsible for hepatic GK gene transcription. The upstream $\beta$-cell specific promoter has $70 \%$ sequence similarity among human, rat and mouse species.

\subsubsection{Glucokinase promoter regulation}

DNaseI hypersensitive analysis and DNaseI footprint assays of the liver specific GK promoter revealed that, both in rats and mice, the hepatic GK promoter encompasses $\sim 7 \mathrm{~kb}$ of 5 ' -flanking sequence (Postic et al., 1995). DNaseI footprinting assays identified seven elements A - G (in 3' to 5' direction), specifically interacting with liver enriched factors (lynedjian et al., 1996). Recent studies have identified two binding sites for hepatocyte nuclear factor-6 (HNF-6, the prototype of the ONECUT family of transcription factors), located at the most distal (-7613/-7622) and the more proximal (-877/-868) sites of the promoter (Lannoy et al., 2002). Further, analysis of the more proximal part of the liver specific promoter showed the existence of additional footprints named as P2 (-87/-80) and P1 (-54/-35) (lynedjian, 1998a). The element P2 has been shown to be bound by the basic helix-loop-helix transcription factors, upstream stimulatory factor-1 and -2 (USF-1, -2) (Iynedjian, 1998b), as well as by hypoxia-inducible factor-1 (HIF-1) (Roth et al., 2004b). The P1 element was identified to contain a binding site for hepatocyte nuclear factor- $4 \alpha$ (HNF-4 a) (Roth et al., 2002).

The liver tissue exhibits a metabolic zonation and a zonated gene expression. The zonated pattern may be the result of the gradients in nutrients, hormones and oxygen which are formed due to the blood flow through the sinusoids and the metabolism of the cells. Especially oxygen 
or insulin mainly contributes to the zonated gene expression in liver. The liver GK gene expression is mainly stimulated by insulin in the hypoxic perivenous zone of the liver (lynedjian et al., 1989), (Krones et al., 2000), involving HIF-1 and HNF-4 to play an important role during this process. Previous results have shown that the cooperation between HIF-1, HNF-4 and the co-activator p300 contributed to the insulin-dependent GK induction (Roth et al., 2004a). The insulin signalling pathway involved in the GK gene expression was the $\mathrm{PI} / 3 \mathrm{~K} /$ protein kinase $\mathrm{B}$ pathway, which also regulates the insulin-dependent expression of several other genes required for carbohydrate metabolism such as glucose 6-phosphatase (G-6-Pase), glucose transporter-1 (GLUT-1) and sterol regulatory element binding protein-1 (SREBP-1) (lynedjian PB et al., 2000). Very recent reports implicated sterol regulatory element binding protein (SREBP) as an insulindependent activator for transcription of hepatic GK. It has been shown that GK promoter activity was induced by SREBP-1a, and found that SREBP-1c binds to two sterol response elements designated (SREa -205/-197) and (SREb -183/-174) (Kim et al., 2004). However, the mutual relationship between the SREa and SREb is not well understood in the SREBP-1c-mediated activation of liver GK by insulin.

Furthermore, FoxO transcription factors are important targets of insulin signaling and contribute to the regulation of cell growth, differentiation, and metabolism. Insulin has a dynamic effect on the localization of FoxO. PKB/Akt pathway of insulin signaling inactivates the transactivation and promotes nuclear exclusion of FoxO. FoxO proteins exert both positive and negative effects on gene expression. Studies with adenoviral vectors in isolated hepatocytes reveal that FoxO1 stimulates gluconeogenic genes (PEPCK) and suppress glycolytic genes including glucokinase and SREBP-1c (Zhang et al., 2006). However, FoxO1-mediated repression of glucokinase gene was not understood completely.

\subsection{Sterol regulatory element binding proteins (SREBPs)}

SREBPs are membrane bound transcription factors, involved in cholesterol metabolism. SREBPs are basic helix-loop-helix leucine-zipper (bHLH-zip) transcription factors, which are different from other bHLH-zip proteins in that they are able to bind the typical E-box inverted DNA repeat (5'-CANNTG-3') as well as the direct DNA repeat of SRE (5'-TCANCCAC-3') (Parraga et al., 1998). So far, three SREBP isoforms have been identified and characterized in mammalian cells. They are designated as SREBP-1a, SREBP-1c and SREBP-2. SREBP-1a and $-1 \mathrm{c}$ are derived from a single gene located on human chromosome 17p11.2 through the use of alternative transcription start sites that produce different forms of exon 1. By contrast SREBP-2 is derived from a second gene located on human chromosome 22q13. SREBP-1a is a potent transcriptional activator having a long transactivation domain, but SREBP-1c is a much weaker 
activator since it lacks $\mathrm{N}$ terminal 29 acidic amino acids present in SREBP-1a. In vivo studies suggested that SREBP-1 proteins are potentially activating lipogenic genes whereas SREBP-2 activates predominantly genes necessary for cholesterol homoeostasis.

SREBPs are endoplasmic reticulum membrane-bound transcription factors (Fig 3). Insulin induces SREBP transcription via a PI3-kinase pathway (lynedjian et al., 2000); proteolytic cleavage and release of active SREBP may or may not be dependent on insulin. However, nanoelectrospray mass spectrometry and peptide sequencing studies have identified that, serine 117 in SREBP-1 may be a major phosphorylation site of the MAP kinases ERK 1/2 (Kotzka et al., 2004). The SREBPs and SREBP cleavage activating protein (SCAP) form a complex that is stable in both the presence and the absence of sterols. The amino terminus of SCAP consists of a sterol sensing domain and when the cellular sterol levels are low SCAP escorts SREBP from the ER to the Golgi apparatus, where the site-1 serine protease (S1P) and the site-2 metallo protease (S2P) cleave and release transcriptionally active SREBP. The released SREBPs are translocated into the nucleus and bind to its target gene promoters containing SRE or E-boxes (Fig 3).

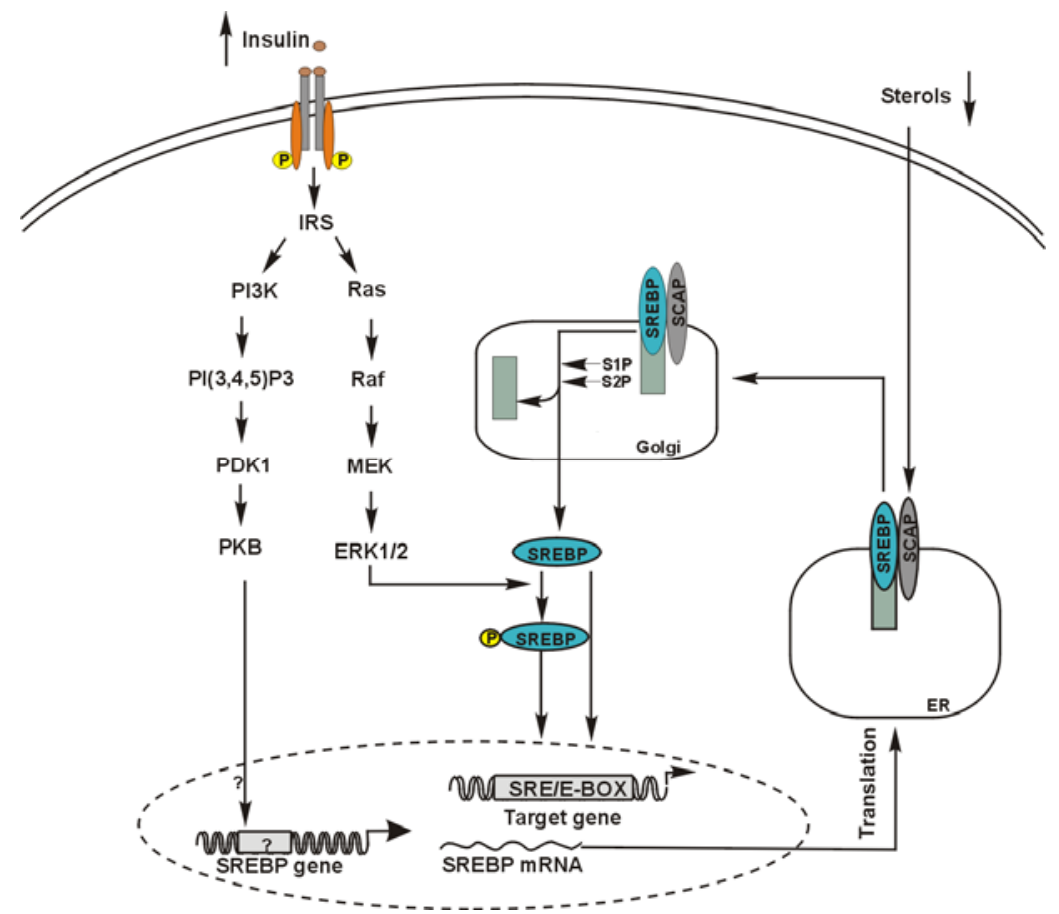

Figure 3. Insulin signalling and SREBP activation pathways When the cellular sterol levels are normal sterol regulatory element binding protein (SREBP) forms a complex with SREBP cleavage activating protein (SCAP) in the endoplasmic reticulum (ER). When sterol levels decrease, SCAP escorts SREBP to the golgi apparatus where site 1 protease $(\mathrm{S} 1 \mathrm{P})$ and site 2 protease (S2P) cleave and release active SREBP. The active SREBP migrates into the nucleus and activates transcription of genes such as glucokinase or those involved in cholesterol and fatty acid synthesis by binding to sterol response elements (SRE) or E-boxes. Insulin, through activation of the phosphatidylinositol 3-kinase pathway, increases SREBP-1 expression and thus the amount of SREBP-1. In addition, SREBPs may be regulated via phosphorylation since they appear to be a direct substrate of ERK1/2. 


\subsection{FoxO transcription factors}

The forkhead proteins belong to the FOX superfamily of proteins consisting of more than four hundred transcription factors. Each factor is characterized by a conserved DNA binding domain of 110 amino acids referred as forkhead box or winged helix domain. The forkhead box 'Other' (FoxO) proteins constitute a class of the FOX protein family, which includes FOXO1 (FKHR), FOXO3a (FKHRL1), FOXO4 (AFX) and FOXO6. The FOXO proteins are the vertebrate orthologs of the Caenorhabditis elegans DAF16 protein and they are components of a highly conserved signaling pathway, which connects growth and stress signals to transcriptional regulation (Ogg et al., 1997). The FoxO proteins have an important role in mediating the effects of insulin and growth factors on diverse physiological functions, comprising cell proliferation, apoptosis and metabolism. Early studies on the regulation of insulin-like growth factor binding protein-1 (IGFBP-1), provided an important evidence that FoxO proteins interact with insulin responsive sequences [IREs-(T/C)(G/A)AAACAA] and are regulated through the phosphatidylinositol 3-kinase and protein kinase B pathway (Unterman et al., 1994).

Transcriptional activity of the FoxO proteins requires nuclear localization, which is favored by the absence of growth signals. In response to insulin or growth signals, FoxO factors are phosphorylated by several kinases including protein kinase $B$, serum and glucocorticoidregulated kinase (SGK), casein kinase1 (CK1), and DYRK1A (a member of the dual-specificity tyrosine-phosphorylated and regulated kinase group) \{(Arden and Biggs, III, 2002), (Brunet et al., 2001), (Guo et al., 1999)\}. Phosphorylation of FoxO factors by PKB/Akt occurs at three conserved residues namely N-terminal Thr24, Forkhead domain Ser256, and C-terminal Ser319, which results in disrupting the interaction with the other transcriptional coactivators, affecting the DNA-binding activity, and masking the nuclear localization signal. This facilitates the binding of 14-3-3 proteins leading to nuclear exclusion of FoxO (Fig 4).

FoxO transcription factors are acetylated at conserved lysine residues located in the DNAbinding domain (Fukuoka et al., 2003) by p300 and co-activators displaying histone acetyltransferase activity. This leads to attenuation of FoxO as a transcription factor. Conversely, SIRT1 a member of the Sir2 family of NAD-dependent deacetylases (Brunet et al., 2004) binds to and deacetylates FoxO (Fig 4). This interaction with SIRT1 affects the transcriptional regulatory functions of FoxO and is depending upon the FoxO target genes. The rate of deacetylation activity of SIRT1 has been shown to be doubled by treating with a compound called resveratrol. Resveratrol is a polyphenol found in Polygonum capsidatum, including mulberries, pea nuts and grapevines. It has a broad range of biological effects besides deacetalytion, including chemopreventive properties against several cancers, cardiovascular diseases, viral infections, diabetes and protection of cells from lipid accumulation. 
Pharmacokinetic and pharmacodynamic studies demonstrated that the main target organs of resveratrol are liver and kidney (Shankar et al., 2007).

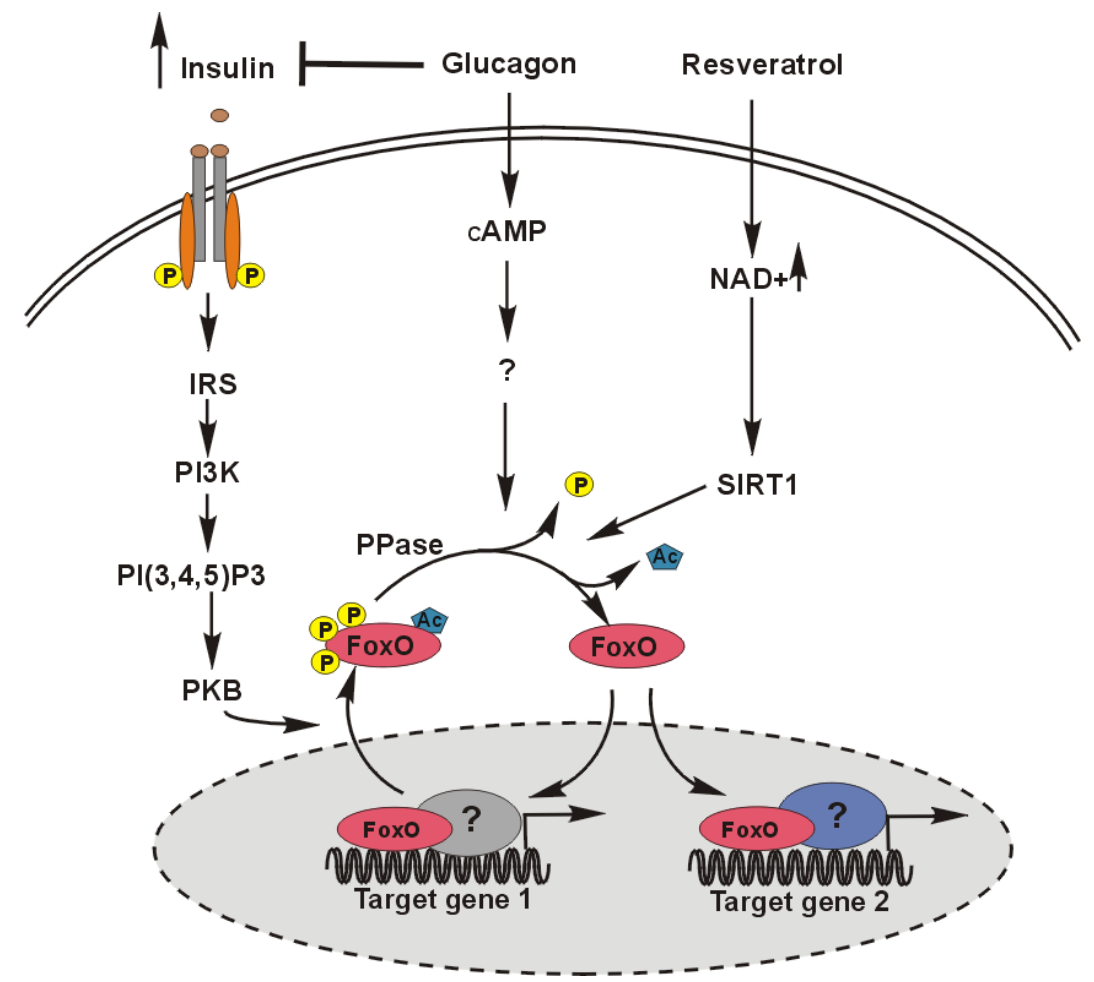

Figure 4. Activation and inactivation of FoxO mediated gene expression FoxO transcription factors are predominantly nuclear and are presumed to be active. Insulin via PKB mediates phosphorylation of FoxOs on three conserved residues in the nucleus, which initiates their export to the cytoplasm. This would lead to the repression of gene expression. Activation of FoxO by glucagon via CAMP leads to nuclear import and induction of target genes. Treatment with resveratrol increases $N A D^{+}$-dependent SIRT1 deacetylases, which are known to interact and deacetylate cytoplasmic inactive acetylated FoxOs into active. Thus deacetylated FoxOs may be imported into the nucleus and act on target genes.

Insulin receptor substrates (IRS); phosphoinositide 3-kinase (PI3K); protein kinase B (PKB); phosphatidylinositol 3,4,5-triphosphate (PI[3,4,5]P3); pyrophosphatase (PPase); cyclic adenosine monophosphate (cAMP); Silent information regulator 1 (SIRT1).

\subsection{Hepatocyte nuclear factor 4 (HNF4a)}

HNF4 $\alpha$ is a member of the nuclear hormone receptor family of transcription factors consisting of two zinc fingers in the DNA binding domain. The gene encoding HNF4a is located on chromosome 20 and is expressed in the liver, kidney, pancreas, small intestine, testis and colon. HNF4a knockout mice are embryonic lethal due to a failure in gastrulation and the expression of many genes involved in liver development ( $\mathrm{Li}$ et al., 2000). Besides organ development, HNF4a has an important role in glucose and lipid homeostasis (Ladias et al., 1992). Mutations in the HNF4 $\alpha$ gene cause maturity-onset diabetes of the young type-1 (MODY-1). HNF4a regulates genes at the transcriptional level by interacting with the HNF4 binding elements on the promoter 
or enhancer (Bogan et al., 2000). The HNF4a protein contains several functional domains: a ligand-independent activation domain (AF1), a zinc finger DNA binding domain, and a liganddependent activation domain (AF2). Crystal structure studies of the ligand binding domain had identified fatty acids or related molecules might act as endogenous ligands for HNF4a (DhePaganon et al., 2002).

\subsection{Aim of the study}

Glucokinase is predominantly expressed in the perivenous zone of the liver acinus where the concentration of insulin is high due to metabolic zonation. Insulin regulates several transcription factors including hypoxia-inducible factor- $1 \alpha$ (HIF-1 $\alpha$ ), forkhead transcription factors (FoxO), and sterol regulatory element binding proteins (SREBP). It is well known that, the transcription factors SREBP and HNF4 $\alpha$ activate the GK promoter. However, the molecular mechanisms underlying the regulation of GK gene by SREBP and HNF4 $\alpha$ are poorly understood. Therefore, the purpose of the current study was to investigate the insulin-dependent SREBP mediated glucokinase gene expression and to map the SREBP responsive elements within the liverspecific GK promoter. Insulin has dynamic effects on FoxO transcription factors and these factors are transcriptionally active when insulin signaling is absent. FoxO factors are known to be positive regulators of gluconeogenic genes and negative regulators of glycolytic genes. The effects of FoxO factors on glucokinase gene expression are not well known. Therefore, we intended to investigate the regulation of glucokinase gene by FoxO factors and to identify putative binding elements for FoxO. 


\section{Materials}

\subsection{Animals}

Male Wistar rats ( 200-300 g) were housed in controlled environmental conditions of $12 \mathrm{~h}$ light $112 \mathrm{~h}$ dark cycle (light from 07.00 to $19.00 \mathrm{~h}$ ) according to the German legislation on the protection of animals. Rats were fed ad libitum with laboratory diet (Altromin breed fodder) and free access to water. The rats consumed $12-15 \mathrm{~g}$ food and $12-25 \mathrm{ml}$ water per day and had a $30-40 \mathrm{~g}$ gain of weight per week. Rats were anaesthetized with pentobarbital $(60 \mathrm{mg} / \mathrm{kg}$ body weight) prior to the preparation of hepatocytes between 09.00 and $10.00 \mathrm{~h}$.

\subsection{Bacterial strains, vectors and plasmid constructs}

Escherichia coli bacterial strain's DH5a and XL1 blue (Hanahan, 1983) were used for transformation of various plasmids and ligation reactions.

\subsubsection{Vectors}

\subsubsection{1 pBluescript-KS II vector}

pBluescript-KS II vector is designed for DNA cloning, sequencing, in vitro mutagenesis and in vitro transcription in a single system (Stratagene, Heidelberg). The pBluescript KS II is a phagemid and is derived from the vector pUC 19 consisting of $2961 \mathrm{bp}$. This vector consists of T3 and T7 RNA polymerase promoters, necessary for the in vitro transcription, a multiple cloning site (polylinker) containing sites for different restriction endonucleases, and primer sequences (universal) necessary for DNA sequencing (Fig. 5).

\subsubsection{2 pTZ57R/T (T/A cloning vector to clone PCR fragments)}

The vector pTZ57R was pre-cleaved with Eco321, an isoschizomer of EcoR V and treated with terminal deoxynucleotidyl transferase to create 3' -ddT overhangs at both ends to generate $\mathrm{pTZ57R/T}$ vector (2886 bp). This specially designed cloning vector has high efficiency and allows the cloning of Taq-amplified PCR fragments without any post-PCR treatment. The T/A cloning method is especially suitable for cloning of PCR fragments amplified with primers that carry dG or dC at their 5'-ends (Fig. 6). 


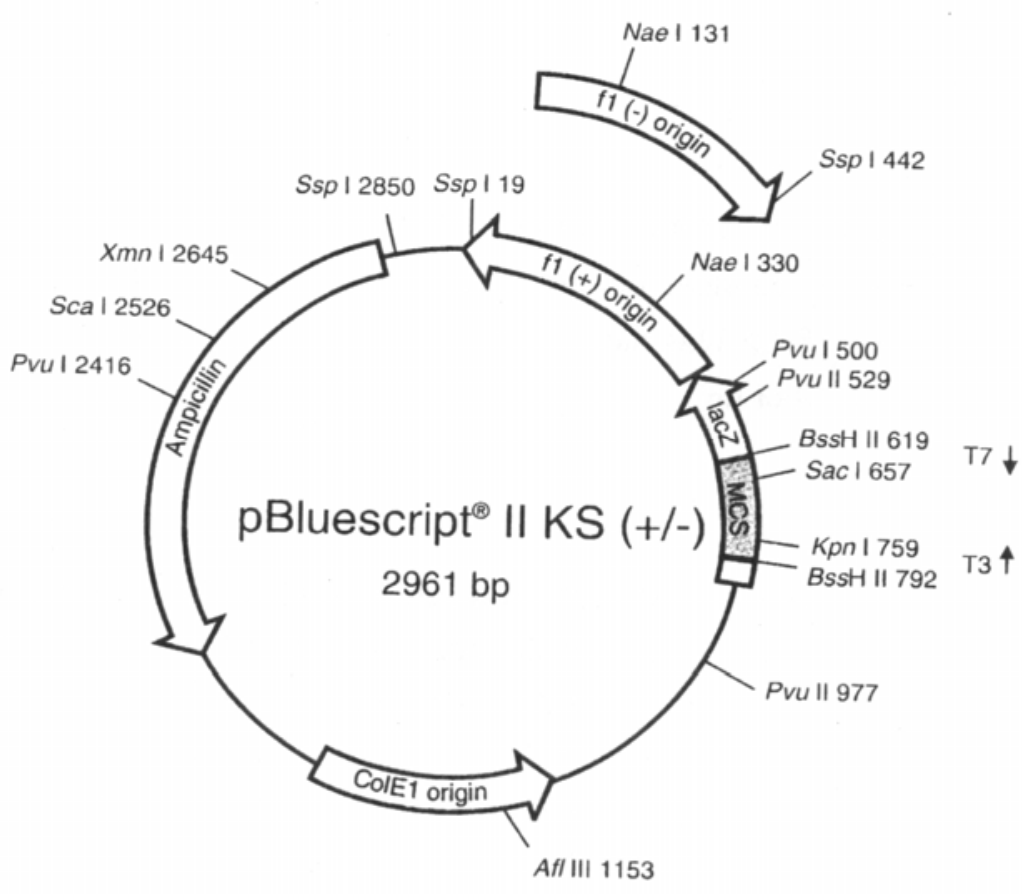

Figure 5. The vector pBluescript vector (pBS-KS II). The vector contains the origin of replication ColE1 ori, the ampicillin resistance gene for antibiotic selection, and the $L a c Z$ gene coding for $\beta$-galactosidase which provides the possibility for blue/white colour selection of recombinant clones. The multiple cloning site is flanked by T3 and T7 promoters and by the sequences for T3 and T7 primers, KS and SK primers, universal (M13) forward and reverse primers for sequencing of DNA fragments inserted into the MCS within the lacZ gene. KS and SK represent two orientations of the MCS within the lacZ gene; KS represents the orientation of the MCS in which lacZ transcription proceeds from Kpn I to Sac I, while SK from Sac I to Kpn I. 


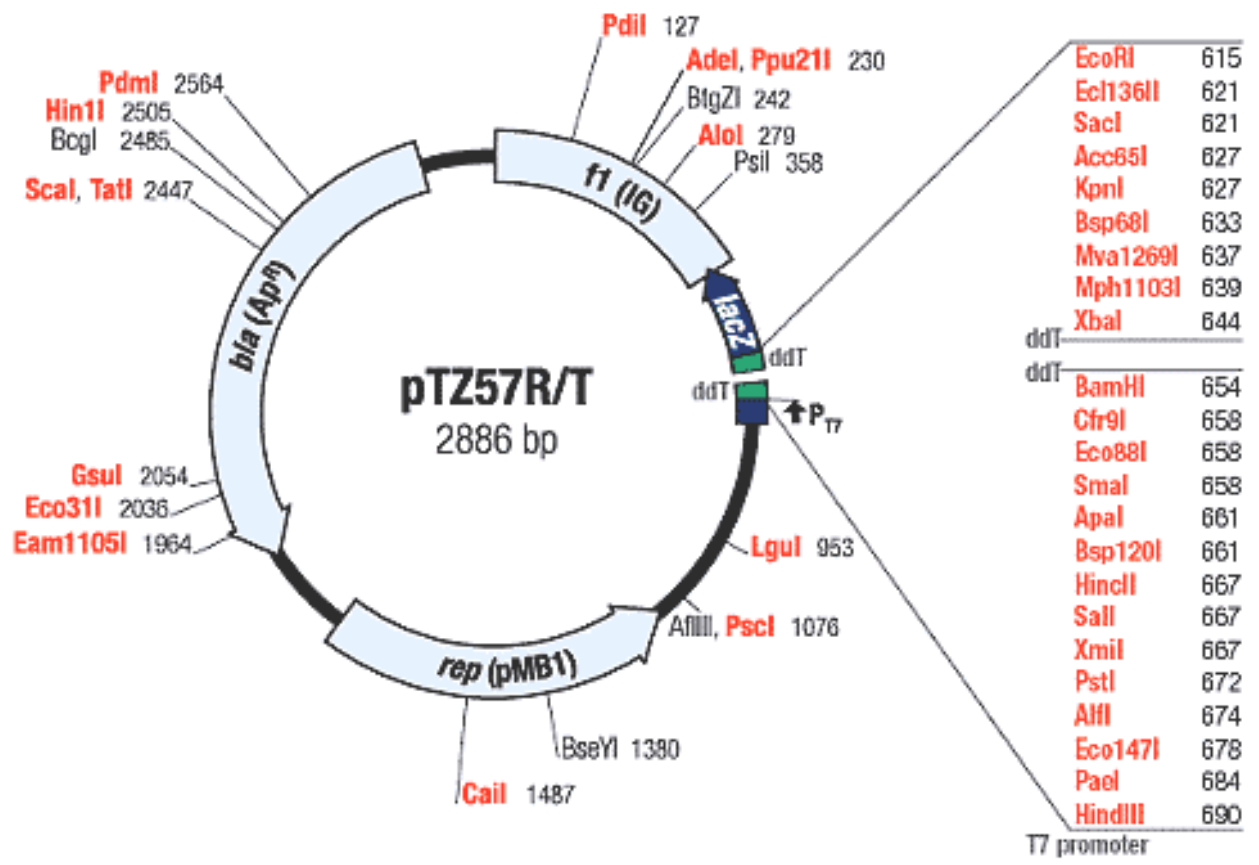

Figure 6. The pTZ57R/T vector. This is a linear vector consisting of 3'-ddT overhangs on both ends to prevent recircularization of vector during ligation. The position of the genetic elements is shown on the map. The plasmid consist of $\mathrm{f} 1$ (IG) - the intergenic region of phage $\mathrm{f1}$; rep (pMB1) replicon responsible for DNA replication and high copy number. The bla gene 2688-2756 codes for ampicillin resistance, the lac $Z$ gene encoding the $\mathrm{N}$-terminal fragment of beta-galactosidase which allows blue/white screening of recombinant plasmids.

\subsubsection{3 pGL3-Basic and pGL3-Promoter vectors}

The pGL3-Basic vector lacks eukaryotic promoter and enhancer sequences, which allows maximum flexibility in cloning putative regulatory sequences (mainly promoters). The vector contains multiple cloning site (MCS) followed by the firefly luciferase gene (luc,+ 1649 ) and the SV40 late polyA signal (221 bp). The plasmid consists of an ampicillin resistance gene ( $\beta$ lactamase; Amp ; $857 \mathrm{bp}$ ) and two origins of replication, ColE1 ori and f1 ori (454 bp). The plasmid also consists of two primer sequences RV3 and GL2, which allows sequencing of the cloned fragments. Expression of luciferase activity in cells transfected with this plasmid depends on insertion and proper orientation of functional regulatory sequences upstream from luc+. 


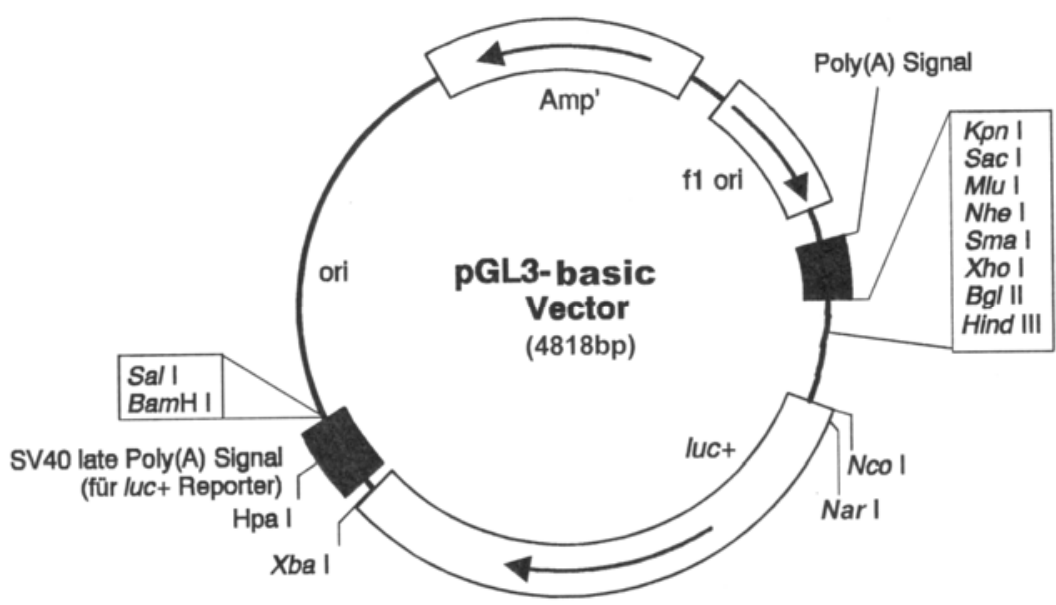

Figure 7. Structure of the pGL3-Basic vector. luc+, cDNA encoding the modified firefly luciferase; Ampr, gene conferring the ampicillin resistance in E.coli; f1 ori, origin of replication derived from filamentous phage; ori, origine of replication in E.coli. Arrows within luc+ and $\mathrm{Amp}^{r}$ gene indicate the direction of transcription; the arrow in the f1 ori indicates the direction of single-strand DNA synthesis.

Both pGL3-Basic and pGL3-Promoter vectors are similar except an SV40 promoter upstream of the luciferase gene within the pGL3-Promoter vector. DNA fragments containing putative enhancer elements can be inserted either upstream of the SV40 promoter luc+ transcriptional unit of promoter vector.

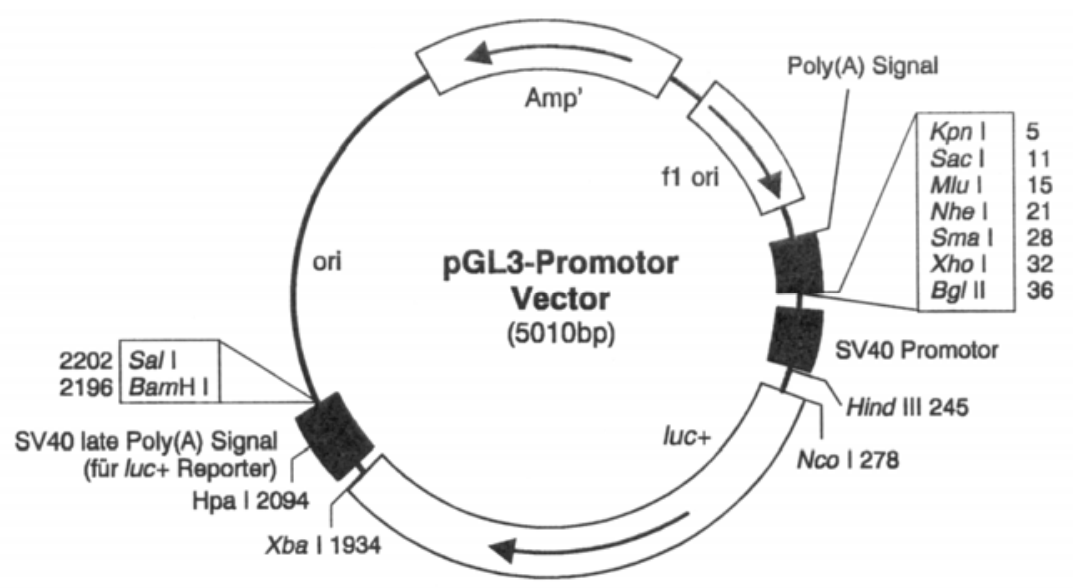

Figure 8. Structure of the pGL3-Promoter vector. The multiple cloning site ( $41 \mathrm{bp})$ is followed by the SV 40 promoter (195 bp), firefly luciferase gene (luc+, $1649 \mathrm{bp}$ ) and a SV 40 late polyA signal (221 bp). Another, upstream polyA signal (153 bp), is located directly before the multiple cloning site. The plasmid also contains the ampicillin resistance gene ( $857 \mathrm{bp})$ and two origins of replication, ColE1 ori and f1 ori (454 bp). The luc+ gene is transcribed clockwise and the Ampr gene is transcribed counterclockwise. 


\subsubsection{Plasmid constructs}

\subsubsection{Reporter gene plasmid constructs}

\subsection{Glucokinase promoter pGL3-Basic constructs}

The wild type rat glucokinase promoter $(1448 /+15)$ along with the deletion constructs was cloned into Bgl II and Hind III restriction sites, in front of the Luc+ gene of the vector pGL3-Basic to create the pGL3rGK-1448 Luc, pGL3rGK-919 Luc, pGL3rGK-781 Luc, pGL3rGK-748 Luc, and pGL3rGK-333 Luc constructs. The wild type pGL3rGK-1448 Luc construct was used as a template to generate different mutation constructs pGL3rGK-mSRE1, pGL3rGK-mSRE2, pGL3rGK-mSRE3, pGL3rGK-mSRE2+mSRE3, pGL3rGK-mHNF4, pGL3rGK-mHRE, pGL3rGKmHRE+mHNF4, pGL3rGK-mE-box, pGL3rGK-mFPB1, pGL3rGK-mFPB2, pGL3rGKdmFPB1+2, pGL3rGK-mFBEa, pGL3rGK-mFBEb, and pGL3rGK-dmFBEab using the QuickChange XL site-directed mutagenesis kit (stratagene).

Glucokinase promoter deletion constructs

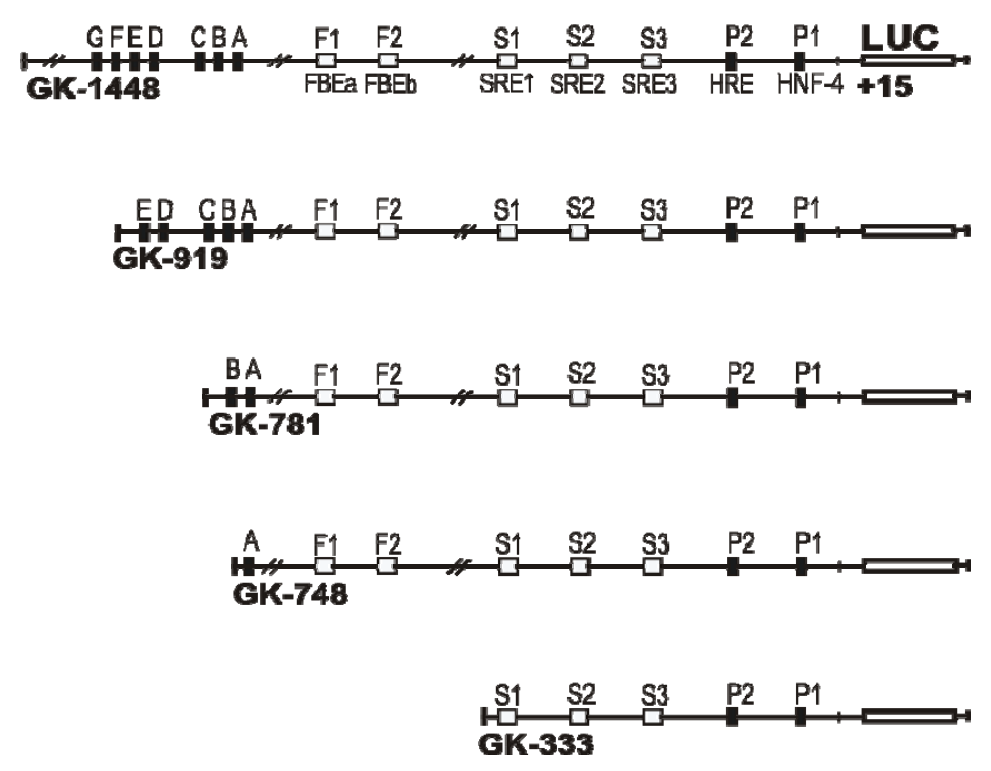

Figure 9. Rat glucokinase promoter deletion constructs. The wild type rat glucokinase promoter GK-1448 and the deletion constructs GK-919 LUC, GK-781 LUC, GK-748 LUC, and GK-333 LUC were cloned into the pGL3Basic vector. Black boxes A-G, P1 and P2 indicate foot-printed regions. White boxes indicate elements identified only by sequence similarity. Elements $\mathrm{P} 1$ and $\mathrm{P} 2$ correspond to the binding elements for HNF-4 and HIF1. White boxes S1, S2, and S3 are putative SREBP responsive elements (SRE); F1 and F2 are putative FoxO binding elements (FBE). 
$\underline{\text { Glucokinase promoter mutation constructs }}$

GK-1448SRE1m

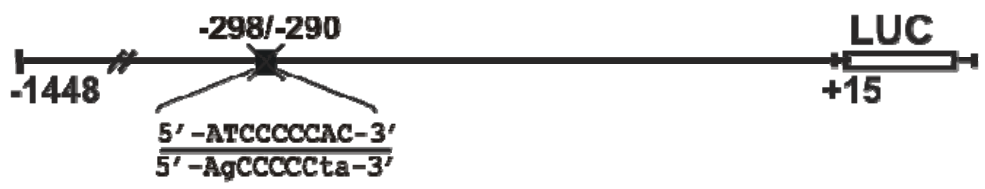

GK-1448SRE2m

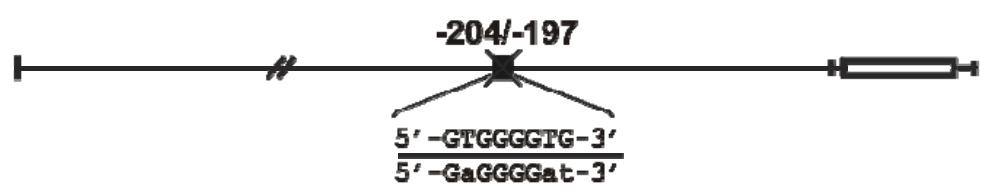

GK-1448SRE3m

GK-1448mSRE2+mSRE3
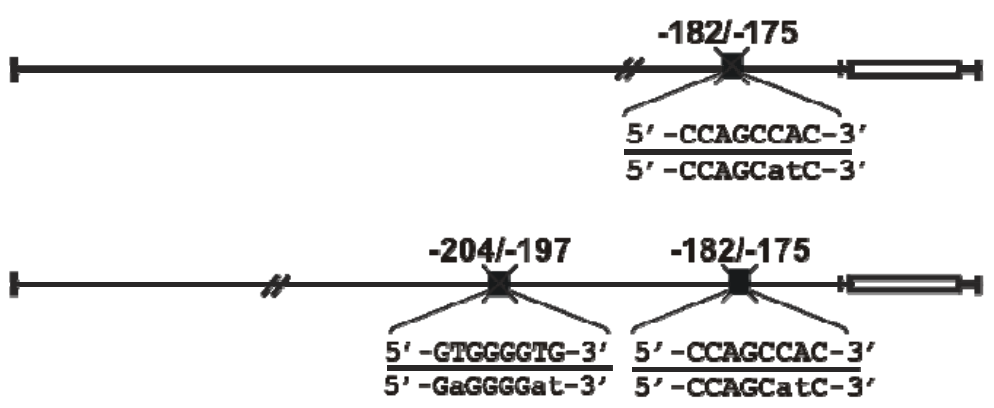

GK-1448HREm

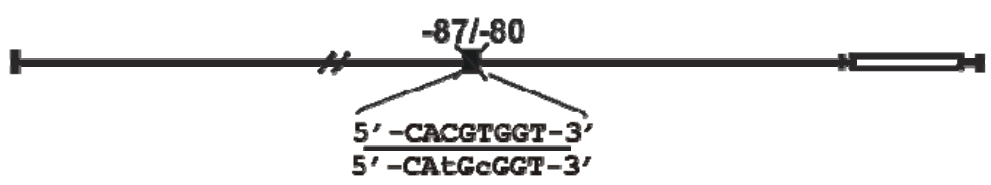

GK-1448HNFm

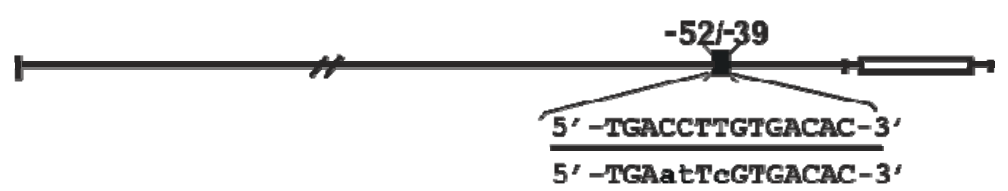

GK-1448HREm+HNFm

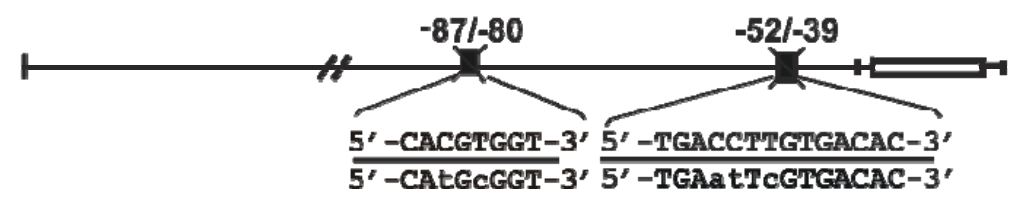

Figure 10. Rat glucokinase promoter mutation constructs. The rat wild-type glucokinase promoter construct GK-1448 was used as a template to generate all the mutation constructs. Putative SREBP responsive elements were mutated alone or in combination to generate GK-1448 mSRE1, mSRE2, mSRE3 and a double mutant GK-1448mSRE2+mSRE3. Mutations were incorporated at HNF4 and HIF binding sites to create GK-1448mHNF4, GK-1448mHRE and a double mutant GK-1448mHRE+mHNF4. The wild-type sequences are shown on the upper strand whereas the mutated sequences are indicated down with lower case letters. The numbers above the line indicate the position of the elements. 
$\underline{\text { Glucokinase promoter mutation constructs }}$

GK-1448mE-box

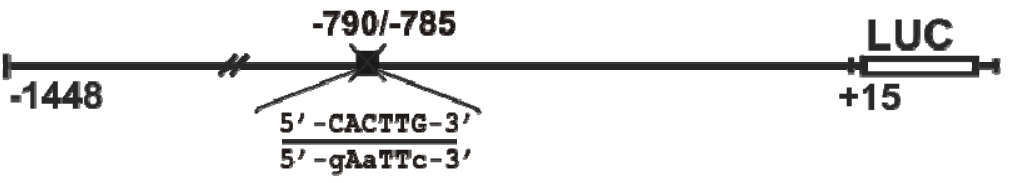

GK-1448mFPB1

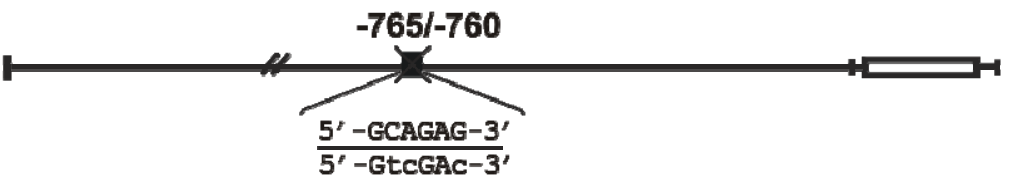

GK-1448mFPB2

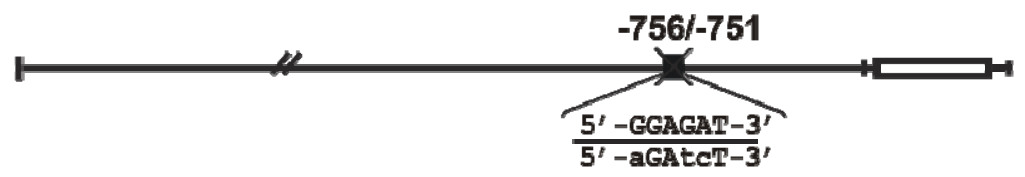

GK-1448dmFPB1+2

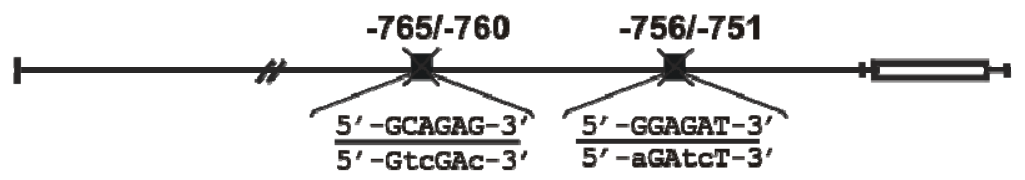

GK-1448mFBEa

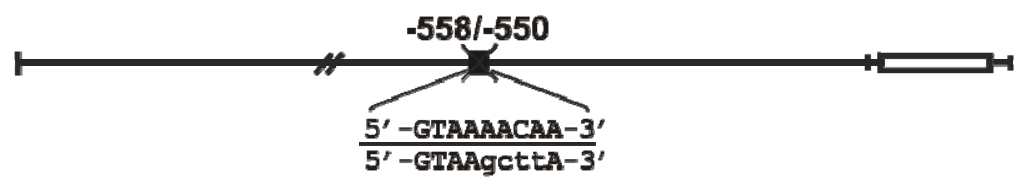

GK-1448mFBEb

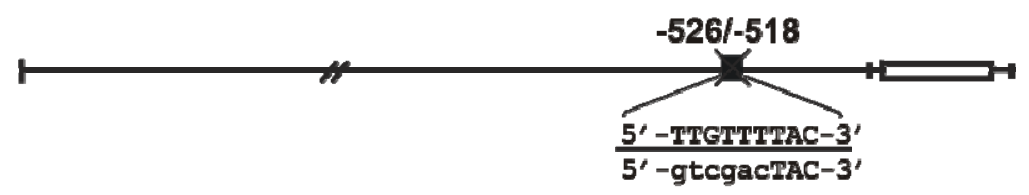

GK-1448dmFBEab

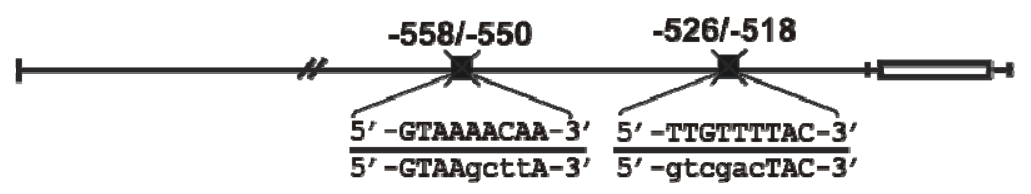

Figure 11. Rat glucokinase promoter mutation constructs. The mutation constructs shown in the above diagram were generated from rat wild-type glucokinase promoter construct GK-1448. Mutations were incorporated at E-box, foot print B1, B2 and both together to generate GK-1448mE-box, GK1448mFPB1, GK-1448mFPB2 and GK-1448dmFPB1+2. Mutations were created in the putative FoxO binding elements to generate GK-1448mFBEa, GK-1448mFBEb and both together GK-1448dmFBEab. The wild-type sequences are shown on the upper strand whereas the mutated sequences are indicated down with lower case letters. The numbers above the line indicate the position of the element. 


\subsubsection{2 pGL3-Promoter constructs}

The plasmid construct pGL3-SR/SP-Luc was generated by cloning oligonucleotides carrying the sequence for three copies of sterol regulatory element binding elements (SRE) and one SP1 binding element (SPE) in front of the SV 40 promoter in the pGL3-Promoter vector. Similarly, the oligonucleotides consisting of four copies of SREs were cloned in front of the SV 40 promoter in the pGL3-Promoter vector to generate the pGL3-4SRE-Luc construct. The oligonucleotides were designed in a way to obtain an EcoR I restriction enzyme site between the $3^{\text {rd }}$ and $4^{\text {th }}$ binding element. Since this site is not present in the parental vector this will allow the identification of the positive clones. Both Kpn I and Xho I sites were incorporated at the ends for the cloning into the pGL3-Promoter plasmid.

PGL3-SR/SP LUC

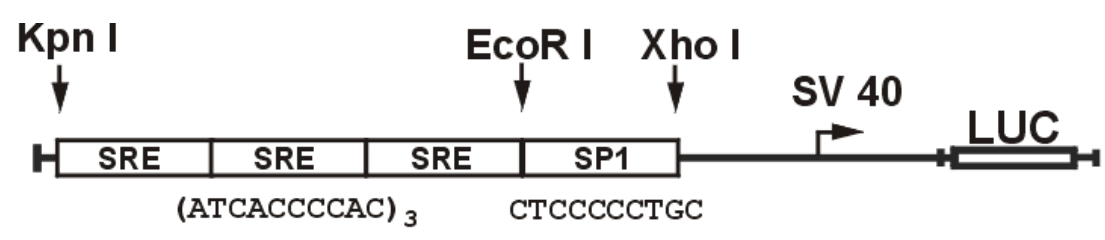

PGL3-4SRE LUC

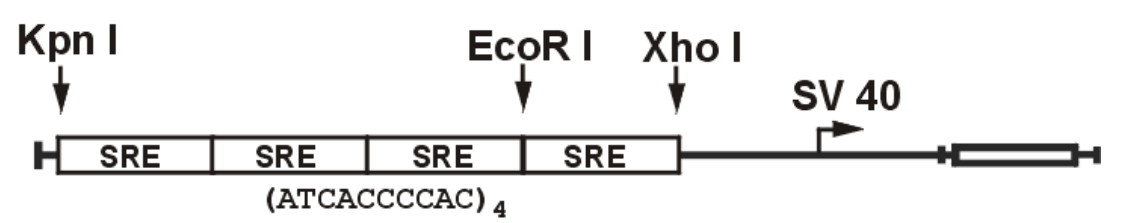

Figure 12. Luciferase gene constructs with oligonucleotides carrying SREBP1 and SP1 responsive elements from fatty acid synthase promoter as enhancers. The double stranded oligonucleotides carrying the FAS-SRE's and FAS-SP1 were cloned into the Kpn I and Xho I restriction sites of pGL3Promoter vector. The sequences shown in the above figure are the consensus sequence for the binding of SREBP1 and SP1. The number under the brackets indicates the number of repeats. 


\subsubsection{Expression Plasmids}

Expression plasmid constructs used in this work are listed below.

\begin{tabular}{|c|c|c|}
\hline Plasmid & Description & Reference \\
\hline pCMV4-SREBP1a460 & $\begin{array}{l}\text { cDNA coding the } 5 \text {-untranslated region and amino } \\
\text { acids } 1-460 \text { of nuclear human SREBP1a under the } \\
\text { control of the CMV promoter in pcDNA4 vector } \\
\text { (AMP', Invitrogen) }\end{array}$ & $\begin{array}{l}\text { Shimano H et } \\
\text { al., } 1997\end{array}$ \\
\hline pcDNA3-FLAG FKHR & $\begin{array}{l}\text { Full length ORF coding for human FKHR tagged with } \\
\text { FLAG tag under the control of the CMV promoter in } \\
\text { pcDNA3 (AMPr', Invitrogen) }\end{array}$ & $\begin{array}{l}\text { Tang et al., } \\
1999\end{array}$ \\
\hline $\begin{array}{l}\text { pcDNA3-FLAG-FKHR } \\
\text { AAA }\end{array}$ & $\begin{array}{l}\text { human FKHR cDNA with triple mutations at Thr24, } \\
\text { Ser256, and Ser319 to Ala with FLAG tag under the } \\
\text { control of the CMV promoter in pcDNA3 (AMP }{ }^{r} \text {, } \\
\text { Invitrogen) }\end{array}$ & $\begin{array}{l}\text { Tang et al., } \\
1999\end{array}$ \\
\hline pCMX HNF4 & $\begin{array}{l}\text { cDNA encoding the rat HNF4 (NR2A1) under the } \\
\left.\text { control of the CMV promoter in pCMX vector (Amp }{ }^{r}\right)\end{array}$ & $\begin{array}{l}\text { Sladeck et al., } \\
2000\end{array}$ \\
\hline $\begin{array}{l}\text { pcDNA3.1 myc-His - } \\
\text { SIRT1 }\end{array}$ & $\begin{array}{l}\text { human SIRT1 full length ORF tagged with myc and } \\
\text { His tags under the control of CMV promoter in } \\
\text { pcDNA } 3.1 \text { (Ampr }{ }^{r} \text { Invitrogen) }\end{array}$ & $\begin{array}{l}\text { Untermann TG } \\
\text { et al., } 2005\end{array}$ \\
\hline
\end{tabular}




\subsection{Oligonucleotides}

HPLC purified synthetic oligonucleotides were obtained from MWG (Ebersberg) and Operon biotechnologies (Cologne, Germany).

\subsubsection{Primers for sequencing}

\begin{tabular}{llc}
\hline Vector & \multicolumn{1}{c}{ Primer } & Sequence 5' $\longrightarrow$ 3' \\
\hline pBS KSII & T7 promoter Primer & $5^{\prime}$ - TAA TAC GAC TCA CTA TAG GGA GA -3' \\
& T3 promoter primer & $5^{\prime}$ - ATT AAC CCT CAC TAA AGG GA -3' \\
& M13 forward & $5^{\prime}$ - TGT AAA ACG ACG GCC AG -3' \\
& M13 reverse & $5^{\prime}$ - ACA GCT ATG ACC ATG ATT -3' \\
\hline pTZ57R/T & T7 promoter Primer & $5^{\prime}$ - TAA TAC GAC TCA CTA TAG GGA GA -3' \\
\hline pGL3 & RV3 primer (Forward) & $5^{\prime}$ - CTT TAT GTT TTT GGC GTC TTC C -3' \\
& GL2 primer (Reverse) & $5^{\prime}$ - CTA GCA AAA TAG GCT GTC CC -3' \\
\hline
\end{tabular}

\subsubsection{Oligonucleotides for PCR reaction}

Primers used to generate deletion constructs

\begin{tabular}{lc}
\hline Primer name & \multicolumn{1}{c}{ Sequence 5' $\longrightarrow$ 3' } \\
\hline GK 1 & 5'- CTT GGG AGA TCT TGG CAT TCC G -3' \\
GK 2 & 5'- GTG GCA GAT CTT TTT AGC AGA G -3' \\
GK 3 & 5'- CAG CAA GAT CTG AGG ATG TTG G -3' \\
GK 4 & 5'- CTC CGC AGA TCT AAT CCC ACG A -3' \\
9 GK & 5'- GTC ATA TGA GAT CTG GTG AGG -3' \\
RGK & 5'- GGA ATG CCA AGC TTA AGG AC -3' \\
\hline
\end{tabular}




\subsubsection{Primers used for site directed mutagenesis}

\begin{tabular}{|c|c|}
\hline Primer name & Sequence $5^{\prime} \longrightarrow 3^{\prime}$ \\
\hline m SRE1 s & 5'- CCC ACG AGG AGC CCC CTA TAT TCA CAA GTC TGA AGC C -3' \\
\hline m SRE1 as & 5'- GGC TTC AGA CTT GTG AAT ATA GGG GGC TCC TCG TGG G -3' \\
\hline m SRE2 S & 5'- CCA GTC TGA AGG GAG GGG ATG GAG TGG GCA GGC -3' \\
\hline $\mathrm{m}$ SRE2 as & 5'- GCC TGC CCA CTC CAT CCC CTC CCT TCA GAC TGG -3' \\
\hline m SRE $3 \mathrm{~s}$ & 5'- GGG CAG GCT CCA GCA TCC TCA TTA ACC TCT CC -3' \\
\hline $\mathrm{m}$ SRE 3 as & 5'- GGA GAG GTT AAT GAG GAT GCT GGA GCC TGC CC -3' \\
\hline m E-box s & 5'- CAC CCT ATG TAC CCT GAC CGA ATT CCC AGT GGC AGC -3' \\
\hline $\mathrm{m}$ E-box as & 5'- GCT GCC ACT GGG AAT TCG GTC AGG GTA CAT AGG GTG -3' \\
\hline m FP B1 s & 5'- CTT GCC AGT GGC AGC TAA TTT TAG TCG ACC TTG GAG ATG CC -3' \\
\hline $\mathrm{m}$ FP B1 as & 5'- GGC ATC TCC AAG GTC GAC TAA AAT TAG CTG CCA CTG GCA AG -3' \\
\hline m FP B2 s & 5'- GCA GAG CTT AGA TCT GCC AGC AAG TGC AGA GGA TGT TGG -3' \\
\hline $\mathrm{m}$ FP B2 as & 5'- CCA ACA TCC TCT GCA CTT GCT GGC AGA TCT AAG CTC TGC -3' \\
\hline \multirow[t]{2}{*}{ m FKHR a s } & 5'- GGG TTC AAG GCA ACT TAA GGA GAT TCT ATA ACA GTA AGC TTA AAA \\
\hline & ATC TGA TTA AAA CGC -3' \\
\hline \multirow[t]{2}{*}{ m FKHR a as } & 5'- GCG TTT TAA TCA GAT TTT TAA GCT TAC TGT TAT AGA ATC TCC TTA \\
\hline & AGT TGC CTT GAA CCC -3' \\
\hline \multirow[t]{2}{*}{ m FKHR b s } & 5'- CTG ATT AAA ACG CAT CGT CGA CTA CTT GGG GTG GGG GGT GTC \\
\hline & AGG GC -3' \\
\hline \multirow[t]{2}{*}{ m FKHR b as } & 5'- GCC CTG ACA CCC CCC ACC CCA AGT AGT CGA CTA TGC GTT TTA \\
\hline & ATC AG -3 \\
\hline
\end{tabular}




\subsubsection{Oligonucleotides used for $p$ GL3-SRE and SRE/SP construction}

The sequences of oligonucleotides comprising FAS-SRE and FAS-SP1 binding elements used to construct the pGL3-4SRE and pGL3-SR/SP are shown below.

4 SRE S 5'- CAA AAT CAC CCC ACT GCA AAA TCA CCC CAC TGC AAA ATC ACC CCA CTG AAT TCA AAA TCA CCC CAC TGC -3'

4SRE as 5'- TCG AGC AGT GGG GTG ATT TGA ATT CAG TGG GGT GAT TTT GCA GTG GGG GTG ATT TTG CAG TGG GGT GAT TTT GGT AC -3'

SR/SP s 5'- CAA AAT CAC CCC ACT GCA AAA TCA CCC CAC TGC AAA ATC ACC CCA CTG AAT TCA ACT CCT CCC CCT GC -3'

SR/SP as 5'- TCG AGC AGG GGG AGG AGT GAA TTC AGT GGG GTG ATT TTGCAG TGG GGT GAT TTT GCA GTG GGG TGA TTT TGG TAC -3'

\subsection{Antibodies}

\begin{tabular}{|c|c|c|c|c|}
\hline Antibodies & Epitope & Source & Dilution & Company \\
\hline $\begin{array}{l}\text { Glucokinase } \\
\text { (C-20) }\end{array}$ & C-terminus of $\mathrm{h} \mathrm{GCK}$ & Goat polyclonal & $1: 250$ & Santa Cruz \\
\hline SREBP & AA $301-407$ of SREBP-1 & $\begin{array}{c}\text { Mouse } \\
\text { monoclonal }\end{array}$ & $1: 2000$ & Santa Cruz \\
\hline FOXO1 & AA 471-598 of $h$ FKHR & Rabbit polyclonal & $1: 1000$ & Santa Cruz \\
\hline $\begin{array}{l}\text { Acetylated } \\
\text { FOXO1 }\end{array}$ & AA K $242 / 245$ of FKHR & Rabbit polyclonal & $1: 1000$ & $\begin{array}{l}\text { Prof. Akiyoshi } \\
\text { Fukamizu, } \\
\text { Japan. }\end{array}$ \\
\hline FLAG Tag & $\begin{array}{l}\text { Flag-tag ('N-DYKDDDDK- } \\
\text { C') fused to either N' / C' }\end{array}$ & $\begin{array}{c}\text { Mouse } \\
\text { monoclonal }\end{array}$ & $1: 1000$ & Sigma \\
\hline Myc Tag & $\begin{array}{l}\text { Myc-tag (N'-EQKLISEEDL- } \\
\text { C') fused to either N' / C' }\end{array}$ & $\begin{array}{c}\text { Mouse } \\
\text { monoclonal }\end{array}$ & $1: 1000$ & Cell signalling \\
\hline
\end{tabular}




\subsection{Protease inhibitors}

Complete, Mini, EDTA free protease inhibitor cocktail tablets (Roche) inhibit a broad spectrum of serine and cysteine proteases. One tablet in $10 \mathrm{ml}$ of extraction buffer is sufficient for the inhibition of the proteolytic activity of proteases such as serine, cystine, trypsin and acid proteases in $10 \mathrm{ml}$ of extraction buffer.

\subsection{Enzymes}

\subsubsection{Restriction endonucleases}

Type II restriction endonucleases to generate 5' or 3' sticky ends used in this study were obtained from TaKaRa and MBI Fermentas. The enzymes were used with optimized buffers supplied by the company.

\subsubsection{DNA and RNA modifying enzymes}

\section{Enzyme}

Taq DNA polymerase

T4 DNA ligase

T4 polynucleotide kinase

Shrimp alkaline phosphatase (SAP)

T3 and T7 RNA polymerases

RNase A (DNase-free)

\section{Company}

TaKaRa

MBI Fermentas

Amersham

Roche

Roche

Qiagen

\subsubsection{Enzymes used in glucokinase enzyme activity assays}

The enzyme glucose 6-phosphate dehydrogenase (G6PDH) converts glucose 6-phosphate to 6phosphogluconate, which in turn is converted into ribulose-5-phosphate by 6 -phosphogluconic acid dehydrogenase (6PGDH). Both enzymes were obtained from Sigma-Aldrich.

\subsubsection{Collagenase}

The collagenase (Biochrom AG) is a protease which degrades collagen fibrils, which are the major fibrous component of animal extracellular connective tissue. The liver connective tissue 
was digested with collagenase for the preparation of rat primary hepatocytes. Collagenase has no specific activity for any single substrate (single protein) but could recognize specific structural patterns inside protein chains.

\subsubsection{Lysozyme}

Bacterial cell wall was destroyed by using lysozyme (Applichem), which hydrolyzes the glycoside bond of the bacterial mureine.

\subsection{Stock Solutions}

All stock solutions were, unless mentioned, prepared in sterile deionized $\mathrm{H}_{2} \mathrm{O}$ at room temperature according to the laboratory manual 'Molecular cloning' (Sambrook and Russell). The solutions used for RNA studies were prepared with DEPC-treated $\mathrm{H}_{2} \mathrm{O}$.

Ammonium acetate $7.5 \mathrm{M}$

$\mathrm{NH}_{4} \mathrm{Ac}$

The solution was autoclaved

$\underline{\text { Ammonium per sulphate (APS) }}$

APS

APS was prepared fresh always.

Blocking reagent $10 \%$

$50 \mathrm{mg}$ of blocking reagent was diluted in $500 \mathrm{ml}$ of $1 \mathrm{X}$ maleic acid buffer with little warming. The solution was autoclaved and stored at $4^{\circ} \mathrm{C}$.

Lithium chloride $4 \mathrm{M}$

$100 \mathrm{mg} / \mathrm{ml}$

Final concentration

$10 \%$
$57.8 \mathrm{~g} / 100 \mathrm{ml}$

$7.5 \mathrm{M}$

$$
7.5 \mathrm{M}
$$

Final concentration
$\mathrm{LiCl}$

The solution was autoclaved.

Magnesium chloride $1 \mathrm{M}$

$\mathrm{MgCl}_{2}$ 
The solution was sterile filtered.

Sodium acetate $3 \mathrm{M}(\mathrm{pH} 5.2)$

Final concentration

$\mathrm{NaAc}$

$24.61 \mathrm{~g}$

$300 \mathrm{mM}$

$\mathrm{H}_{2} \mathrm{O}$

to $100 \mathrm{ml}$

The $\mathrm{pH}$ was adjusted with concentrated acetic acid (needed in large amounts) to 5.2. The solution was autoclaved.

Sodium acetate $2 \mathrm{M}(\mathrm{pH} 4.1)$

Final concentration

$3 \mathrm{M} \mathrm{NaAc}$

2 parts

$2 \mathrm{M}$

Acetic acid (Conc)

1 part

The $\mathrm{pH}$ was adjusted with concentrated acetic acid to 4.1 and autoclaved.

$\underline{10 \times P B S}$

Final concentration

$\mathrm{NaCl}$

$81.82 \mathrm{~g} / \mathrm{I}$

$1.4 \mathrm{M}$

$\mathrm{KCl}$

$2.02 \mathrm{~g} / \mathrm{I}$

$27 \mathrm{mM}$

$\mathrm{Na}_{2} \mathrm{HPO}_{4}$

$16.02 \mathrm{~g} / \mathrm{l}$

$90 \mathrm{mM}$

$\mathrm{KH}_{2} \mathrm{PO}_{4}$

$2.04 \mathrm{~g} / \mathrm{I}$

$15 \mathrm{mM}$

The $\mathrm{pH}$ was adjusted to 7.0 and autoclaved.

$10 \%$ SDS

Final concentration

SDS

$10 \mathrm{~g} / 100 \mathrm{ml}$

$10 \%$

$\underline{20 \times \text { SSC }}$

Final concentration

$\mathrm{NaCl}$

$175.32 \mathrm{~g} / \mathrm{I}$

$3 \mathrm{M}$

Sodium citrate

$88.25 \mathrm{~g} / 1$

$0.3 \mathrm{M}$

$\underline{\text { Tris } / \mathrm{HCl} 1 \mathrm{M}}$

Final concentration

Tris

$12.11 \mathrm{~g} / \mathrm{I}$

$1 \mathrm{M}$ 
$\mathrm{HCl}$ was used to adjust different $\mathrm{pH}$ values $7.5 ; 8.0 ; 9.0$ and the solutions were autoclaved.

$\underline{\text { Tris } / \mathrm{HCl} 0.1 \mathrm{M}}$

Tris

$\mathrm{HCl}$ was used to adjust different $\mathrm{pH}$ values $7.5 ; 8.0 ; 9.0$ and the solutions were autoclaved.
Ampicillin

Ampcillin powder
Final concentration

Final concentration
$1.211 \mathrm{~g} / \mathrm{I}$
$0.1 \mathrm{M}$

Adjusted the $\mathrm{pH}$ to 7.0 with $\mathrm{NaOH}$ and sterile filtered.

$\underline{\text { Calcium chloride }}$

Final concentration

$\mathrm{CaCl}_{2} \cdot 2 \mathrm{H}_{2} \mathrm{O}$

$3.675 \mathrm{~g} / 10 \mathrm{ml}$

$2.5 \mathrm{M}$

The solution was sterile filtered and stored at $-20^{\circ} \mathrm{C}$

Ethidium bromide

Final concentration

$\mathrm{EtBr}$

$50 \mathrm{mg} / 50 \mathrm{ml}$

$10 \mathrm{mg} / \mathrm{ml}$

EDTA

Final concentration

EDTA

$18.6 \mathrm{~g} / 100 \mathrm{ml}$

$0.5 \mathrm{M}$

Adjusted the $\mathrm{pH}$ to 8.0 and stored at RT.

\subsection{Chemicals}

Chemical

\section{Company}

Acrylamide (30\% acrylamide: N,N-methylene-bisacrylamide)

Roth (Karlsruhe)

Agar

Applichem (Darmstadt)

Agarose

Invitrogen (Karlsruhe)

Ammonium persulphate (APS)

Serva (Heidelberg)

Ampicillin (Amp)

Serva (Heidelberg) 
Antifoam A

Bacto agar

Bacto trypton

Blocking reagent

Bromophenolblue

Chloroform

CDTA

CSPD

Diethylpyrocarbonate (DEPC)

Dimethylsulfoxide (DMSO)

Dithiothreitol (DTT)

dNTPs

Ethanol

Ethidium bromide (EtBr)

Formaldehyde (37\%)

Glycerol

Glycine

Guanidin thiocyanate

Hepes

Insulin

Isopropanol

Luciferase cell lysis reagent

$\beta$-mercaptoethanol ( $\beta$-ME)
Sigma (Taufkirchen)

Applichem (Darmstadt)

Applichem (Darmstadt)

Roche (Mannheim)

Serva (Heidelberg)

Merck (Darmstadt)

Sigma (Taufkirchen)

Roche (Mannheim)

Roth (Karlsruhe)

Sigma (Taufkirchen)

Sigma (Taufkirchen)

Roche (Mannheim)

Merck (Darmstadt)

Serva (Heidelberg)

Applichem (Darmstadt)

Applichem (Darmstadt)

Applichem (Darmstadt)

Applichem (Darmstadt)

Applichem (Darmstadt)

Sigma (Taufkirchen)

Merck (Darmstadt)

Promega (Mannheim)

Serva (Heidelberg) 
Maleic acid

MEM, M199 medium

Nembutal

NP-40

$\mathrm{N}$-lauroylsarcosin

3-(N-morpholin)-propanesulfonic acid (MOPS)

Non-fat dried milk

Paraformaldehyde

Penicillin G potassium salt

Phenol

Phenylmethanesulfonyl fluoride (PMSF)

Ponceau S

PEG 4000

Sodium dodecyl sulfate (SDS)

TEMED

Tris(hydroxymethyl)aminomethane (Tris)

Triton X-100

Trypan Blue

Trypsin

Tween ${ }^{\circledR} 20$

X-ray film developer LX24

X-ray film fixer AL4
Applichem (Darmstadt)

PAA (Cölbe)

Sigma (Taufkirchen)

Applichem (Darmstadt)

Sigma (Taufkirchen)

Applichem (Darmstadt)

Applichem (Darmstadt)

Serva (Heidelberg)

Serva (Heidelberg)

Applichem (Darmstadt)

Sigma (Taufkirchen)

Sigma (Taufkirchen)

Serva (Heidelberg)

Serva (Heidelberg)

Applichem (Darmstadt)

Sigma (Taufkirchen)

Sigma (Taufkirchen)

Sigma (Taufkirchen)

PAA (Cölbe)

Applichem (Darmstadt)

Kodak (Rochester, USA)

Kodak (Rochester, USA) 


\subsection{Detection, purification and synthesis kits}

\section{Kit name}

Jet star Plasmid purification Kit

QIAEXII Gel extraction Kit

DIG-Nucleic-Acid detection kit

Luciferase Assay Kit

ECL-Kit

Synthetic oligonucleotides 5'-end labeling Kit

QuickChange XL Site-Directed Mutagenesis Kit

\section{Manufacturer}

Genomed (Löhne)

Qiagen (Hilden)

Roche (Mannheim)

Berthold (Pforzheim)

Amersham (Freiburg)

MBI Fermentas (St.Leon-Rot)

Strategene (Amsterdam)

\subsection{Consumables}

\section{Product name}

3MM whatmann paper

Sterile syringe filters $0.2 \mu \mathrm{m}$

Vasofix Braunüle® $20 \mathrm{G} 1^{1 / 4}, 14 \mathrm{G} 2$

Electroporation cuvetts

Nylon membrane Hybond-N+

PVDF membranes Immobilon ${ }^{\mathrm{TM}} \mathrm{P}$

Tissue culture plastic ware

\section{Company}

Whatman Biometra (Göttingen)

Sartorius (Göttingen)

Braun (Melsungen)

BioRad (Munich)

Amersham Pharmacia (Freiburg)

Amersham Pharmacia (Freiburg)

Sarstedt (Nümbrecht), Eppendorf (Hamburg), Greiner (Flacht), Roth (Karlsruhe) 


\subsection{Instruments}

Device name

Autoclave

Auto Lumat (Luminometer)

Automatic DNA Sequencer

Beckman High speed centrifuge

Electric power apparatus

Electroporator

Electroblotting apparatus

Gel documentation

Heating shaker

Heating stirrer

Hybridization ovens

Incubator with gas flow

Incubator with shaking

Microwave oven

PCR thermocyclers

Peristaltic pump

$\mathrm{pH}$ meter

Photometer

RNA-/DNA-calculator
Model

CE 087

LB 953

$373 \mathrm{~A}$

J2-21

P 25/30

Gene Pulser II

Company

Systec (Wettenberg)

Berthold (Pforzheim)

Applied Biosystems (Weiterstadt)

Beckman (USA)

Biometra (Göttingen)

BioRad (Munich)

Uni. Workshop

DigiDoc-It ${ }^{\circledR}$

Thermomixer 5436

RCT basic

OV 3

Cytoperm 8080

3-25

KOR-6105

Gene Amp 2400

Cyclo 1

535 Multi Cal

$\lambda$ UVIVIS

GeneQuant II
New Brunswick Scientific

(Nuertingen)

UVP (Cambridge)

Eppendorf (Hamburg)

Kika labortechnik (Staufen)

Biometra (Göttingen)

Heraeus (Hanau)

Daewoo Electronics (Butzbach)

Perkin-Elmer (Langen)

Roth (Karlsruhe)

Schütt Labortechnik (Göttingen)

Perkin-Elmer (Langen)

Pharmacia (Ratingen (Breitscheid) 


$\begin{array}{lll}\text { Spectrophotometer } & \text { DU 640 } & \text { Beckman }^{\circledR} \text { (USA) } \\ \text { Speed Vac } & \text { Savant SC110 } & \text { Schütt labortechnik (Göttingen) } \\ \text { Sterile benchs } & \text { TL 2472, HB 2448 } & \text { Heraeus (Hanau) } \\ \text { Sterile pump } & \text { DBP Nr. P 24333991 } & \text { Schleicher \& Schüll (Dassel) } \\ \text { Table-top centrifuges } & 5414 \text { and 5415 C } & \text { Eppendorf (Hamburg) } \\ \text { Table-top cooling centrifuges } & 5403,5415 \mathrm{R} & \text { Eppendorf (Hamburg) } \\ \text { Thermostats } & 450 \text { LE; Type R 10/2 } & \text { Meßgeräte-Werk Lauda } \\ & 5320 & \text { Eppendorf (Hamburg) } \\ \text { Ultra-sound sonicator } & \text { Sonifier }{ }^{\circledR} \mathrm{B}-12 & \text { Branson,(Schwäbisch Gmünd) } \\ \text { Ultraviolet stratalinker } & 1800 & \text { Strategene (Amsterdam) } \\ \text { Water bath } & \text { K2R; NB/S8 } & \text { Meßgeräte-Werk Lauda } \\ \text { Water deionization system } & & \text { Bruno Kummer (Frieberg) } \\ \text { X-Ray film cassettes } & 13 \mathrm{~cm} \times 18 \mathrm{~cm} & \text { Intas (Göttingen) }\end{array}$

\subsection{Software}

Program Name

Company I Organization

Doc It

UVP (Cambridge)

BLAST

NCBI

Corel Draw

Corel corporation

MS office

Microsoft

DNA star

Lasergene

Image J

$\mathrm{NIH}$

Clone manager Suite 7

Sci Ed Central 


\section{Methods}

\subsection{Cell Biology}

All cell lines used in this study were grown at $37^{\circ} \mathrm{C}$ with humidified air containing $5 \% \mathrm{CO}_{2}$, and $16 \% \mathrm{O}_{2}$ in a cell culture incubator. HepG2 and HEK293-T cell lines cultured in $175 \mathrm{~cm}^{2}$ cellculture flask were maintained in minimum essential medium supplemented with $10 \%(\mathrm{w} / \mathrm{v})$ fetal bovine serum, $1 \%$ non essential amino acids (PAA) and $0.5 \%(\mathrm{w} / \mathrm{v})$ antibiotic. For sub-culturing, a $80-90 \%$ confluent flask was rinsed twice with $10-15 \mathrm{ml} 1 \times$ PBS and except HEK cells, treated with $1 \%$ trypsin / EDTA for approximately 2-3 min and the reaction was stopped by adding $5 \mathrm{ml}$ of growth medium with $10 \%$ FBS which contains trypsin inhibitors. Then the cells were harvested by centrifugation and the pellet was resuspended in $5 \mathrm{ml}$ culture medium, counted in a Neubauer chamber and seeded onto plates at required ratios shown below.

Purpose Cell number/vol. suspension plated $\varnothing$ of the culture dish

Transfection $\quad 1 \times 10^{6} / 1.5 \mathrm{ml} \quad 60 \mathrm{~mm}$

Protein isolation $2 \times 10^{6} / 3.0 \mathrm{ml} \quad 60 \mathrm{~mm}$

RNA isolation $\quad 3 \times 10^{6} / 9.0 \mathrm{ml} \quad 100 \mathrm{~mm}$

\subsubsection{Isolation of primary rat hepatocytes}

Primary hepatocytes from the rat liver were isolated by the collagenase perfusion method, according to the method of Berry and Friend (1969) under aseptic conditions.

\subsubsection{Liver perfusion}

Male Wistar rats ( 200-300 g) were housed a controlled environmental conditions with a $12 \mathrm{~h}$ light $12 \mathrm{~h}$ dark cycle (light from 07.00 to $19.00 \mathrm{~h}$ ). They were fed ad libitum with standard laboratory diet (Altromin) and free access to water. Rats were anaesthetized with pentobarbital $(60 \mathrm{mg} / \mathrm{kg}$ body weight). Isolation of hepatocytes by liver perfusion is a two step process consisting of non-reciculative in situ pre-perfusion and recirculative collagenase perfusion.

1. Non-reciculative in situ pre-perfusion of the liver: Following coeliotomy (an incision through the abdominal wall to gain access into the abdominal cavity), the hepatic portal vein was cannulated with a $1.3 \times 45 \mathrm{~mm}$ size needle, and the pre-perfusion of the liver 
was started with 150-200 ml pre-perfusion medium (Krebs-Ringer solution with EGTA) at a flow rate of $30 \mathrm{ml} / \mathrm{min}$ until the liver was free from blood. Then, the inferior vena cava was ligated just above the diaphragm to close the whole body circulation; the inferior vena cava was cut beneath the liver and cannulated with a $22 \times 50 \mathrm{~mm}$ sized needle.

2. Recirculative collagenase perfusion: The pre-perfused liver was now perfused with collagenase perfusion medium at a flow rate of $30 \mathrm{ml} / \mathrm{min}$ until the liver became soft, due to digestion of the connective tissue, which will take up to 10-15 min. During perfusion, the perfusate was returned to the reservoir via a plastic tube connected to the needle inserted in the inferior vena cava and recirculated. To prevent distension of the liver and possible cell damage, the rat was positioned about $10 \mathrm{~cm}$ above the reservoir, so the drainage of the liver could be assisted by a siphoning effect.

Pre-perfusion and perfusion solutions were pumped through an oxygenator, from which they were directed into the portal vein with a pressure of $10-15 \mathrm{~cm}$ of water.

$\underline{\text { Krebs Ringer stock solution }}$

$\mathrm{NaCl}$

$\mathrm{KCl}$

$\mathrm{MgSO}_{4} \times 7 \mathrm{H}_{2} \mathrm{O}$

$\mathrm{KH}_{2} \mathrm{PO}_{4}$

$\mathrm{NaHCO}_{3}$

HEPES
$7 \quad \mathrm{~g} / \mathrm{l}$

$0.36 \mathrm{~g} / \mathrm{l}$

$0.296 \mathrm{~g} / \mathrm{l}$

$0.163 \mathrm{~g} / \mathrm{l}$

$2.016 \mathrm{~g} / \mathrm{l}$

$3.356 \mathrm{~g} / \mathrm{l}$
Final concentration

$120.0 \mathrm{mM}$

$4.8 \mathrm{mM}$

$1.2 \mathrm{mM}$

$1.2 \mathrm{mM}$

$24.4 \mathrm{mM}$

$15 \mathrm{mM}$

The solution was equilibrated with carbogen and adjusted to $\mathrm{pH} 7.35$.

Preperfusion solution

EGTA
$0.1 \mathrm{~g} / \mathrm{l}$

Dissolved in Krebs Ringer stock solution.
Final concentration

$0.25 \mathrm{mM}$ 
Collagenase perfusion solution

$\mathrm{CaCl}_{2} \times 2 \mathrm{H}_{2} \mathrm{O}$

Collagenase
Final concentration

$4 \mathrm{mM}$

Collagenase was dissolved in Krebs Ringer stock solution just before the preparation of hepatocytes, equilibrated with carbogen $\left(5 \% \mathrm{CO}_{2}\right.$ in Oxygen) for $30 \mathrm{~min}$ and finally sterile filtered.

\subsubsection{Preparation of the hepatocyte suspension}

Once persuion was done, the liver was carefully removed and transferred into a glass cup filled with 20-30 ml of culture medium M199 (PAA). The soft liver was then broken up with a blunt spatula and the Glisson's capsule i.e. the outer capsule of connective fibrous tissue surrounding the liver was removed carefully. The obtained primary suspension was filtered through a nylon mesh with a pore size of $79 \mu \mathrm{m}$ to remove the remainders of the Glisson's capsule as well as big cell aggregates. The filtrate was then centrifuged for 3 times at $20 \times g$ for 2 min to remove the non-parenchymal cells and cell debris. After the final centrifugation one gram wet weight of the sedimented cells was resuspended in about $50 \mathrm{ml}$ of M199 to adjust the density of the cell suspension to about $10^{6} / 2.5 \mathrm{ml}$.

\subsubsection{Culture of primary rat hepatocytes}

Freshly isolated hepatocytes resuspended in M199 were supplemented with $4 \%$ fetal calf serum, $1 \%$ antibiotics (penicillin-strptomycine), $100 \mu \mathrm{M}$ dexamethasone and $1 \mathrm{nM}$ insulin as permissive hormones. Then they were plated as per the requirement and cultured in gas controlled incubators with a water vapour saturated atmosphere of $16 \% \mathrm{O}_{2}, 5 \% \mathrm{CO}_{2}$ and $97 \%$ humidity at $37^{\circ} \mathrm{C}$. After the initial $4 \mathrm{~h}$ attachment phase $(5 \mathrm{~h}$ for transfected cells) the medium was changed, and the hepatocytes were further cultured in M199 with the same concentrations of hormones and antibiotics as before, except fetal calf serum. A volume of $2.5 \mathrm{ml}$ medium per $60 \mathrm{~mm}$ culture dish and $6 \mathrm{ml}$ per $100 \mathrm{~mm}$ culture dish was added. After $24 \mathrm{~h}$ the medium was changed again and the culture was continued for another $19 \mathrm{~h}$. 


\subsubsection{Hormone and antibiotic stock solutions}

All solutions were filter sterilized and stored at $-20^{\circ} \mathrm{C}$.

Antibiotics

Penicillin G, sodium salt $\quad 0.64 \mathrm{~g} / 100 \mathrm{ml}$

Streptomycine sulphate $\quad 1.17 \mathrm{~g} / 100 \mathrm{ml}$

Dissolved in $0.9 \% \mathrm{NaCl}$ solution

Dexamethasone $(100 \mu \mathrm{M})$

Dexamethasone $3.92 \mathrm{mg} / 100 \mathrm{ml}$

Dexamethasone was first dissolved in $0.5 \mathrm{ml}$ of ethanol and then filled with $0.9 \% \mathrm{NaCl}$ solution to $100 \mathrm{ml}$.

$\underline{\text { Insulin }(10 \mu \mathrm{M})}$

Insulin $\quad 6 \mathrm{mg} / 100 \mathrm{ml}$

Bovine serum albumin $\quad 100 \mathrm{mg} / 100 \mathrm{ml}$

Insulin was dissolved in $0.9 \% \mathrm{NaCl}$ at a $\mathrm{pH}$ of 2.5 , neutralized and then bovine serum albumin was added.

\subsubsection{Transfection of hepatocytes, HepG2 and HEK293-T cells}

Primary rat heptocytes, HEK293-T and HepG2 cells were transfected by a modified calcium phosphate precipitation method (Graham and van der Eb, 1973). The modifications are mostly regarding the type of cells used, the time and duration of transfection \{(Parker and Stark, 1979); (Chen and Okayama, 1987); (Chen and Okayama, 1988); (Ginot et al., 1989); (Pasco and Fagan, 1989); (Rippe et al., 1990)\}. The principle of the method is that the uptake of DNA is markedly enhanced when the nucleic acid is presented as a co-precipitate of calcium phosphate and DNA in the presence of a phosphate-buffered solution. The insoluble precipitate attaches to the cell surface and is brought into the cells by endocytosis. 
Plasmid DNA

$\mathrm{H}_{2} \mathrm{O}$

$2.5 \mathrm{M} \mathrm{CaCl}_{2}$

$2 \times$ Hepes
$2.5 \mu \mathrm{g}$

to $67.5 \mu \mathrm{l}$

$7.5 \mu \mathrm{l}$

$75 \mu \mathrm{l}$
$125 \mathrm{mM}$

$1 \mathrm{X}$

The transfection mixture was prepared in polystyrol tubes to prevent adhesion of the DNA to the walls and was allowed to form the co-precipitate of DNA and calcium phosphate. Finally, $150 \mu \mathrm{l}$ of the mixture was added to $1.5 \mathrm{ml}$ of the freshly plated heptocytes in suspension or to $2.5 \mathrm{ml}$ of precultured HepG2 or HEK293-T cells in $60 \mathrm{~mm}$ culture dishes. After $5 \mathrm{~h}$ transfection the medium was changed and the hepatocytes were further cultured in M199 with the same concentrations of hormones and antibiotics as mentioned except fetal calf serum. After $24 \mathrm{~h}$ the cells were grown for additional $24 \mathrm{~h}$ in fresh culture medium of $2.5 \mathrm{ml}$ per $60 \mathrm{~mm}$ culture dish, 6 $\mathrm{ml}$ per $100 \mathrm{~mm}$ culture dish and $17 \mathrm{ml}$ per $150 \mathrm{~mm}$ culture dish.

\section{$\underline{2 \times \text { Hepes }}$}

Hepes

$\mathrm{NaCl}$

$\mathrm{Na}_{2} \mathrm{HPO}_{4}$
$1.2 \mathrm{~g} / 100 \mathrm{ml}$

$1.6 \mathrm{~g} / 100 \mathrm{ml}$

$0.3 \mathrm{~g} / 100 \mathrm{ml}$

\section{Final Concentration}

$50 \mathrm{mM}$

$280 \mathrm{mM}$

$1.5 \mathrm{mM}$

The $\mathrm{pH}$ was adjusted with $5 \mathrm{~N} \mathrm{NaOH}$ to 7.05 and the buffer was stored at $-20^{\circ} \mathrm{C}$ as $10 \mathrm{ml}$ aliquots.

\section{Calcium chloride $2.5 \mathrm{M}$}

$\mathrm{CaCl}_{2}$

$36.75 \mathrm{~g} / 100 \mathrm{ml}$

Final Concentration

$2.5 \mathrm{M}$

The solution was filter sterilized and store in aliquots at $-20^{\circ} \mathrm{C}$.

\subsubsection{Luciferase reporter gene assay}

Luciferase activity in the cells transfected with reporter vectors containing the luciferase gene from North American firefly (Photinus pyralis) was detected using the Luciferase Assay Kit 
(Berthold, Pforzheim). The luciferase assay is based on the enzyme-catalyzed chemiluminescence where the firefly luciferase enzyme catalyses oxidative decarboxylation of luciferin in the presence of ATP and $\mathrm{Mg}^{2+}$ ions yielding photons as well as AMP, $\mathrm{CO}_{2}$ and oxyluciferine. The light emission measured at $562 \mathrm{~nm}$ depends on the concentration of the luciferase enzyme; therefore, it allows quantitative estimation of the expression level of the reporter gene.

Prior to measure the cells were washed with $2.5 \mathrm{ml} 1 \times$ PBS and $500 \mu \mathrm{llysis}$ buffer were applied. The cells were allowed to lyse on a shaker for approximately $30 \mathrm{~min}$, scraped, vortexed and centrifuged for $2 \mathrm{~min}$ at $16000 \times g$ (14 $000 \mathrm{rpm}$ at a tabletop centrifuge eppendorf, rotor 5415C). In case of primary rat hepatocytes, the cell lysates were snap frozen in liquid nitrogen, subsequently thawed at RT and centrifuged. Twenty $\mu$ of the supernatant from the transfected cells were automatically mixed in the luminometer with $100 \mu$ l luciferase assay reagent, prepared directly before use by mixing equal parts of solution $\mathrm{A}$ and $\mathrm{B}$. The reaction was measured 10 times for $2 \mathrm{~s}$. The intensity of luminescence is constant for $20 \mathrm{~s}$ and then decreases with a half-life of $5 \mathrm{~min}$.

$\underline{5 X \text { Lysis buffer }}$

Final concentration

Tris

$25 \mathrm{ml}$ of $1 \mathrm{M}$

$125 \mathrm{mM}$

CDTA

$10 \mathrm{ml}$ of $200 \mathrm{mM}$

$10 \mathrm{mM}$

DTT

$4 \mathrm{ml}$ of $500 \mathrm{mM}$

$10 \mathrm{mM}$

Glycerol

$115 \mathrm{ml}$ of $85 \%$

$50 \%$

Triton X-100

$10 \mathrm{ml}$ of $100 \%$

$5 \%$

$\mathrm{H}_{2} \mathrm{O}$

to $200 \mathrm{ml}$

The $\mathrm{pH}$ was adjusted to 7.8 with $\mathrm{H}_{3} \mathrm{PO}_{4}$ and the solution was autoclaved.

\subsubsection{Freezing of cells}

Cells from an $80-90 \%$ confluent dish were trypsinized and resuspended in 2-3 $\mathrm{ml}$ of growth medium. Cells were then centrifuged at $1000 \mathrm{~g}$ for $2 \mathrm{~min}$ and resuspended in $1.0 \mathrm{ml}$ of fresh culture medium. Then $0.5 \mathrm{ml}$ of cells were aliquoted into cryovials and an equal volume of 
medium containing $20 \%$ DMSO was added, to get a final concentration of $10 \%$. The vials were kept on ice for $15 \mathrm{~min}$, and then transferred to $-20{ }^{\circ} \mathrm{C}$ for $4 \mathrm{~h}$ and then to $-70{ }^{\circ} \mathrm{C}$ for $48-72 \mathrm{~h}$. Cells were finally transferred to liquid nitrogen storage.

\subsubsection{Treatment of hepatocytes with different compounds}

Freshly isolated hepatocytes were allowed to attach for $5 \mathrm{~h}$ and culture medium was changed. After $24 \mathrm{~h}$ the hepatocytes were treated with insulin, TO-901317, resveratrol, glucagon, CAMP at different concentrations specified for each experiment. For Northern blots the cells were treated for $16 \mathrm{~h}$, for Western blots and luciferase assays the cells were treated for $24 \mathrm{~h}$ before harvesting without changing the medium.

\subsection{Molecular biological methods}

\subsubsection{Polymerase chain reaction}

The polymerase chain reaction (PCR) is an in vitro method for exponentially amplifying DNA fragments from a template DNA (Mullis and Faloona, 1987). PCR reactions were carried out in a buffer containing $10 \mathrm{mM}$ Tris (pH8.8), $1.5 \mathrm{mM} \mathrm{MgCl}_{2}$ and $10 \mathrm{mM}$ dNTP (each) were used per reaction, along with $2.5 \mathrm{U}$ of thermostable DNA dependent DNA polymerase (Taq). The reaction volume was usually $50 \mu \mathrm{l}$. PCRs were carried out for 25-30 cycles, with a denaturing temperature of $95{ }^{\circ} \mathrm{C}$ for $1 \mathrm{~min}$, annealing temperature of $50-55{ }^{\circ} \mathrm{C}$ for $1 \mathrm{~min}$ (depending upon the sequence of the primer), and extension temperature of $72{ }^{\circ} \mathrm{C}$ for 1-2 min depending upon the length of the product to be amplified. Products of the PCR reaction were analyzed on 1-2\% agarose gels containing $0.2 \mathrm{mg} / \mathrm{ml}$ ethidium bromide. In cases where the reaction products were used for restriction digestion or sub-cloning, the PCR amplified fragments were purified through Qiagen PCR purification columns.

A $50 \mu$ l of standard polymerase chain reaction mixture contains:

$\begin{array}{lc}\text { Template DNA } & 10 \mathrm{ng} \\ 10 \times \text { Taq buffer (with } 1.5 \mathrm{mM} \mathrm{MgCl}_{2} \text { ) } & 5 \mu \mathrm{l} \\ 10 \mathrm{mM} \text { dNTPs (each) } & 1 \mu \mathrm{l} \\ 10 \mathrm{pmol} / \mu \mathrm{l} \text { primers } & 2.5 \mu \mathrm{l} \\ \text { Taq polymerase } & 2.5 \mathrm{U} \\ \mathrm{H}_{2} \mathrm{O} & \text { up to } 50 \mu \mathrm{l}\end{array}$

The PCR reaction was carried out in a programmable thermal cycler (Perkin Elmer). 


\subsubsection{Purification of PCR products}

The PCR products were purified from the reaction mixture by sodium acetate/ethanol precipitation or by separating the PCR products on an agarose gel and the fragments of interest were purified using QIAquick gel extraction kit (Qiagen) following the manufacturer protocol. The purified PCR products were cloned into a T/A cloning vector and subcloned into pGL3-Basic by using the following methods.

\subsubsection{Cloning of PCR fragments into (pTZ57R/T) the TIA cloning vector}

The T/A cloning system is a convenient system for direct one-step cloning of PCR-amplified DNA fragements. DNA polymerases, that lack $3^{\prime} \rightarrow 5^{\prime}$ exonuclease activity possess deoxynucleotidyl transferase (TdT) activity in addition to primer extension activity which frequently results in the addition of extra adenines at 3'-ends of amplified DNA molecules. This makes it possible to clone the PCR product directly into a linearized cloning vector with single 3' $-T$ overhangs. The 3'-A overhangs of the PCR product complement the 3'-T overhangs of the vector and allow fast ligation by T4 DNA polymerase. This ligation mixture can then be transformed into competent bacterial cells.

A ratio of 1:3 vector to insert was used for ligation reaction.

Ligation of PCR product into T/A Vector:

Plasmid vector pTZ57R/T $(\sim 0.150 \mu \mathrm{g}) \quad 3 \mu \mathrm{l}$

Purified PCR fragment $\quad(\sim 0.450 \mu \mathrm{g}) \quad 4 \mu \mathrm{l}$

10X ligation buffer $\quad 3 \mu \mathrm{l}$

PEG 4000 solution $\quad 3 \mu \mathrm{l}$

Deionized water to $29 \mu \mathrm{l}$

T4 DNA ligase, $5 \mathrm{U} \quad 2 \mu \mathrm{l}$

The ligation reaction was incubated at $20^{\circ} \mathrm{C}$ for $1 \mathrm{~h}$. T4 DNA ligase catalyzes the formation of a phosphodiester bond between free 5'-phosphate and 3'-OH groups of double-stranded DNA fragments resulting in the formation of recombinant DNA molecules. The ligation reaction occurs when the ends are compatible; at least one of the ends must be phosphorylated; ATP and 
optimal ligation buffer are available. The ligation reaction was carried out at $20^{\circ} \mathrm{C}$ for one $\mathrm{h}$. Then 8 to $10 \mu \mathrm{l}$ of the reaction mixture was chemically transformed into competent E.coli cells.

\subsection{Subcloning}

Subcloning is a technique used to move a particular gene of interest from a parent vector to a destination vector in order to further study its functionality. In our case the PCR fragments cloned into the T/A cloning vector were excised with suitable restriction enzymes and subcloned into dephosphorylated pGL3 Basic vector.

\subsection{Dephosphorylation of linearized vector}

To prevent the recircularization of a linearized plasmid vector in ligation reactions, an enzymatic removal of 5'-terminal phosphate residues using shrimp alkaline phosphatase (SAP) was performed in $10 \times$ SAP dephosphorylation buffer (Roche) for $1 \mathrm{~h}$ at $37^{\circ} \mathrm{C}$. The reaction was stopped by heating the sample at $65{ }^{\circ} \mathrm{C}$ for $10 \mathrm{~min}$ and the DNA fragments were purified from agarose gel pieces using QIAquick Gel Extraction Kit (Qiagen) and quantified against a $\lambda$-Hind III DNA ladder.

\subsubsection{In vitro site-specific mutagenesis}

Site directed mutagenesis is an invaluable PCR based technique used to generate a mutation at a defined site in a DNA molecule to understand the gene expression and protein structurefunction relationships. The QuikChange ${ }^{R} X L$ site-directed mutagenesis kit (Stratagene) was used to create the point mutations in putative transcription factor binding elements. The procedure to generate the point mutations was carried out according to the manufacturer instruction manual.

\subsubsection{Synthetic double stranded oligonucleotide cloning into pGL3 promoter vector}

Artificially synthesized oligonucleotides containing the FAS-4SRE's and FAS-3SRE1SP were cloned into Xho I and Kpn I restriction sites of the pGL3-promoter vector. The cloning procedure had the following steps: 


\section{Preparation of oligonucleotides for cloning into pGL3 promoter vector}

Both sense and antisense oligodeoxynucleotides which had to be cloned were phosphorylated at their 5'-ends by T4 polynucleotide kinase. Phosphorylated sense and antisense oligonucleotides were annealed in a $1.5 \mathrm{ml}$ tube. The annealing reaction was carried out in a water bath heated up to $90{ }^{\circ} \mathrm{C}$. Then the water was allowed to cool to room temperature for at least $6 \mathrm{~h}$, which facilitates the annealing of oligodeoxynucleotides. The annealed oligodeoxynucleotides were precipitated with NaAc/ethanol. The precipitated dsoligodeoxyribonucleotides were washed with $70 \%$ ethanol, dried under vacuum and dissolved in $30 \mu \mathrm{H}_{2} \mathrm{O}$. One $\mu \mathrm{l}$ of annealed mixture was checked on a $10 \%$ native acrylamide gel.

\section{Phosphorylation of ss-oligodeoxynucleotide}

Oligo (sense or antisense)

$2 \mu g$

$5 \mathrm{X}$ ligase buffer (5 mM ATP)

$4 \mu \mathrm{l}$

T4 polynucleotide kinase (10 $\mathrm{U} / \mu \mathrm{l})$

$1.5 \mu \mathrm{l}$

$\mathrm{H}_{2} \mathrm{O}$

to $20 \mu \mathrm{l}$

The mixture was incubated at $37^{\circ} \mathrm{C}$ for $60 \mathrm{~min}$.

Polyacrylamide gels allow much better separation of DNA fragments than agarose gels. They can separate molecules of DNA whose lengths differ only by $1 \mathrm{bp}$ in $1000 \mathrm{bp}$. The annealed samples were loaded on native acrylamide gel and electrophoresis in $1 \mathrm{X}$ TBE buffer for $30 \mathrm{~min}$ at $15 \mathrm{~mA}$ was performed. Then, the gel was soaked for $10 \mathrm{~min}$ in ethidium bromide solution (10 $\mu \mathrm{l}$ ethidium bromide in $10 \mathrm{ml}$ of 1 X TBE buffer) and the DNA was visualized under UV light.

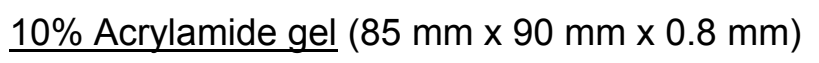

Final Concentration

Acrylamide

$3.3 \mathrm{ml}$ (Rotiphorese ${ }^{\mathrm{R}}$ Gel30 (10\% Acrylamide/0.8 \% Bisacrylamide)

TBE

$0.5 \mathrm{ml} 20 \times$ TBE buffer

$1 \times$ TBE

$\mathrm{H}_{2} \mathrm{O}$

to $10 \mathrm{ml}$

TEMED

$2 \mu l$

$10 \%$ APS

$70 \mu \mathrm{l}$ 
$\underline{20 \times T B E}$

Tris

Borate

EDTA
$108.99 \mathrm{~g} / \mathrm{l}, \mathrm{pH} 8.5$

$55.94 \mathrm{~g} / \mathrm{l}$,

$7.44 \mathrm{~g} / \mathrm{l}$
Final Concentration

$900 \mathrm{mM}$

$900 \mathrm{mM}$

$20 \mathrm{mM}$

\section{Preparation of the pGL3-Promoter vector for ligation}

The pGL3-Promoter vector was linearized with Xho I and Kpn I. To prevent religation of the linearized vector its 5 '-ends were dephosphorylated by adding SAP to the restriction mixture and further incubation for $1 \mathrm{~h}$ at $37^{\circ} \mathrm{C}$. After one hour the SAP activity was inactivated by heating the reaction at $65^{\circ} \mathrm{C}$ for $10 \mathrm{~min}$.

The dephosphorylated mixture was loaded on to a $1 \%$ agarose gel and the linearized vector was isolated from the agarose gel with the QIAEX II Gel Extraction Kit (Qiagen) and quantified.

\section{Ligation of annealed oligonucleotides into linearized pGL3-Promoter}

The 5'-phosphorylated ds-oligodeoxynucleotides were ligated into the linearized and dephosphorylated pGL3-Promoter vector by T4 ligase. The enzyme can only catalyze binding of the 5'-phosphorylated ends of the ds-oligodeoxynucleotides with the 3'-OH ends of the vector; the 3'-OH ends of the ds-oligodeoxynucleotide and the 5'-dephosphorylated ends of the vector could be ligated only by the specific enzymes present in E.coli. Therefore E.coli cells were transformed with the ligation mixture immediately after ligation reaction. The ligation reaction was incubated at $16^{\circ} \mathrm{C}$ and then transformed in competent $E$.coli cells.

\section{Ligation reaction}

ds-oligonucleotide (5'-phosphorylated) $\quad 100 \mathrm{ng}$

Vector (5'-dephosphorylated) $\quad 50 \mathrm{ng}$

$5 \mathrm{X}$ ligase buffer (5 mM ATP) $\quad 4 \mu \mathrm{l}$

T4 ligase $\quad(1 \mathrm{U} / \mu \mathrm{l}) \quad 0.5 \mu \mathrm{l}$

$\mathrm{H}_{2} \mathrm{O} \quad$ to $20 \mu \mathrm{l}$ 


\subsubsection{E.coli competent cell preparation}

Competent cells are bacteria which can accept extra-chromosomal DNA or plasmids. In nature, bacterial cells do not have the ability to accept foreign DNA from the surroundings. But bacterial cells can be made competent in several ways for transformation with the external plasmids. A single colony of E.coli strain XL1 blue was inoculated in $5 \mathrm{ml}$ LB medium and cultured overnight at $37^{\circ} \mathrm{C}$ with moderate shaking. This pre-culture was inoculated into $500 \mathrm{ml}$ of LB medium (1:100 dilution) and allowed to grow while shaking until they reached an $\mathrm{OD}_{550}$ of $0.4-0.5$ (3-5h). The bacterial cells were harvested by centrifugation at $1000 \times g$ for $15 \mathrm{~min}(2500 \mathrm{rpm}$, Beckman GSA rotor). The pellet was washed with $1 / 10$ volume $(5-10 \mathrm{ml})$ of ice cold TSS buffer $(1 \%(\mathrm{w} / \mathrm{v}) \mathrm{NaCl}$, $1 \%(\mathrm{w} / \mathrm{v})$ tryptone, $0.5 \%(\mathrm{w} / \mathrm{v})$ yeast extract, $30 \mathrm{mM} \mathrm{MgCl}, 10 \%(\mathrm{w} / \mathrm{v})$ PEG 4000, 5\% (v/v) DMSO, $\mathrm{pH} 6.5$, sterile filtered). The cells were aliquoted into $100 \mu \mathrm{l}$ volumes, frozen in an ethanol $/ \mathrm{CO}_{2}$ bath and stored at $-80{ }^{\circ} \mathrm{C}$.

For the preparation of electrocompetent cells, cells were grown to reach $0.6-0.8 \mathrm{OD}_{600}$ and centrifuged for $15 \mathrm{~min}$ at $3500 \times \mathrm{g}$ (4800 rpm, Beckman GSA rotor). The pellet was washed twice with ice-cold $10 \%$ glycerol at $4000 \times g$ for 15 min (5000 rpm, Beckman GSA). The pellet was dissolved and aliquoted into volumes of $100 \mu$, immediately frozen in liquid $\mathrm{N}_{2}$ and stored at $-80^{\circ} \mathrm{C}$.

$\underline{\text { LB medium }}$

Trypton $10 \mathrm{~g} / \mathrm{l}$

Yeast extract $5 \mathrm{~g} / \mathrm{l}$

$\mathrm{NaCl} \quad 10 \mathrm{~g} / \mathrm{l}$

The $\mathrm{pH}$ was adjusted with $\mathrm{NaOH}$ to 7.3 . The medium was autoclaved after preparation.

The efficiency of the competent cells was tested by a test transformation with a plasmid carrying ampicillin resistance gene.

\subsubsection{Transformation of competent E.coli cells}

An aliquot of $100 \mu \mathrm{l}$ competent cells was thawed on ice, the ligation mixture or the plasmid DNA which had to be transformed was added carefully, the sample was mixed gently by tapping the eppendorf and then incubated on ice for $30 \mathrm{~min}$. After a $2 \mathrm{~min}$ heat shock at $42^{\circ} \mathrm{C}$, the cells were 
cooled on ice for $10 \mathrm{~min}$. Then $500 \mu \mathrm{l}$ of SOC medium was added and the culture was cultured for $45 \mathrm{~min}$ at $37^{\circ} \mathrm{C}$ on a roller. A $200 \mu \mathrm{l}$ aliquot was plated on an LB agar dish containing ampicillin and incubated at $37^{\circ} \mathrm{C}$ overnight.

In case of electroporation the DNA was introduced into electrocompetent E.coli cells by exposing them to a short-high-voltage (2.5 volts) electrical discharge.

\subsubsection{Ampicillin agar dishes}

$500 \mathrm{ml}$ of LB medium containing $6.25 \mathrm{~g}$ of bactoagar was autoclaved. After cooling to $50{ }^{\circ} \mathrm{C}$ ampicillin was added to the final concentration of $40 \mu \mathrm{g} / \mathrm{ml}$. A ten $\mathrm{ml}$ of the LB-agar with ampicillin was plated into sterile petri dishes and allowed to solidify under a sterile hood. The dried dishes were stored in dark at $4^{\circ} \mathrm{C}$.

\subsubsection{Isolation of plasmid DNA (mini preparation)}

Transformed bacterial colonies with the ligation mixture or with a plasmid, grown on LBampicillin agar plates, were inoculated with $5 \mathrm{ml}$ ampicillin containing LB medium. Plasmid DNA was isolated from the $5 \mathrm{ml}$ culture by minipreparation.

Three $\mathrm{ml}$ of the bacterial culture was centrifuged in a table top centrifuge at $3000 \times g(6000 \mathrm{rpm}$ in a tabletop centrifuge eppendorf, rotor $5415 \mathrm{C}$ ) for $10 \mathrm{~min}$. The medium was drained and the bacterial pellet was resuspended in $150 \mu \mathrm{l}$ of sterile TELT-solution and $3 \mu \mathrm{l}$ of the lysozyme (50 $\mathrm{mg} / \mathrm{ml}$ in $10 \mathrm{mM}$ Tris/HCl pH 7.5, 0.1 Mm EDTA) was added for efficient lysis of the cells. The solution was mixed well and heated at $95^{\circ} \mathrm{C}$ for $2 \mathrm{~min}$ and cooled on ice. The resulting bacterial lysate was centrifuged at $16000 \times \mathrm{g}$ for $10 \mathrm{~min}$ (14 $000 \mathrm{rpm}$ at a tabletop centrifuge eppendorf, rotor $5415 \mathrm{C}$ ) to remove the bacterial debris. The supernatant containing the plasmid DNA was precipitated by adding $100 \mu \mathrm{l}$ isopropanol $\left(10 \mathrm{~min}\right.$ at $-20^{\circ} \mathrm{C}$ ) and centrifuged at $16000 \times g(14$ $000 \mathrm{rpm}$ at a tabletop centrifuge eppendorf, rotor $5415 \mathrm{C}$ ) for $20 \mathrm{~min}$. The precipitated plasmid DNA was washed with $70 \%(\mathrm{v} / \mathrm{v})$ ethanol and centrifuged for $5 \mathrm{~min}$. The pellet was air-dried for 10-20 min. The plasmid DNA was dissolved in 20-30 $\mu$ l of deionized water and used for restriction analysis. 
$\underline{\text { TELT buffer }}$

Tris/ $\mathrm{HCl}, \mathrm{pH} 7.5$

EDTA

$\mathrm{LiCl}$

Triton-X-100
Final concentration

$$
50 \mathrm{mM}
$$

$62.2 \mathrm{mM}$

$2.5 \mathrm{M}$

$0.4 \%(v / v)$

The buffer was autoclaved and stored at room temperature.

\subsubsection{Restriction digestion}

Restriction analysis of DNA was performed by using type II restriction endonucleases, which generate fragments with 5', 3' sticky overhangs or blunt ends after digestion. The reactions were set in appropriate buffers optimized for the enzyme (s) and supplied by the manufacturer (TaKaRa and MBI Fermentas)

\section{Restriction mixture:}

Plasmid DNA

$10 X$ buffer (Enzyme specific)

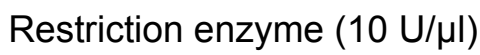

Deionized water
$3-5 \mu l$

$2 \mu \mathrm{l}$

$0.5 \mu \mathrm{l}$

to $20 \mu \mathrm{l}$

The reaction mixture was kept at $37^{\circ} \mathrm{C}$ for an $\mathrm{h}$ and the restriction digestion product was analyzed by agarose gel electrophoresis. The reaction sample was mixed with $3 \mu$ of loading buffer and loaded onto a $1 \%$ agarose gel. To determine the size of DNA fragments a DNA molecular weight standard was used. The electrophoresis was performed for 20-30 min with 50 volts/cm. The negatively charged DNA migrated from the cathode (-) to anode (+). To visualize DNA, the gel was treated with ethidium bromide which intercalates between the bases of DNA double strands forming a complex fluorescent under UV light.

For preparation of the $1 \%$ gel, $1 \mathrm{~g}$ of agarose was dissolved by boiling in $100 \mathrm{ml}$ of $1 \mathrm{x}$ TAE buffer. After the agarose solution was cooled to $60{ }^{\circ} \mathrm{C}$ it was poured into a gel chamber $(8 \mathrm{~cm} X$ $5 \mathrm{~cm} \times 0.4 \mathrm{~cm}$ ). The restriction samples were loaded onto the gel pockets. When the electrophoresis was finished, the gel was soaked in $500 \mathrm{ml}$ of 1 X TAE buffer with $10 \mu \mathrm{l}$ of ethidium bromide and the bands were detected under UV light $(245 \mathrm{~nm})$. The DNA fragment profile was visualized under UV light and photographed. The estimation of the sizes and amount 
of the DNA fragments was done by comparison with a size standard marker ( 1 kb DNA ladder, 100 bp ladder)

Ethidium bromide solution

Ethidium bromide

$10 \mathrm{mg} / \mathrm{ml}$

Stored at $4^{\circ} \mathrm{C}$, protected from light.

10X TAE (Tris/Acetate/EDTA)

Final concentration

Tris

$6.1 \mathrm{~g} / 100 \mathrm{ml}$

$0.5 \mathrm{M}$

Sodium acetate

$1.6 \mathrm{~g} / 100 \mathrm{ml}$

$0.2 \mathrm{M}$

EDTA

$0.7 \mathrm{~g} / 100 \mathrm{ml}$

$0.02 \mathrm{M}$

The $\mathrm{pH}$ was adjusted with acetic acid to 7.4 , the buffer was autoclaved.

Loading Buffer

Final concentration

Bromophenol blue

$0.01 \mathrm{~g} / 100 \mathrm{ml}$

$0.01 \%$

Glycerol

$40 \mathrm{ml} / 100 \mathrm{ml}$

$40 \%$

$10 \times$ TAE buffer

$10 \mathrm{ml} / 100 \mathrm{ml}$

$1 \mathrm{x}$

The buffer was autoclaved and stored at $4{ }^{\circ} \mathrm{C}$.

\subsubsection{Isolation of plasmid DNA in large scale (Maxipreparation)}

For the preparation of larger amounts of high copy plasmids, the DNA Jet Star Maxi-kit (Genomed) was used. The isolation procedure was carried out according to the manufacturer's instructions. (Genomed Plasmid Purification Handbook, 2000)

\subsubsection{Estimation of nucleic acid concentration}

The concentration of nucleic acids was determined using a spectrophotometer (GeneQuant, Pharmacia) by measuring the absorption at $260 \mathrm{~nm}$ of 100 fold diluted samples in a quartz cuvette. An $\mathrm{OD}_{260}$ of 1 in a case of $1 \mathrm{~cm}$ cuvette corresponds to $50 \mu \mathrm{g} / \mathrm{ml}$ double-stranded DNA, 
$40 \mu \mathrm{g} / \mathrm{ml}$ RNA, $37 \mu \mathrm{g} / \mathrm{ml}$ single-stranded DNA and $30 \mu \mathrm{g} / \mathrm{ml}$ oligonucleotides (Sambrook et al., 1989).

The ratio between $A_{260} / A_{280}$ is used to estimate the purity of the nucleic acid, since proteins absorb at $280 \mathrm{~nm}$ because of the aromatic character of tryptophan, tyrosine, histidine and phenylalanine that absorb light at $280 \mathrm{~nm}$ (Millinder \& Clack). DNA or RNA preparations with a ratio of $\mathrm{OD}_{260} / \mathrm{OD}_{280}$ in the range of 1.8-2.0 were regarded as pure and protein-free. Absorption at $230 \mathrm{~nm}$ reflects contamination of the sample by substances such as carbohydrates, peptides, phenols or aromatic compounds. For pure samples the ratio between $\mathrm{OD}_{260} / \mathrm{OD}_{230}$ should be approximately 2.2 .

\subsubsection{Plasmid Sequencing}

The sequence of the cloned DNA fragments was checked by using BigDye ${ }^{T M}$ Terminator Enhanced Terminators Cycle Sequencing kit from Perkin-Elmer, based on the chain-termination principle (Sanger et al., 1992). A premix solution containing 4 dideoxynucleotides (terminators) whose incorporation in the newly-synthesized complementary chain leads to an premature interruption of its elongation. The four terminators are labeled with four different fluorescent dyes and the terminated chains can be specifically detected by capillary electrophoresis on an $A B I$ Model 373A capillary sequncer (Applied Biosystems) during which $40 \mathrm{~mW}$ argon lasers (488 nm and $514 \mathrm{~nm}$ ) stimulate the fluorescence of dye-labeled polynucleotides.

Sequencing reaction

Plasmid

Primer $(2.5 \mathrm{pmol} / \mu \mathrm{l})$

Sequencing mix

Deionized water
Final Concentration

$$
2-3 \mu \mathrm{l}
$$

$2 \mu \mathrm{l}$

$3 \mu \mathrm{l}$

to $10 \mu \mathrm{l}$

The sequencing reaction was subjected to 25 cycles of $30 \mathrm{sec}$ at $96^{\circ} \mathrm{C} ; 15 \mathrm{sec}$ at $55^{\circ} \mathrm{C} ; 4 \mathrm{~min}$ at $60^{\circ} \mathrm{C}$ in a thermocycler. The sequencing reaction products were precipitated by NaAc/Ethanol method. Thus precipitated sequencing reaction product was washed with $70 \%$ ethanol and vacuum dried for $5 \mathrm{~min}$ and resuspended in $25 \mu \mathrm{l}$ of deionized water. After denaturation for 2 min at $95^{\circ} \mathrm{C}$ and immediate cooling on ice, the sample was transferred into a special tube for 
sequencing and kept on ice until loading on an ABI-prism ${ }^{\mathrm{TM}} 310$ capillary electrophoresis sequencing station (Perkin-Elmer) for analysis.

\subsubsection{Preparation of digoxigenin-labeled RNA probes}

The detection of mRNA on northern blots was performed after hybridization with digoxigenin labeled, single-stranded RNA probes. The RNA probes were synthesized by an in vitro transcription catalyzed by T3, T7 and SP6 RNA polymerases. The plasmids containing the target gene sequence were linearized by a restriction enzyme allowing generation of uniform length of transcripts. The RNA probes were synthesized with the DIG-RNA-labeling kit (Roche, Mannheim). One digoxigenin-11-uridinemonophosphate (DIG-UMP) residue is incorporated approximately every $20-25$ nucleotides.

Digoxigenin labeled RNA probes for glucokinase, SREBP-1a, and $\beta$-actin, were prepared from the vectors pBS-GK, pcDNA 3.1 SREBP1 $\triangle 90$, and pBS-actin which were linearized by HindlII, Kpn I and Xba I, respectively.

$\underline{\text { In vitro transcription }}$

Linearized plasmid $11 \mu \mathrm{l}(\sim 10 \mu \mathrm{g})$

$10 \mathrm{X}$ transcription buffer $2 \mu l$

10 X labeling mix (ATP, CTP, GTP, UTP, DIG-UTP) $2 \mu \mathrm{l}$

RNasin $(40 U / \mu l)$ $1 \mu \mathrm{l}$

T7/T3 RNA polymerase (20 U/ $\mathrm{\mu l})$ $2 \mu l$

DEPC- $\mathrm{H}_{2} \mathrm{O}$ $2 \mu l$

The reaction mixture was incubated at $37^{\circ} \mathrm{C}$ for $1.5 \mathrm{~h}$. Then $0.5 \mu$ of RNA polymerase was again added and the incubation was prolonged for another $1 \mathrm{~h}$. Synthesized digoxigenin-labeled RNA was precipitated with $2.5 \mu \mathrm{l} 4 \mathrm{M} \mathrm{LiCl}$ and $75 \mu \mathrm{l}$ absolute ethanol at $-20^{\circ} \mathrm{C}$ for at least $2 \mathrm{~h}$. After centrifugation at $4^{\circ} \mathrm{C}, 12000 \times g(10000 \mathrm{rpm}$, ss-34 rotor) for $10 \mathrm{~min}$, the pellet was washed with $80 \%$ ethanol and dried in a speed-vacuum. The pellet was dissolved in $100 \mu \mathrm{LEPC}-\mathrm{H}_{2} \mathrm{O}$ and stored at $-20^{\circ} \mathrm{C}$. 


\section{Estimation of labeling efficiency}

The labeling efficiency of the probe was estimated by comparing the DIG-labeled probe with a DIG-labeled control DNA provided in the labeling kit. The freshly labeled transcript $(1 \mu \mathrm{l})$ as well as the digoxigenin-labeled control DNA (0.04-5 ng) was spotted on a nylon membrane (Amersham). The nucleic acids were cross-linked to the membrane in an UV cross-linker for 2 $\min$ at $1200 \mu \mathrm{J}$. The membrane was washed for $5 \mathrm{~min}$ in buffer 1 and incubated with $1 \%$ blocking reagent for $20 \mathrm{~min}$. The membrane was then incubated for $20 \mathrm{~min}$ in $20 \mathrm{ml}$ of antidigoxigenin antibody solution (1:10000 in $1 \%$ blocking reagent). The unbound antibody conjugate was removed by washing the membrane twice in buffer 1 for 15 min. After 2 min equilibration in buffer 3 , the color substrate solution containing $45 \mu \mathrm{l} \mathrm{NBT}$ and $35 \mu \mathrm{l}$ of Xphosphate in $10 \mathrm{ml}$ of buffer 3 was added. The color spots started to appear within $3 \mathrm{~min}$. The reaction was stopped by washing the membrane with TE buffer.

\section{$\underline{\text { NBT }}$}

NBT
$74 \mathrm{mg} / \mathrm{ml}$ in $70 \%$ DMF

The solution was stored at $-20^{\circ} \mathrm{C}$ and protected from light.

$\underline{\text { X-phosphate }}$

X-phosphate

$50 \mathrm{mg} / \mathrm{ml}$ in DMF
Final concentration

$0.41 \mathrm{mM}$

The solution was stored at $-20^{\circ} \mathrm{C}$.

\subsubsection{Isolation of RNA from primary rat hepatocytes}

Total RNA from primary rat hepatocytes was isolated by a modified method described by Chomczynski and Sacchi (Chomczynski and Sacchi, 1987). After a combined phenol/chloroform/isoamyl alcohol extraction the RNA was precipitated from the water phase and further purified by washing in ethanol.

$2 \times 10^{6}$ cells cultured on $60 \mathrm{~mm}$ culture dishes were washed twice with $0.9 \% \mathrm{NaCl}$. The cells were scraped with a disposable cell scraper in $1.5 \mathrm{ml}$ of PeQLab buffer, homogenized by pipeting up and down and transferred into $2 \mathrm{ml}$ cryocups. $300 \mu \mathrm{l}$ of chloroform was added and mixed gently by inverting the tubes. The tubes were incubated at room temperature for $10 \mathrm{~min}$ and centrifuged at $10000 \mathrm{~g}$ for $15 \mathrm{~min}$ at $4{ }^{\circ} \mathrm{C}$. The upper phase having RNA was transferred to 
new $2 \mathrm{ml}$ tubes containing $750 \mu \mathrm{l}$ of isopropanol and the RNA was precipitated for $15 \mathrm{~min}$ at room temperature. After centrifugation at $10000 \mathrm{~g}$ for $15 \mathrm{~min}$ at $4{ }^{\circ} \mathrm{C}$ the RNA pellet was washed twice with $1 \mathrm{ml}$ of ice cold $75 \%$ ethanol. The purified RNA was dried in a vacuum centrifuge for 5 min and dissolved in $40 \mu \mathrm{l} 0.1 \%$ SDS. The concentration of RNA was measured and stored at $20^{\circ} \mathrm{C}$.

\section{Solutions for RNA isolation}

All the solutions for RNA experiments were prepared with DEPC- $\mathrm{H}_{2} \mathrm{O}$. By addition of DEPC to deionized water for $12 \mathrm{~h}$ RNases in water were inactivated. Then the water was autoclaved.

GTC buffer

Guanidinium thiocyanate

Sodium citrate $(1 \mathrm{M})$

N-lauroyl sarcosine

2-mercaptoethanol

$30 \%$ antifoam A

DEPC- $\mathrm{H}_{2} \mathrm{O}$

\section{Final Concentration}

$48.2 \mathrm{~g}$

$4 \mathrm{M}$

$2.5 \mathrm{ml}$

$25 \mathrm{mM}$

$0.5 \mathrm{~g}$

$17 \mathrm{mM}$

$0.7 \mathrm{ml}$

$0.1 \mathrm{M}$

$0.33 \mathrm{ml}$

$0.1 \%$

The solution was warmed for $30 \mathrm{~min}$ at $65^{\circ} \mathrm{C}$. The $\mathrm{pH}$ was adjusted with $1 \mathrm{~N} \mathrm{NaOH}$ to 7.0 and 2mercaptoethanol was added at the end.

\section{$\underline{\text { PeQLab Buffer }}$}

Phenol (water saturated)

$8 \mathrm{ml}$

$\mathrm{NaAc}(2 \mathrm{M}) \mathrm{pH} 4.1$

$0.2 \mathrm{ml}$

GTC buffer

$10 \mathrm{ml}$

DEPC- $\mathrm{H}_{2} \mathrm{O}$

up to $20 \mathrm{ml}$

\section{Phenol (water saturated)}

$2 / 3$ volume of phenol was mixed with $1 / 3$ volume of $\mathrm{H}_{2} \mathrm{O}$. After phase separation the solution was stored at $4^{\circ} \mathrm{C}$ and protected from light. 


\subsubsection{Northern blot analysis}

Northern blot is one of a series of blotting techniques used to transfer RNA onto a carrier to quantify RNA expression. The Northern blot takes its name from its predecessor, the Southern blot, which was named after the biologist Edwin Southern. In Northern blot, RNA is separated in a denaturing agarose gel, transferred by capillary transfer to a nitrocellulose membrane (vacuum blot) and fixed by UV crosslinking. The RNA of interest is identified by hybridization with a specific RNA probe. In order to prevent the contamination with RNases all the solutions used in Northern blot were autoclaved and the apparatus used for electrophoresis were kept in $3 \% \mathrm{H}_{2} \mathrm{O}_{2}$ for $1 \mathrm{~h}$ before use.

\subsubsection{Denaturation of RNA}

The RNA samples to be analyzed on a blot having $30 \mu \mathrm{g}$ and $16.5 \mu \mathrm{l}$ of loading buffer were denatured at $68{ }^{\circ} \mathrm{C}$ for $20 \mathrm{~min}$ and subsequently cooled on ice for $2 \mathrm{~min}$. The denatured RNA samples were loaded on a denaturing formaldehyde agarose gel along with $5 \mu$ of sample buffer.

\section{Loading buffer}

Formamide

$14.3 \times$ MOPS

$37 \%$ formaldehyde

The buffer was aliquoted and stored at $-20{ }^{\circ} \mathrm{C}$
Final concentration

$15 \mathrm{ml}$

$66.6 \%$

$2.1 \mathrm{ml}$

$5.4 \mathrm{ml}$

$8.9 \%$

$26.7 \mathrm{mM}$

$\underline{14.3 \times \text { MOPS }}$

Final concentration

MOPS

$286 \mathrm{mM}$

$\mathrm{NaAc}$

$0.58 \mathrm{~g}$

$7.1 \mathrm{mM}$

EDTA

$0.5 \mathrm{~g}$

$1.3 \mathrm{mM}$

DEPC- $\mathrm{H}_{2} \mathrm{O}$

to $100 \mathrm{ml}$

The $\mathrm{pH}$ was adjusted with $\mathrm{NaOH}$ to 7.0 and the solution was autoclaved. 
Sample buffer

Glycerin

0.5 M EDTA

Bromophenol blue

DEPC- $\mathrm{H}_{2} \mathrm{O}$
$5 \mathrm{ml}$

$20 \mu \mathrm{l}$

$10 \mathrm{mg}$
Final concentration

$50 \%$

$1 \mathrm{mM}$

$0.1 \%$

to $10 \mathrm{ml}$ The buffer was aliquoted and stored at $-20^{\circ} \mathrm{C}$

\subsubsection{Denaturing agarose gel electrophoresis of RNA}

Denatured RNA samples were resolved on a $1.5 \%$ formaldehyde agarose gel and electrophoresis was performed at 110 volts for $2 \mathrm{~h}$. For preparation of a $1.5 \%$ gel $1.2 \mathrm{~g}$ agarose were dissolved in $65 \mathrm{ml}$ DEPC- $\mathrm{H}_{2} \mathrm{O}$. Then $8 \mathrm{ml}$ of $10 \mathrm{X}$ MOPS and $6.7 \mathrm{ml}$ of formaldehyde were added. After mixing, the gel was poured into the prepared gel plate $(10 \times 14 \mathrm{~cm})$ and allowed to solidify at room temperature. Then the gel was transferred into an electrophoresis chamber filled with $1 \times$ MOPS buffer.

After gel electrophoresis the formaldehyde was washed out by shaking the gel in $150 \mathrm{ml}$ of a $1 \%$ glycine solution for $20 \mathrm{~min}$. To visualize the RNA under UV light (254 nm) $5 \mu$ of ethidium bromide was added and the gel was further incubated for 5 more min. Two main bands corresponding to $28 \mathrm{~S}$ and $18 \mathrm{~S}$ ribosomal RNA were visible under UV light, then the gal was photographed. Finally, the gel was washed in 20XSSC for 20 min before blotting onto a nylon membrane.

$\underline{10 \times \mathrm{MOPS}}$

MOPS

$\mathrm{NaAc}$

EDTA

DEPC- $\mathrm{H}_{2} \mathrm{O}$
$3.7 \mathrm{~g}$

to 11
Final concentration

$200 \mathrm{mM}$

$50 \mathrm{mM}$

$10 \mathrm{mM}$

The $\mathrm{pH}$ was adjusted to 7.0 with $\mathrm{NaOH}$. The solution was autoclaved. 


\subsubsection{RNA blotting onto nylon membrane}

The resolved RNA in the gel was transferred onto a nylon membrane (Hybond $\mathrm{N}^{+}$, Amersham) by capillary blotting. The nylon membrane was presoaked in 2 X SSC for $10 \mathrm{~min}$. The blotting equipment was prepared in the following way; A plastic tray filled with $700 \mathrm{ml}$ of $10 \times$ SSC buffer, a flat surfaced glass stand was fixed above the buffer level and covered with three layers of $3 \mathrm{~mm}$ thick filter paper (presaturated in $20 \times$ SSC) with their ends dipped in the buffer underneath; RNA gel with the upper side downwards and surrounded by foil stripes to prevent drying out of papers; the nylon membrane was put on top of the gel; 3 layers of $3 \mathrm{~mm}$ filter papers with the size of the gel; approx. $10 \mathrm{~cm}$ of paper towels; an equally distributed weight of approx. $1 \mathrm{~kg}$. The capillary blotting was carried out for at least $16-18 \mathrm{~h}$, the arrangement was dismantled and the RNA was irreversibly cross-linked by UV radiation in an UV cross-linker (Stratagene) for $2 \mathrm{~min}$ at $1200 \mu \mathrm{J}$.

\subsubsection{Hybridization of RNA with digoxigenin-labeled RNA probes}

The RNA blot was placed in a hybridization glass tube and pre-hybridized with $10 \mathrm{ml}$ of hybridization solution at $65-68^{\circ} \mathrm{C}$ in a hybridization oven. After $1 \mathrm{~h}$ of incubation, the prehybridization solution was replaced with the $10 \mathrm{ml}$ of hybridization solution containing $150 \mathrm{ng}$ of digoxigenin-labeled antisense RNA probe. The hybridization was performed at $65^{\circ} \mathrm{C}$ overnight. The unbound probe was removed by washing with $2 \times$ SSC / $0.1 \%$ SDS for $2 \times 5$ min and $0.1 X$ SSC $/ 0.1 \%$ SDS for $2 \times 15 \min$ at $65^{\circ} \mathrm{C}$.

Pre- and hybridization solutions

Final Concentration

Deionized formamide

$10 \%$ blocking reagent

$20 \%$ SDS

$10 \%$ N-lauroylsarcosine

$20 \times$ SSC
$12.5 \mathrm{ml}$

$6 \mathrm{ml}$

$25 \mu \mathrm{l}$

$250 \mu \mathrm{l}$

$6.25 \mathrm{ml}$
$50 \% \quad(v / v)$

$2.5 \%(w / v)$

$0.02 \%(w / v)$

$0.1 \%(w / v)$

$5 x$

The solution was stored at $4^{\circ} \mathrm{C}$. 


\subsubsection{Detection and quantification}

The detection of hybrids between the RNA of interest and the digoxigenin-labeled asRNA was performed using anti-digoxigenin antibodies conjugated to alkaline phosphotase (enzyme immunoassay). During the following dephosphorylation of dinatrium 3-(4-methoxyspiro[1,2dioxetane-3,2-(5'-chloro)tricycle\{3.3.1.1.7 $\}$ decan\}-4-yl)-phenylphosphat (CSPD) by alkaline phosphatase a chemiluminescent unstable product was formed which produced light of $477 \mathrm{~nm}$. This light signal can be recorded on X-ray films. The quantification was made densitometrically.

The detection was performed with the DIG nucleic acid detection kit (Roche) according to the manufacturer instructions. After hybridization and posthybridization washes of the nylon membrane it was equilibrated in $1 \mathrm{X}$ maleic acid buffer for $1 \mathrm{~min}$. To prevent nonspecific binding

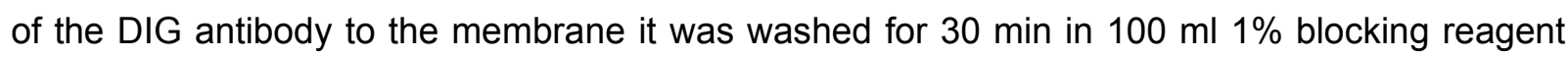
(10\% blocking reagent diluted to $1 \%$ with $1 \times$ maleic acid buffer). Then, the nylon membrane was incubated for $30 \mathrm{~min}$ at room temperature in 20-30 ml diluted antibody solution (antidigoxigenin $\mathrm{Fab}$ fragments, conjugated to alkaline phosphatase, in $1 \%$ blocking reagent at a concentration of $75 \mathrm{mU} / \mathrm{ml}=1: 10000$ dilution which is equal to $5 \mu \mathrm{l}$ antibody in $50 \mathrm{ml} 1 \%$ blocking reagent). The unbound antibody was removed by washing in maleic acid buffer, containing $0.3 \%$ Tween $-2 \times 15$ min. The washed membrane was equilibrated in buffer 3 for $1-2$ min and wrapped in transparent foil along with the diluted CSPD solution for $5 \mathrm{~min}$. (CSPD in buffer 3 at a concentration of $2.5 \mathrm{mM}=1: 1000=1 \mu \mathrm{l}$ CSPD in $1 \mathrm{ml}$ buffer 3 ). The liquid was completely removed and the membrane was incubated for $10 \mathrm{~min}$ at $37^{\circ} \mathrm{C}$. Then the membrane was exposed to a X-ray film for 30-90 min.

For quantification of the RNA bands, IMAGE J software was used.

Buffer 1 (Maleic acid buffer)

Final concentration
Maleic acid
$11.61 \mathrm{~g}$
$0.1 \mathrm{M}$
$\mathrm{NaCl}$
$8.78 \mathrm{~g}$
$0.15 \mathrm{M}$

$\mathrm{H}_{2} \mathrm{O}$

to 11

The $\mathrm{pH}$ was adjusted to 7.5 with solid $\mathrm{NaOH}$. The solution was autoclaved.

Buffer 2

$450 \mathrm{ml}$ of buffer 1

$50 \mathrm{ml} 10 \mathrm{X}$ blocking reagent 
Buffer 3

Final concentration

Tris

$12.11 \mathrm{~g}$

$0.1 \mathrm{M}$

$\mathrm{NaCl}$

$5.84 \mathrm{~g}$

$0.1 \mathrm{M}$

$\mathrm{MgCl}_{2}$

$10.17 \mathrm{~g}$

$50 \mathrm{mM}$

$\mathrm{H}_{2} \mathrm{O}$

to 1 I

The $\mathrm{pH}$ was adjusted with $\mathrm{HCl}$ to 9.5 . Then the buffer was autoclaved and sterile filtered, $\mathrm{MgCl}_{2}$ was added at the end.

\subsection{Biochemical methods}

\subsubsection{Total protein isolation from the cultured cells}

Cultured cells were washed twice with 1 X PBS and scraped off the plate into $150 \mu$ lysis buffer. The cells were destroyed thoroughly by ultrasonication on ice for $10 \mathrm{~min}$ or $25 \mathrm{~min}$ for primary hepatocytes respectively. The sonicated samples were centrifuged at $4{ }^{\circ} \mathrm{C}, 10000 \times g(12000$ rpm, SS-34 rotor) for $20 \mathrm{~min}$. The supernatant was collected into a new tube. The concentration of the protein from the cell lysate was measured with Bradford method.

Lysis buffer

Tris/ $\mathrm{HCl} \mathrm{pH} 8.0(1 \mathrm{M})$

$\operatorname{EDTA}(0.5)$

$\mathrm{NaCl}(5 \mathrm{M})$

NP-40

$\mathrm{H}_{2} \mathrm{O}$

DTT
$12.5 \mathrm{ml}$

$2.5 \mathrm{ml}$

$7.5 \mathrm{ml}$

$1.25 \mathrm{ml}$

up to $250 \mathrm{ml}$

$100 \mu \mathrm{l}$
Final concentration

$50 \mathrm{mM}$

$5 \mathrm{mM}$

$150 \mathrm{mM}$

$0.5 \%(v / v)$

$5 \mathrm{mM}$

Protease inhibitor cocktail tablet (Roche) $1 / 10 \mathrm{ml}$ buffer

DTT and protease inhibitor tablet was added freshly before use. Lysis buffer without DTT and protease inhibitor tablet can be stored at $4{ }^{\circ} \mathrm{C}$. 


\subsubsection{Estimation of protein concentration}

Protein concentration from cell lysates was measured by a colorimetric assay (Bradford, 1976), which is based on a spectral shift in the absorption maximum (from $465 \mathrm{~nm}$ to $596 \mathrm{~nm}$ ) of the coomassie Briliant Blue G-250 dye upon its binding to hydrophobic residues in the proteins. Two $\mu \mathrm{l}$ of cell extracts and water up to $100 \mu \mathrm{l}$ was mixed with $1 \mathrm{ml}$ of Bradford reagent incubated for 5 min at RT. The optical density of the samples was measured at $578 \mathrm{~nm}$. A water dilution of pure Bradford reagent was used as a blank control. Protein concentration of the samples was calculated with the help of a standard curve derived from different BSA protein amounts $(2 \mu \mathrm{g}, 4$ $\mu \mathrm{g}, 6 \mu \mathrm{g}, 8 \mu \mathrm{g}, 16 \mu \mathrm{g}$ ) measured in the same experiment.

\begin{tabular}{|c|c|c|}
\hline \multirow[t]{4}{*}{ Bradford reagent } & Serva Blue & 100 \\
\hline & $95 \%$ Ethanol (v/v) & 50 \\
\hline & $85 \%$ Phosphoric acid (v/v) & 100 \\
\hline & $\mathrm{H}_{2} \mathrm{O}$ & 11 \\
\hline
\end{tabular}

\subsubsection{Western blot analysis (Immunoblotting)}

\subsubsection{SDS-polyacrylamide gel electrophoresis of protein (SDS-PAGE)}

In SDS-PAGE the denatured polypeptides bind the strongly anionic detergent SDS and become negatively charged. The amount of SDS bound is always proportional to the molecular weight of the polypeptide and is independent of its sequence. This results in migration of SDS-polypeptide complexes through the polyacrylamide gel according to the size of the polypeptide. By using molecular weight markers, it is possible to estimate the molecular weight of the polypeptide chain(s). In most cases, SDS-PAGE is carried out with a discontinuous buffer system, in which the buffers in the reservoirs are of different $\mathrm{pH}$ and ionic strength from the buffers used to cast the gel. After migrating through a stacking gel of high porosity, the complexes are deposited in a very thin zone (or stack) on the surface of the resolving gel. The ability of discontinuous buffer systems to concentrate all the complexes in the sample into a very small volume greatly increases the resolution of SDS-polyacrylamide gels (Laemmli, 1970).

$100 \mu \mathrm{g}$ of protein from the cell lysate was denatured by boiling at $95^{\circ} \mathrm{C}$ for $5 \mathrm{~min}$ in $1 \mathrm{X}$ loading buffer and cooled on ice immediately before loading on the corresponding polyacrylamide gel. The electrophoresis was performed at $10 \mathrm{mV} / 59 \mathrm{~cm}^{2}$ gel until the samples reached the 
beginning of the resolving gel and the gel was subjected to $20 \mathrm{~mA}$ until the bromophenolblue dye had run out of the gel (for about $2 \mathrm{~h}$ ). The size of the separated proteins was estimated in comparison to the standard protein marker mixture (Amersham) loaded on the gel.

\section{Preparation of SDS-PAGE gel}

$$
\text { Resolving gel (10\%) }
$$

Stacking gel $(4 \%)$

\begin{tabular}{|c|c|c|c|}
\hline Rotiphorese ${ }^{R}$ Gel30 & $2.33 \mathrm{ml}$ & 0.45 & $\mathrm{ml}$ \\
\hline Resolving buffer (1.875 M Tris pH 8.8) & $1.462 \mathrm{ml}$ & - & \\
\hline Stacking buffer (0.6 M Tris pH 6.8) & - & 0.27 & $\mathrm{ml}$ \\
\hline Water & $3.05 \mathrm{ml}$ & 1.9 & $\mathrm{ml}$ \\
\hline $10 \% \operatorname{SDS}(w / v)$ & $69 \mu \mathrm{l}$ & 27 & $\mu l$ \\
\hline $10 \%$ APS (w/v) & $34.5 \mu \mathrm{l}$ & 20 & $\mu l$ \\
\hline TEMED & $2.2 \mu \mathrm{l}$ & 3 & $\mu l$ \\
\hline \multirow[t]{3}{*}{ Running buffer (10X) } & Tris (pH 8.3) & 50 & $\mathrm{ml}$ \\
\hline & Glycine & 384 & $\mathrm{ml}$ \\
\hline & SDS & $0.1 \%$ & $(w / v)$ \\
\hline \multirow[t]{5}{*}{ Loading buffer(4X) } & Tris $(\mathrm{pH} 7.4)$ & 100 & $\mathrm{mM}$ \\
\hline & Bromophenolblue & $0.05 \%$ & $(w / v)$ \\
\hline & SDS & $3 \%$ & $(w / v)$ \\
\hline & Glycerol & $7.5 \%$ & $(v / v)$ \\
\hline & DTT (Fresh) & $5 \%$ & $(\mathrm{v} / \mathrm{v})$ \\
\hline
\end{tabular}

\subsubsection{Electroblotting of immobilized proteins}

Resolved proteins on the SDS-PAGE were electronically transferred to a polyvinylidene fluoride (PVDF) membrane by electroblotting. The PVDF membrane was activated by methanol before transfer of the proteins onto it. The transfer equipment was prepared in the following way: a 
whatmann $3 \mathrm{~mm}$ filter paper washed with anode buffer 1, on which two layers filter papers and the activated PVDF membrane washed with anode buffer 2 was placed into the electroblotting chamber. On the PVDF membrane, the gel and the other two layers of filter papers washed with cathode buffer were placed. The bubbles between the sheets were removed by gentle rolling of a glass pipette on top of the sandwich; the cathode plate was mounted and pressed with a weight approximately $1 \mathrm{~kg}$ for better contact between all layers. The transfer was performed with a constant electric current of $56 \mathrm{~mA}$ per gel for $1 \mathrm{~h} 20 \mathrm{~min}$. The protein transfer was checked by reversible staining of the PVDF membrane with Ponceau $S$ solution.

Anode Buffer 1

Tris ( $\mathrm{pH} 11.3$ with $2 \mathrm{M}$ Borate)

Methanol

Anode buffer 2

Tris $(\mathrm{pH} 10.6)$

Methanol

Cathode buffer

Tris (pH 9.0)

Methanol

Ponceau S

Ponceau S

Glacial Acetic acid

Methanol

$$
\begin{gathered}
3 \mathrm{~g} / \mathrm{l} \\
200 \mathrm{ml} / \mathrm{l}
\end{gathered}
$$

$$
36.4 \mathrm{~g} / \mathrm{l}
$$

$200 \mathrm{ml} / \mathrm{l}$

$$
6 \mathrm{~g} / \mathrm{l}
$$

$200 \mathrm{ml} / \mathrm{l}$

Final concentration

$\begin{array}{ll}300 & \mathrm{mM} \\ 20 \% & (\mathrm{v} / \mathrm{v})\end{array}$


secondary antibody conjugated with horseradish peroxidase (HRP) in blocking buffer at room temperature for $1 \mathrm{~h}$ followed by $3 \times 10 \mathrm{~min}$ washing. The HRP-conjugated secondary antibody was detected using ECL+ (Enhanced Chemiluminescence plus) kit (Amersham). The membrane was incubated with the enzyme substrate for $5 \mathrm{~min}$ at room temperature and the chemiluminescence was detected by exposing the membrane to X-ray film for an optimal time range according to the strength of the signals. Protein expression was quantified using a densitometer.

\subsection{Co-immunoprecipitation}

Co-immunoprecipitation is a technique to reveal protein-protein interactions. An antibody specific to the protein of interest is added to a cell extract. The antibody-protein complex is pulled down using protein $\mathrm{G}$ or $\mathrm{A}$ sepharose beads, which binds most of the antibodies. If there is any protein that interacts with the first protein, they will also be pulled down. Protein present in the pull down was identified by Western blot (if an antibody exists).

HEK-293T cells transfected overnight and allowed for $24 \mathrm{~h}$ to overexpress the proteins which are expected to interact. Cells were washed twice with $1 \mathrm{X}$ PBS and scraped with phospho-buffer and kept on a roller at $4{ }^{\circ} \mathrm{C}$ for $20 \mathrm{~min}$. The cell lysate was centrifuged at $10000 \times \mathrm{g}(12000$ rpm, SS-34 rotor) for $15 \mathrm{~min}$ at $4{ }^{\circ} \mathrm{C}$ and the supernatant was collected into new tubes. The protein concentration of freshly isolated whole cell extract was determined by the Bradford method and $150 \mu \mathrm{g}$ of protein was used for co-immunoprecipitation.

\section{Phospho-buffer}

$5 \times$ TBS

$10 \%$ Triton X-100

0.5 M EDTA

0.5 M EGTA

$125 \mathrm{mM} \mathrm{Na}_{4} \mathrm{P}_{2} \mathrm{O}_{7}$

PMSF (if necessary)

Deionized water
Final concentration

$1 \mathrm{ml}$

$500 \mu \mathrm{l}$

$1 \%(v / v)$

$20 \mu \mathrm{l}$

$2 \mathrm{mM}$

$20 \mu \mathrm{l}$

$2 \mathrm{mM}$

$400 \mu \mathrm{l}$

$10 \mathrm{mM}$

$25 \mu \mathrm{l}$

$0.2 \mathrm{M}$

up to $5 \mathrm{ml}$ 
The buffer was made fresh before each preparation and 1 protease inhibitor tablet was used for $10 \mathrm{ml}$ of the buffer.

\section{Washing sepharose G beads}

Approximately $150 \mu \mathrm{l}$ of the beads were washed twice with lysis buffer (without protease inhibitors). For each wash the beads were mixed gently in $1.5 \mathrm{ml}$ of lysis buffer and centrifuged at $1000 \times g$ (2500 rpm at a tabletop centrifuge Eppendorf, rotor 5415C) for 2 min. After the final wash the beads were resuspended in $500 \mu$ of lysis buffer with protease inhibitors and $\sim 110 \mu \mathrm{l}$ of the beads were used for each pull down reaction.

\section{Pull down of protein-antibody complexes}

Two $\mu \mathrm{g}$ of antibody were added to the freshly isolated $150 \mu \mathrm{g}$ whole cell extract and allowed to bind the target protein for $1 \mathrm{~h}$ at $4{ }^{\circ} \mathrm{C}$ on a roller. After $1 \mathrm{~h}$, the samples were treated with washed beads and incubated overnight at $4{ }^{\circ} \mathrm{C}$ on a roller to pull down the interacting partner of the target protein (antibody-protein complexes). The protein-immune complexes bound to the beads were collected by centrifugation at $1000 \times g(2500 \mathrm{rpm}$ at a tabletop centrifuge Eppendorf, rotor $5415 \mathrm{C}$ ) for $2 \mathrm{~min}$. The collected beads were washed 5 times with lysis buffer. Washed beads were resuspended with $2 \times$ loading buffer, heated to $95{ }^{\circ} \mathrm{C}$ for $7 \mathrm{~min}$ and resolved by SDSPAGE for Western blot analysis.

\subsection{Enzyme activity assays}

To determine the glucokinase enzyme activity, primary rat hepatocytes were washed twice with $0.9 \% \mathrm{NaCl}$ and cells were scraped in the ice cold lysis buffer containing $100 \mathrm{mM} \mathrm{Tris} / \mathrm{HCl} \mathrm{pH}$ 8.3, $150 \mathrm{mM} \mathrm{KCl}, 10 \mathrm{mM} \mathrm{MgCl}_{2}$, and $5 \mathrm{mM} \mathrm{DTT}$. The cells were disrupted with ultrasound in a Polytron for $15 \mathrm{sec}$ at half maximal settings consisting of $\sim 230 \mathrm{~V}(50-60 \mathrm{~Hz})$. The resulting suspension was then centrifuged at $16000 \times g$ (14 $000 \mathrm{rpm}$ at a tabletop centrifuge Eppendorf, rotor $5415 \mathrm{C}$ ) for $30 \mathrm{~min}$; the supernatant was collected into new tubes and stored at $-70^{\circ} \mathrm{C}$. The protein content was determined using the Bradford method.

The majority of enzyme activities can be determined as part of pyridine-dependent reactions in the simple optical assay or in the coupled optical assay. Glucokinase enzyme activity was determined by the coupled optical assay with glucose 6-phosphate dehydrogenase (G6PDH) and 6-phosphogluconate dehydrogenase (6PDGH). 


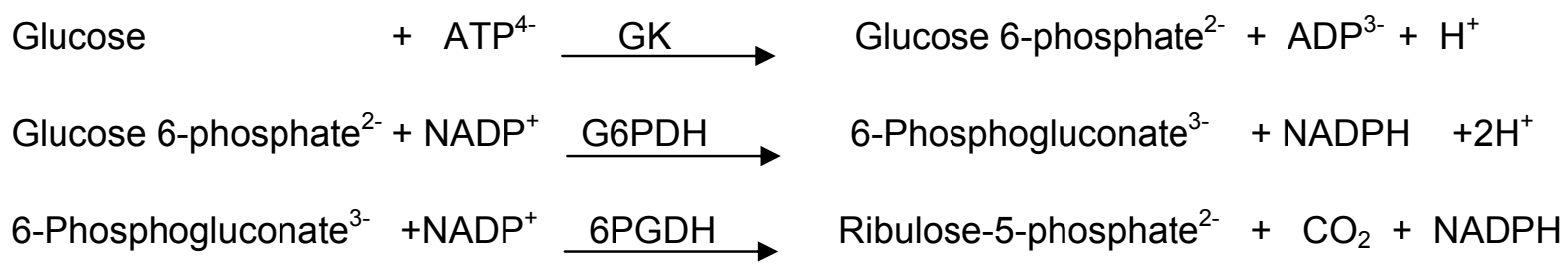

Fifty $\mu \mathrm{g}$ of total protein was mixed with the test solution described below along with different concentrations of glucose as substrate and water. The reaction mixture was mixed thoroughly; incubated at room temperature for $1 \mathrm{~min}$ and then, the change in extinction at $366 \mathrm{~nm}$ was measured. The reaction velocity $(\mathrm{V})$ was calculated using the change in the extinction in dependence of the substrate concentration ([S]), from which the enzyme affinity $\left(K_{M}\right)$ and maximal velocity $\left(\mathrm{V}_{\max }\right)$ were determined. Glucokinase enzyme kinetics was represented graphically by Michaelis-Menten and Lineweaver-Burk plots. The Michaelis-Menten plot depicts the reaction velocity $\vee$ versus ([S]), which gives a hyperbolic plot and the Lineweaver-Burk plot represents the double reciprocal of $1 / \mathrm{V}$ versus $1 /$ ([S]), which gives a straight-line. The MichaelisMenten plot is used to illustrate regulation problems and the Lineweaver-Burk straight lines gives fairly accurate determination of $K_{M}$ and $V_{\text {max. }}$. Plotting $1 / V$ as a function of $1 /$ ([S]), the intercept on $y$-axis gives $1 / V_{\max }$ and the intercept on $x$-axis gives $-1 / K_{M}$.

$$
\begin{array}{cl}
\mathrm{v}=\frac{\mathrm{k}_{2} \cdot(E) \cdot[S]}{K_{M}+[S]}=\frac{V_{\max } \cdot[S]}{K_{M}+[S]} & \text { Michaelis-Menten equation } \\
\frac{1}{v}=\frac{K_{M}}{V_{\max } \cdot[S]}+\frac{1}{V_{\text {max }}} & \text { Lineweaver-Burk equation }
\end{array}
$$

Solutions for enzyme activity assay

Final concentration

Glycylglycine buffer $\mathrm{pH} 7.5$

$$
13.2 \mathrm{~g} / \mathrm{l}
$$

$100 \mathrm{mM}$

Glucose

$180.16 \mathrm{~g} / \mathrm{l}$

$1 \mathrm{M}$

ATP

$0.2756 \mathrm{~g} / 10 \mathrm{ml}$

$50 \mathrm{mM}$

$\mathrm{MgCl}_{2} \times \mathrm{H}_{2} \mathrm{O}$

$0.2033 \mathrm{~g} / 10 \mathrm{ml}$

$100 \mathrm{mM}$

$\mathrm{NADP}^{+}$

$0.0505 \mathrm{~g} / 10 \mathrm{ml}$

$6 \mathrm{mM}$

Mercaptoethanol

$3.52 \mu \mathrm{l} / 10 \mathrm{ml}$

$5 \mathrm{mM}$

G6PDH

$3 \mu \mathrm{l} / 10 \mathrm{ml}$

$0.2 \mathrm{U} / \mathrm{ml}$

6PGDH

$100 \mu \mathrm{l} / 10 \mathrm{ml}$

$0.2 \mathrm{U} / \mathrm{ml}$

All the above solutions except glucose were made in glycylglycine buffer at $\mathrm{pH} 7.5$. 
$\underline{\text { Test solution }}$

Glycylglycine pH 7.5

ATP

$\mathrm{MgCl}_{2} \times 6 \mathrm{H}_{2} \mathrm{O}$

$\mathrm{NADP}^{+}$

Mercaptoethanol

G6PDH

6PGDH

$\underline{\text { Reaction mixture }}$
1
Final concentration

$100 \mathrm{mM} / \mathrm{l}$

$5 \mathrm{mM} / \mathrm{l}$

$10 \mathrm{mM} / \mathrm{l}$

$0.6 \mathrm{mM} / \mathrm{l}$

$5 \mathrm{mM} / \mathrm{l}$

$0.2 \mathrm{U} / \mathrm{ml}$

$0.2 \mathrm{U} / \mathrm{ml}$

Cuvette

2

3

4

5

Amounts in $\mu \mathrm{l}$

\begin{tabular}{lccccc}
\hline Test solution & 250 & 250 & 250 & 250 & 250 \\
\hline Glucose 0.1 M/l & 25 & 50 & 100 & - & - \\
\hline Glucose 1 M/l & - & - & - & 25 & 50 \\
\hline Water & & & Up to $500 \mu \mathrm{l}$ \\
\hline Cell Lysate & \multicolumn{3}{c}{$50 \mu \mathrm{g}$} \\
\end{tabular}




\section{Results}

\subsection{Regulation of glucokinase gene expression by sterol regulatory element binding protein-1 (SREBP-1)}

Previous reports have shown that SREBP is involved in the regulation of glucokinase expression, however, the molecular details at the promoter level are not all known so far. Insulin can activate glucokinase gene expression via PI3K/PKB and it is known to induce SREBP gene expression. However, the role of insulin-induced SREBP mediated glucokinase gene expression is not well understood. By using Matinspector programme we have predicted three putative SREBP binding elements within a $1448 \mathrm{bp}$ fragment of the rat glucokinase promoter. This prompted us to investigate the role of SREBP on glucokinase gene regulation. DNA footprinting assays identified seven elements bound by liver enriched factors on the rat liver glucokinase promoter, but the importance of these elements are not known. In order to understand the above questions we have made deletion constructs and different constructs carrying mutations in the putative SREBP binding sites as well as in the footprinted sites of the rat glucokinase promoter.

\subsubsection{Regulation of rat GK promoter deletion constructs by SREBP-1a}

Freshly isolated rat primary hepatocytes and HepG2 cells were used for cotransfection of glucokinase promoter deletion constructs with an expression vector for SREBP-1a. When primary rat hepatocytes or HepG2 cells were cotransfected with the GK promoter Luc constructs pGI3GK-1448, pGI3GK-919, pGI3GK-781 and the SREBP-1a expression vector, Luc activity was induced by SREBP-1a in the range of about 4-8-fold. By contrast, cotransfection of the SREBP1a expression vector did no longer enhance Luc activity when the pGI3GK-748 or pGI3GK-333 promoter Luc constructs were cotransfected (Fig 13). These data suggest that the GK promoter region -781/-748 is important for SREBP mediated induction. Interestingly the sequence -781/748 includes footprint region $B$ which may then be important for the SREBP effects.

\subsubsection{Mutation in the putative SRE-2 site abrogates the rat GK promoter activity by SREBP-1a}

Since the Matinspector programme proposed three putative SREBP binding elements namely SRE1 (-298/-290, 5'-ATCCCCCAC-3'), SRE2 (-204/-197, 5'-GTGGGGTG-3') and SRE3 (-182/175,5 '- CCAGCCAC-3'), mutations were introduced by site-directed mutagenesis into these elements to generate pGI3GK-1448SRE1m, pGI3GK-1448SRE2m, pGI3GK-1448SRE3m and the constructs were then functionally tested in HepG2 cells and primary hepatocytes. HepG2 
cells cotransfected with constructs carrying mutations in the SRE1 and SRE3 elements were able to show a 4-fold induction by SREBP-1a, however, a mutation in the SRE2 alone or in both SRE2+SRE3 as in the construct pGI3GK-1448mSRE2+mSRE3 abolished SREBP-1a mediated induction (Fig 14). By contrast, rat primary hepatocytes cotransfected with the pGI3GK1448SRE2m, pGI3GK-1448SRE3m or with the double mutant pGI3GK-1448mSRE2+mSRE3 construct abolished the SREBP-1a induced Luc activity (Fig 14). These results indicate that both SRE2 and SRE3 are important for SREBP mediated activation in primary hepatocytes, whereas in HepG2 cells only SRE2 is involved in the SREBP mediated regulation of the rat GK promoter.

\subsubsection{Mutations in the B1 site abolished SREBP-1a-dependent GK promoter activity}

In-vitro DNA footprinting analysis of the rat glucokinase promoter revealed seven elements termed as $A$ to $G$ which were bound by liver enriched factors (lynedjian et al., 1996). Serial deletions of the GK promoter eliminating footprint site G-D did not affect the SREBP-mediated GK promoter activity, but the SREBP effect was lost when the footprint B element was deleted (Fig 15). This prompted us to mutate the footprint site $B$ in the full length GK promoter. We introduced two different mutations in the footprint region $B$ to generate pGI3GK-1448mFPB1 and pGI3GK-1448mFPB2 as well as a construct carrying a double mutation pGI3GK$1448 d m F P B 1+2$. The glucokinase wild type promoter construct pGI3GK-1448 was induced by about 4-fold in both primary hepatocytes and HepG2 cells when cotransfected with the SREBP1a expression vector. Mutations in the footprint B1 and B1+2 abolished SREBP-mediated induction of Luc activity in primary hepatocytes. HepG2 cells cotransfected with pGI3GK$1448 \mathrm{mFPB} 2$ showed an approximately 2 -fold induction by SREBP. These data indicate that the footprint site B1 is most important for GK regulation by SREBP. Since SREBP can also bind to E-box sequences (5'-CANNTG-3') we mutated the E-box sequence within the footprint site C. Transfection of the glucokinase construct pGI3GK-1448mE-box carrying the mutation in the footprint $C$ site was induced by SREBP by about 3-fold in both cell types (Fig 15). These results further underline that the footprint site B1 is important in regulating the GK promoter activity in response to SREBP in both cell types, whereas the E-box sequence did not contribute to the SREBP effect. 


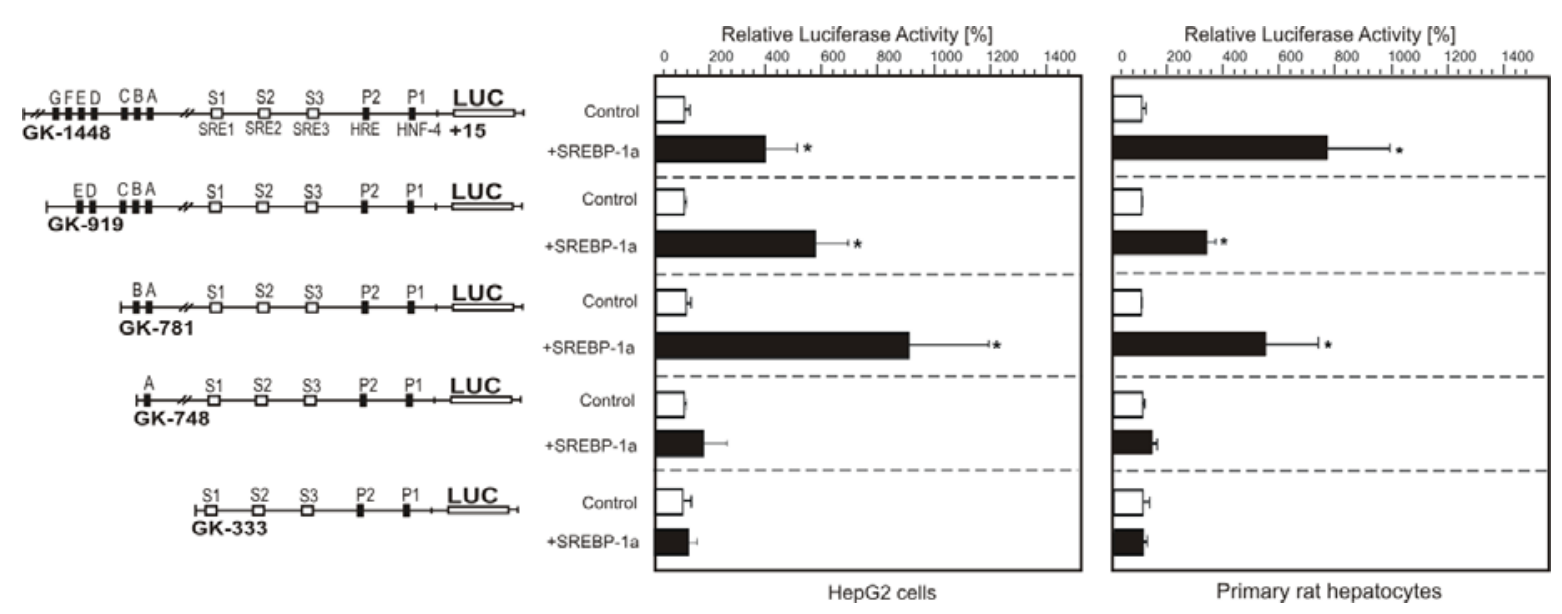

Figure 13. Activation of serially deleted GK promoter-Luc constructs by SREBP-1a in HepG2 cells and primary rat hepatocytes Primary rat hepatocytes and HepG2 cells were transiently cotransfected with the SREBP-1a expression vector and the GK-1448 wild type construct and deletion constructs GK919, GK-781, GK-748, and GK-333. After $5 \mathrm{~h}$ of transfection the medium was changed and cells were cultured for 48 hours. Black boxes A-G and P1\&P2 in the GK promoter indicate foot-printed regions. White boxes indicate elements identified only by sequence similarity. In each experiment the percentage of Luc activity was determined to the GK-1448 control, which was set equal to $100 \%$. The values represent means \pm S.E. of three independent experiments. Statistics, Student's $t$ test for paired values: *, significant differences control versus +SREBP-1a; $p \leq 0.05$.

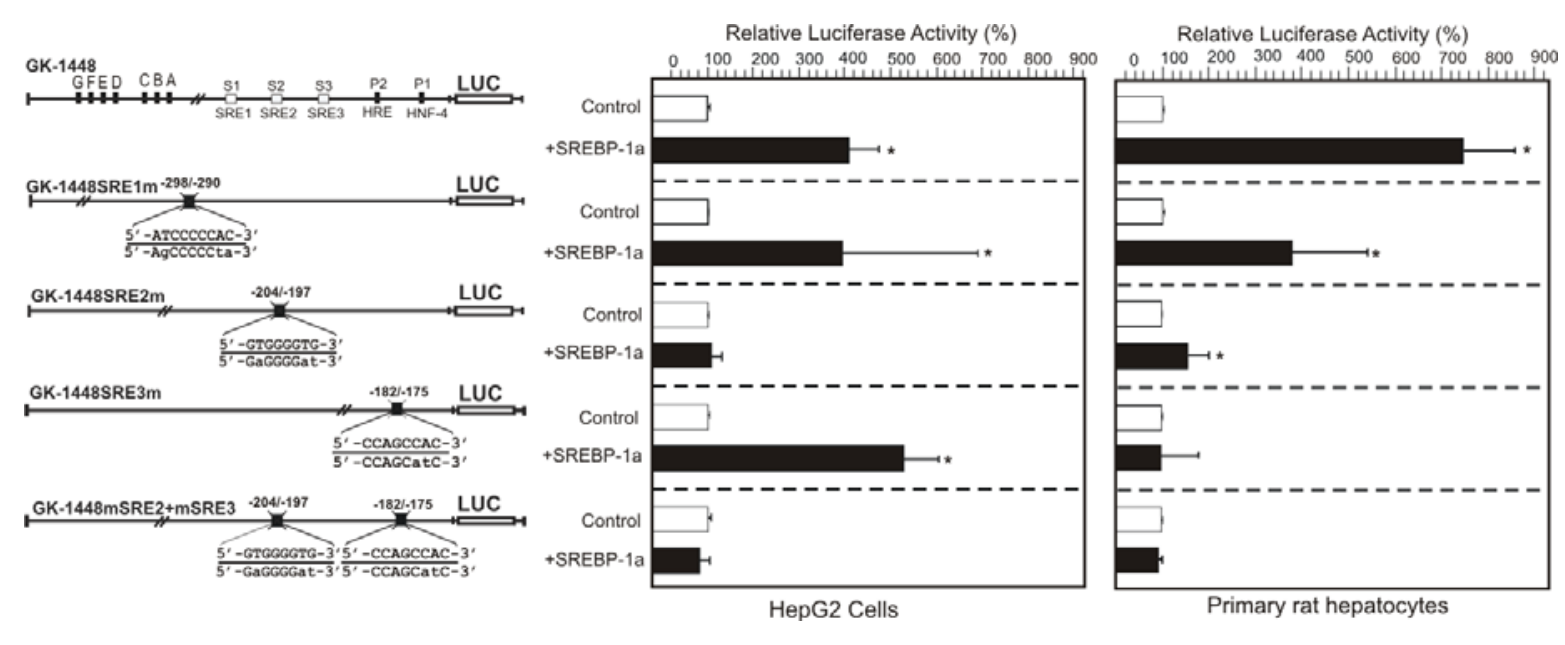

Figure 14. Activation of SRE mutated GK promoter-Luc constructs by SREBP-1a Primary rat hepatocytes and HepG2 cells were transiently cotransfected with the SREBP-1a expression vector and either a GK-1448 wild type construct, a 1448-bp construct mutated at SRE1 (GK-1448SRE1m), a 1448-bp construct mutated at SRE2 (GK-1448SRE2m), a 1448-bp construct mutated at SRE3 (GK-1448SRE3m) or a construct mutated at SRE2 and 3 (GK-1448mSRE2+mSRE3). After $5 \mathrm{~h}$ of transfection the medium was changed and the cells were cultured for 48 hours. In the GK promoter constructs the sequences in the upper strand represent the wild-type sequence. In the lower strand the mutant bases are indicated as lower case letters. In each experiment the percentage of Luc activity was determined to the GK-1448 control, which was set equal to $100 \%$. The values represent means \pm S.E. of three independent experiments. Statistics, Student's $t$ test for paired values: ${ }^{*}$, significant differences control versus + SREBP-1a; $p \leq 0.05$. 


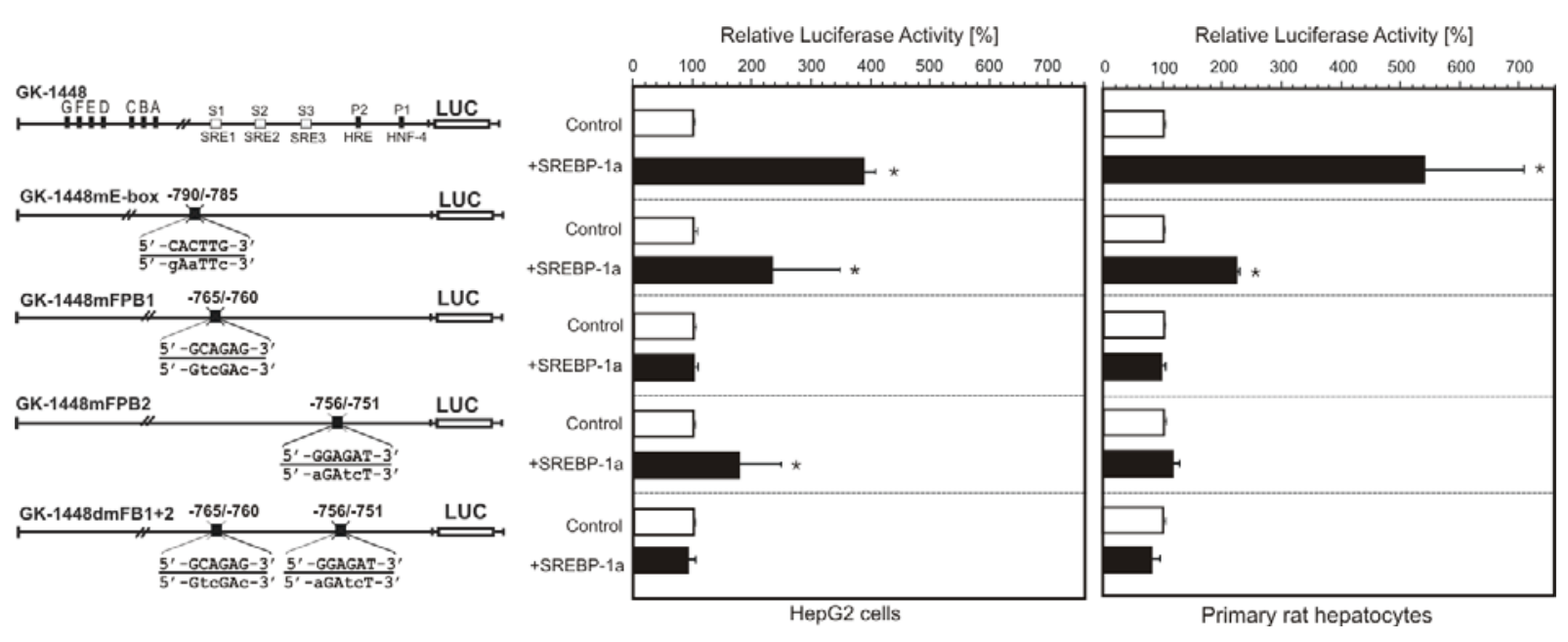

Figure 15. Regulation of Footprint B and E-box mutated GK promoter-Luc constructs by SREBP-1a Primary rat hepatocytes and HepG2 cells were transiently cotransfected with the SREBP-1a expression vector and either a GK-1448 wild type construct, a 1448-bp construct mutated at E-box (GK-1448 mEbox), a 1448-bp construct mutated at footprintB1 (GK-1448 mFPB1), a 1448-bp construct mutated at footprintB2 (GK-1448 mFPB2) or a construct mutated at footprintB1 and B2 (GK-1448 dmFPB1+2). After $5 \mathrm{~h}$ of transfection the medium was changed and the cells were cultured for 48 hours. In the GK promoter constructs the sequences in the upper strand represent the wild-type sequence. In the lower strand the mutant bases are indicated as lower case letters. In each experiment the percentage of Luc activity was determined to the GK-1448 LUC control, which was set equal to $100 \%$. The values represent means \pm S.E. of three independent experiments. Statistics, Student's $t$ test for paired values: ${ }^{*}$, significant differences control versus +SREBP-1a; $p \leq 0.05$.

\subsubsection{Reduction of SREBP-1a-dependent GK promoter activity by mutation of the HRE and HNF4 binding element}

Previously it was shown that the GK gene is regulated by insulin stimulated HIF-1 binding to the HRE together with binding of HNF4 to the HNF4 element in the GK promoter (Roth et al., 2004a). It is known that SREBP-1 interacts with the AF2 domain of HNF-4 (Yamamoto et al., 2004) and that HIF1 $\beta$ can interact with HNF4. This lead us to hypothesize that both the HNF4 and HRE site could be critically involved in the SREBP-mediated GK gene expression. So we have used the GK promoter constructs carrying mutations in the HRE and HNF4 binding elements to study the SREBP mediated effects. Mutation in the HRE site (pGI3GK-1448HREm) reduced the SREBP-1-dependent GK promoter activity by about 2-fold in both HepG2 and hepatocytes. Mutation in the HNF4 site (pGI3GK-1448HNF4m) also reduced the SREBP-1dependent induction by about 2-fold in HepG2 cells whereas the induction by SREBP-1 was completely lost in primary hepatocytes. Cotransfection of the mutant pGI3GK1448HREm+HNF4m carrying mutations in both HRE and the HNF4 site showed a 2-fold induction as with the single mutants in both cell types (Fig 16). These results implicate that full induction of glucokinase gene expression by SREBP-1 requires these transcription factors. 


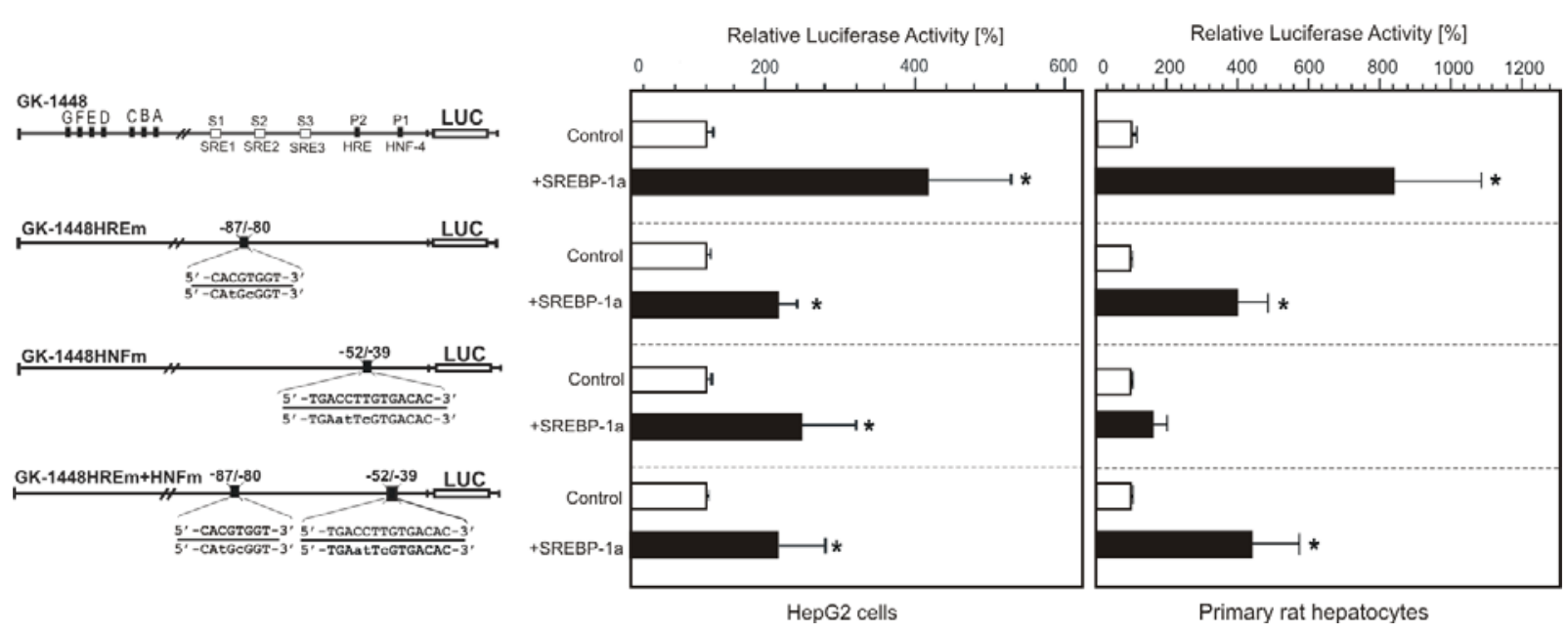

Figure 16. Regulation of HNF4 and HRE mutated GK promoter-Luc constructs by SREBP-1a Primary rat hepatocytes and HepG2 cells were transiently cotransfected with the SREBP-1a expression vector and either a GK-1448 LUC wild type construct, a 1448-bp construct mutated at HRE (GK-1448 HREm), a 1448-bp construct mutated at the HNF-4 site (GK-1448 HNF4m), a 1448-bp construct mutated at the HRE and the HNF4 (GK-1448 HREm+HNF4m). After $5 \mathrm{~h}$ of transfection the medium was changed and the cells were cultured for 48 hours. In the GK promoter constructs the sequences in the upper strand represent the wild-type sequence. In the lower strand the mutant bases are indicated as lower case letters. In each experiment the percentage of Luc activity was determined to the GK-1448 control, which was set equal to $100 \%$. The values represent means \pm S.E. of three independent experiments. Statistics, Student's $t$ test for paired values: ${ }^{*}$, significant differences control versus +SREBP-1a; $p \leq 0.05$.

\subsubsection{Induction of the FAS SRE enhancer Luc gene constructs by SREBP-1a}

To check whether the SREBP-1a expression system works in our cell culture, we have generated two SREBP control plasmids pGI3-4SRE Luc and pGI3-SR/SP Luc constructs harbouring consensus SREBP regulatory element (SRE) and/or a SP1 binding element (SPE) from the fatty acid synthase (FAS) gene. SPE was included since, SP1 transcription factor cooperate to the SREBP-1 to regulate gene expression FAS gene. The plasmid pGI3-4SRE Luc which consists of four SREs was induced by about 4-fold and the pGI3-SR/SP Luc construct which consists of three SREs and one SPE was induced by 14-fold when cotransfected with the SREBP-1a expression vector in rat primary hepatocytes. In HepG2 cells the construct containing four SREs was induced by about 6-fold and the construct containing three SREs and one SPE was induced about 2-fold when cotransfected with SREBP-1a (Fig 17). This shows that overexpression of SREBP-1a works in both primary hepatocytes and HepG2 cells. 


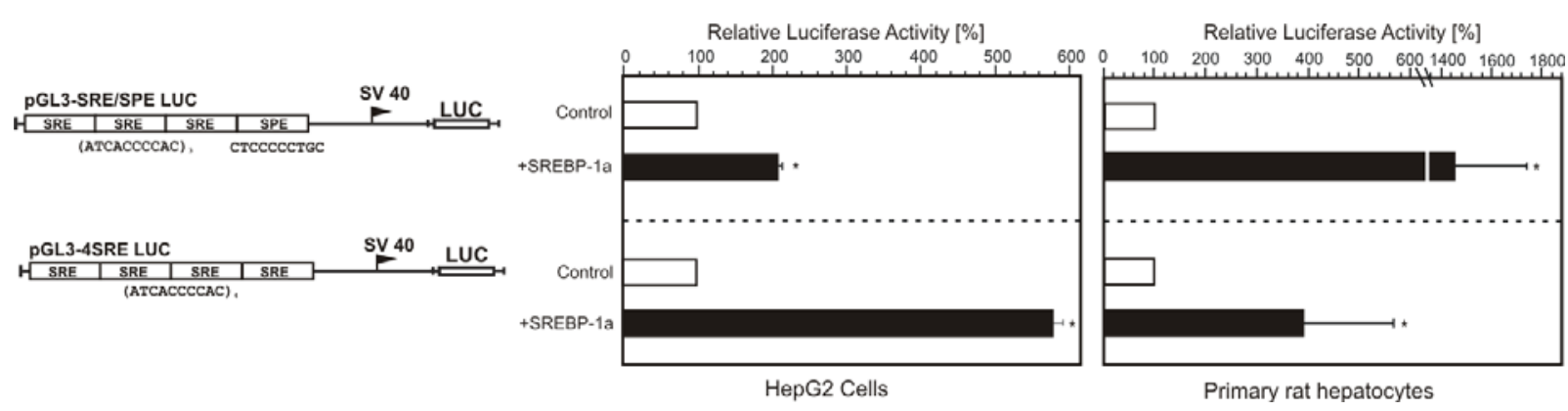

Figure 17. Activation of FAS SRE enhancer Luc gene constructs by SREBP-1a Primary rat hepatocytes were transiently cotransfected with the SREBP-1a expression vector and either a construct carrying three SREs and one SPE (pGL3-SRE/SPE LUC), a construct carrying four SREs (pGL3-4SRE LUC). After $5 \mathrm{~h}$ of transfection the medium was changed and the cells were cultured for 48 hours. The sequences shown in the above figure are the SREBP and SP1 sequences from the fatty acid synthase gene promoter. In each experiment the percentage of Luc activity was determined to the respective control plasmid, which was set equal to $100 \%$. The values represent means \pm S.E. of three independent experiments. Statistics, Student's $t$ test for paired values: ${ }^{*}$, significant differences control versus + SREBP-1a; $p \leq 0.05$.

\subsubsection{Regulation of rat glucokinase gene expression by insulin, the LXR ligand TO- 901317 and by overexpression of SREBP-1a in primary rat hepatocytes}

Insulin is the major regulator of glucokinase in the liver (Roth et al., 2004a). Further, insulin is known to induce several other genes including the transcription factor SREBP. SREBP is thought to be a mediator of insulin effects; however, insulin-dependent SREBP-mediated glucokinase gene expression is still a mystery. TO-901317 is a LXR agonist which stimulates the gene expression of SREBP by binding to the LXR responsive elements present within the SREBP gene promoter. To demonstrate the modulation of glucokinase and SREBP gene expression by insulin and TO-901317, GK mRNA levels from rat primary hepatocytes were measured by northern blot analysis. Besides treating the hepatocytes with insulin and TO901317, primary hepatocytes were transfected with a SREBP-1a expression vector to measure the effects on glucokinase mRNA levels.

Rat primary hepatocytes cultured for $24 \mathrm{~h}$ under standard conditions were treated with $10 \mu \mathrm{M}$ TO-901316 for $16 \mathrm{~h}$ and challenged with $100 \mathrm{nM}$ insulin for $1 \mathrm{~h}$ before the isolation of mRNA. When hepatocytes were stimulated with insulin alone for $1 \mathrm{~h}$ GK mRNA was induced by 4-fold and SREBP mRNA levels were induced by 8-fold (Fig 18 A). TO-901317 treatment alone for 16 $\mathrm{h}$ increased GK mRNA by 4-fold and SREBP mRNA by nearly 35-fold (Fig $18 \mathrm{~A}$ ). Insulin treatment for $16 \mathrm{~h}$ enhanced GK mRNA by 15 -fold and SREBP mRNA induced by 30 -fold (Fig $18 \mathrm{~A}$ ). Treatment of cells with TO-901317 for $16 \mathrm{~h}$ and insulin for $1 \mathrm{~h}$ did not show any additive effect on both the mRNA levels compared to the insulin-independent stimulation for $16 \mathrm{~h}$ (Fig 18 
A). However, the mRNA levels of both genes were clearly enhanced when compared to the $1 \mathrm{~h}$ treatment with insulin alone. When hepatocytes were transfected with the SREBP-1a encoding vector the GK mRNA levels were increased by about 10-fold (Fig $18 \mathrm{~A}$ ). These results indicate that besides insulin, SREBP alone can induce GK gene expression. Treatment with either TO901317 or insulin alone for $16 \mathrm{~h}$ strongly induced SREBP expression which in turn could activate GK expression.
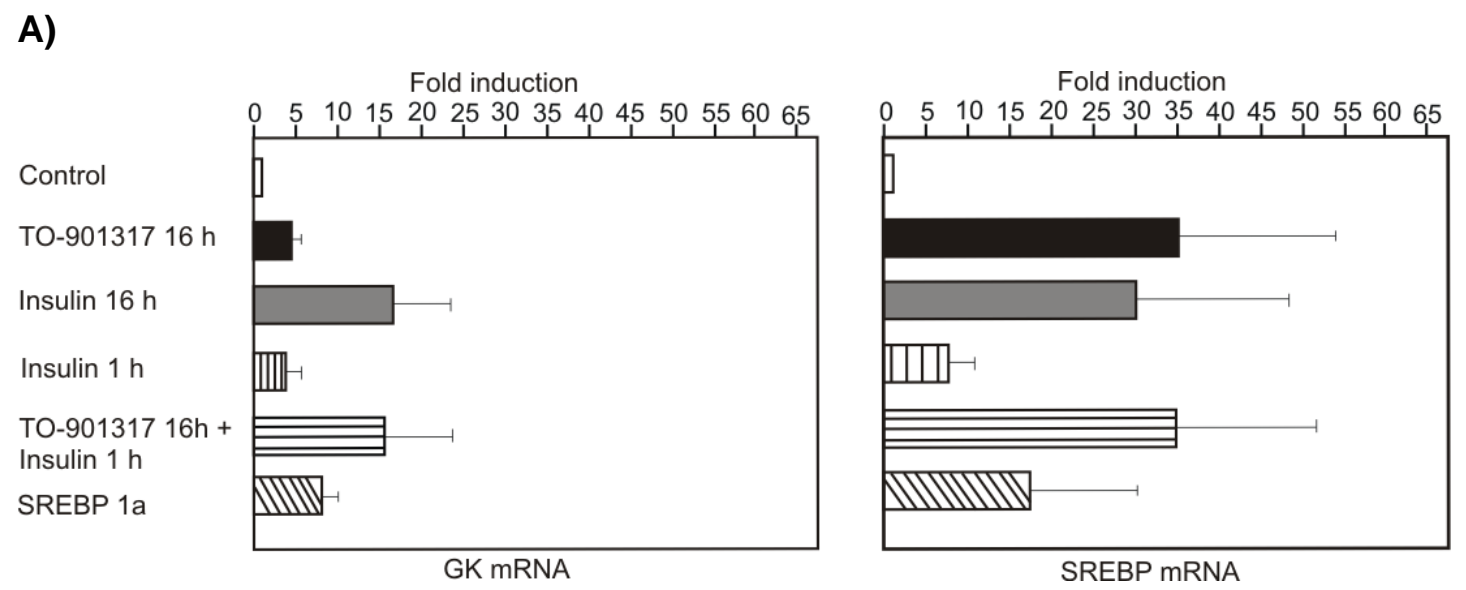

B)

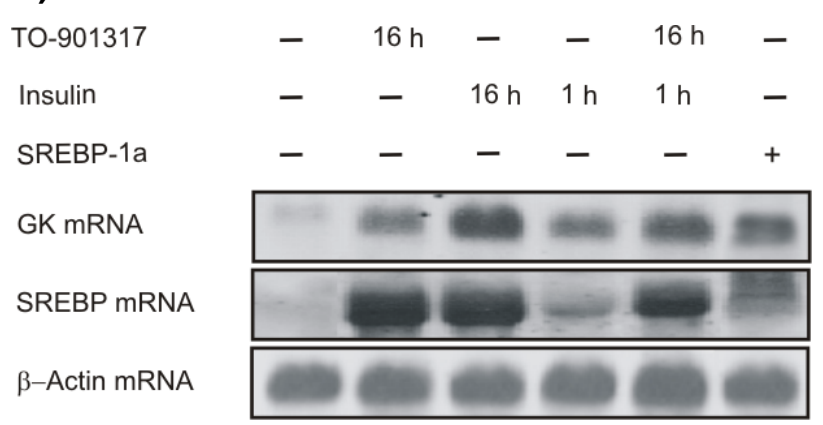

Figure 18. Regulation of GK and SREBP mRNA expression levels by insulin and TO-901317 or by overexpression of SREBP in primary rat hepatocytes

Freshly isolated hepatocytes were cultured $24 \mathrm{~h}$ under standard conditions. One sample was transfected with the SREBP-1a expression vector. At $24 \mathrm{~h}$ the medium was changed and cells were treated with 100 $\mathrm{nM}$ insulin and $10 \mu \mathrm{M}$ TO-901317 and cultured as indicated. A) The GK mRNA levels were measured by Northern blotting. The control mRNA level without insulin was set equal to 1 . The values are from three independent culture experiments. B) Northern blot, $20 \mu \mathrm{g}$ of total RNA prepared form the cultured hepatocytes were hybridized to digoxigenin labeled GK, SREBP-1 and $\beta$-actin antisense RNA probes. Autoradiographic signals were detected by chemiluminescence and densitometry was done using Image $J$ software. 


\subsection{Regulation of rat liver glucokinase gene expression by FoxO transcription factors}

FoxO1 is the most abundant FoxO isoform in several insulin-responsive tissues such as liver, adipose tissue as well as pancreatic $\beta$-cells (Kitamura et al., 2005). FoxO transcription factors contribute to the regulation of cell growth and differentiation. Insulin via PKB/Akt-dependent phosphorylation of FoxO factors inhibits their transcriptional activity by nuclear exclusion. Earlier studies indicated that FoxO proteins bind to insulin responsive sequences (IRSs) in the target gene promoter. In addition to binding DNA target sites in target genes, FoxO proteins interact with and modulate the function of other transcription factors important for the regulation of gene expression in the liver. In contrast to insulin, transgenic mice expressing constitutively active FoxO1 showed stimulated gluconeogenic genes and suppressed expression of genes involved in glycolysis including glucokinase and SREBP (Zhang et al., 2006). However, the molecular mechanism of FoxO mediated suppression of glucokinase gene expression is not known yet. This led us to investigate the role of FoxO1-mediated suppression of glucokinase gene expression.

\subsubsection{Loss of FoxO1-mediated suppression of GK promoter activity by mutating the FBE b site}

Since the glucokinase gene can be down regulated by FoxO factors we looked for FoxO binding sites in the glucokinase promoter sequence and found two putative FoxO1 binding sites ( 5 ' -558 GTAAAACAA -550 3' and 5' -526 TTGTTTTAC -518 3') separated by 21 bases. The 5' sequence is designated as FoxO binding element a (FBEa) and the 3' sequence is designated as FBEb. These putative binding sites were mutated by site directed mutagenesis to generate pGL3GK-1448mFBEa, pGL3GK-1448mFBEb and a double mutant pGL3GK-1448dmFBEab which were then functionally tested in primary hepatocytes and HepG2 cells. When primary rat hepatocytes and HepG2 cells were cotransfected with FoxO1 and GK-1448 containing in the wild type GK promoter Luc activity was reduced by about 7-fold in HepG2 cells; in hepatocytes the GK promoter activity was repressed by 4 -fold (Fig 19). Since FoxO factors interact physically with HNF4 to regulate the gene expression (Hirota et al., 2003) we investigated the role of both transcription factors on GK promoter activity. Cotransfection of an HNF4 vector induced wild type GK promoter activity by about 2-fold in HepG2 cells and about 3-fold in hepatocytes (Fig 19). The HNF4-mediated GK promoter induction was brought down in both cell types when FoxO1 was additionally cotransfected. Cotransfection of FoxO1 with the construct pGI3GK1448mFKHRa carrying a mutation in the putative FoxO1 binding site a did not abolish the 
FoxO1-mediated repression as with the wild type GK promoter. The construct pGI3GK$1448 \mathrm{mFKHRb}$ carrying a mutation in the putative FoxO1 binding site $b$ or a construct pGI3GK$1448 \mathrm{dmFKHRab}$ carrying mutations in both site $a$ and $b$ abolished the repression by FoxO1 in both cell types. Mutations in the FoxO1 sites increased the HNF4-dependent GK promoter activity in comparison to the wild type. However, HNF4-mediated induction was still inhibited in both cell types when FoxO1 and HNF4 were cotransfected together even when the repressive sites were mutated (Fig 19). These results indicate that repression activity of FoxO1 could be due to binding to the putative FoxO binding sites and interaction of FoxO1 with HNF4.

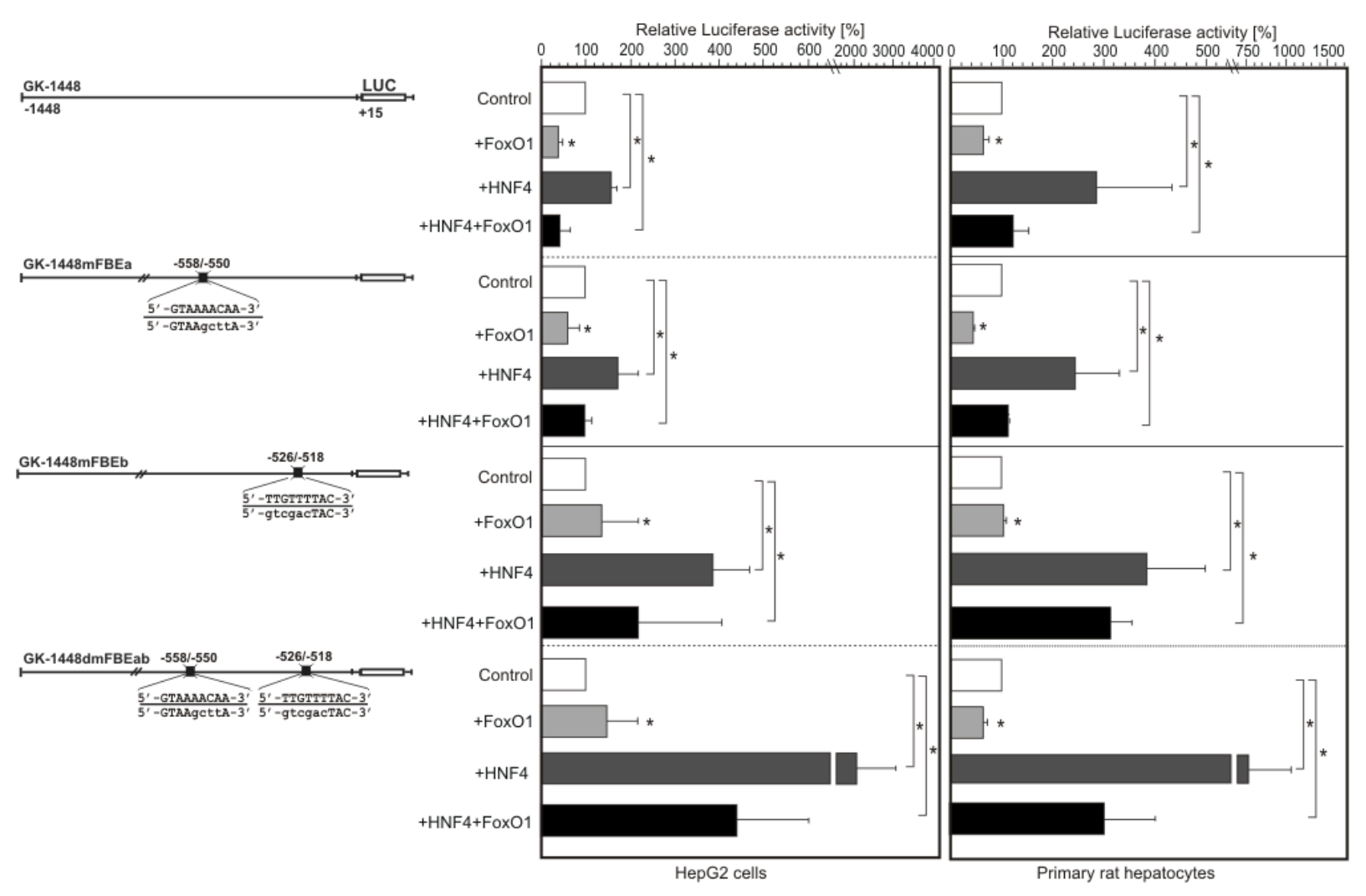

Figure 19. Mutations in the putative FoxO binding elements lead to loss of FoxO1-mediated repression of GK promoter Luc constructs Primary rat hepatocytes and HepG2 cells were transiently cotransfected with the FoxO1 and/or HNF-4 $\alpha$ expression vectors and either a GK-1448 wild type construct or a 1448bp construct mutated at the FBEa (GK-1448 mFBEa), the FBEb (GK-1448 mFBEb), and the FBEa and $b$ (GK-1448 dm FBEab) sites. After $5 \mathrm{~h}$ of transfection the medium was changed and the cells were cultured for 48 hours. In each experiment the percentage of Luc activity was determined to the respective GK-1448 LUC control constructs, which were set equal to $100 \%$. The values represent means \pm S.E. of three independent experiments. Statistics, Student's $t$ test for paired values: * significant differences control versus FoxO1, or versus HNF-4a, versus FoxO1+HNF4a; $p \leq 0.05$. 


\subsubsection{Mutation in the HNF4 binding site leads to loss of FoxO1-mediated repression activity of GK promoter}

Even though mutations in the putative FoxO binding sites, the FoxO1 was able to reduce the HNF4-mediated induction of GK promoter activity. FoxO factors are known to interact physically with the DNA binding domain of HNF4. This led us to generate a mutation construct pGI3GK$1448 \mathrm{HNF} 4 \mathrm{~m}$ containing a mutation in the HNF4 binding site of the GK promoter. Cotransfection of FoxO1 repressed the wild type promoter activity by about 6 -fold in both cell types. HNF4 induced GK promoter activity and the HNF4-mediated induction was inhibited by FoxO1 as in the previous experiment. Mutation of the HNF4 binding site lead to loss of FoxO1 influenced repression of the GK promoter either in the presence of FoxO1 alone or together with HNF4 (Fig 20). These results indicate that FoxO1 can repress GK promoter activity via interaction with HNF4.

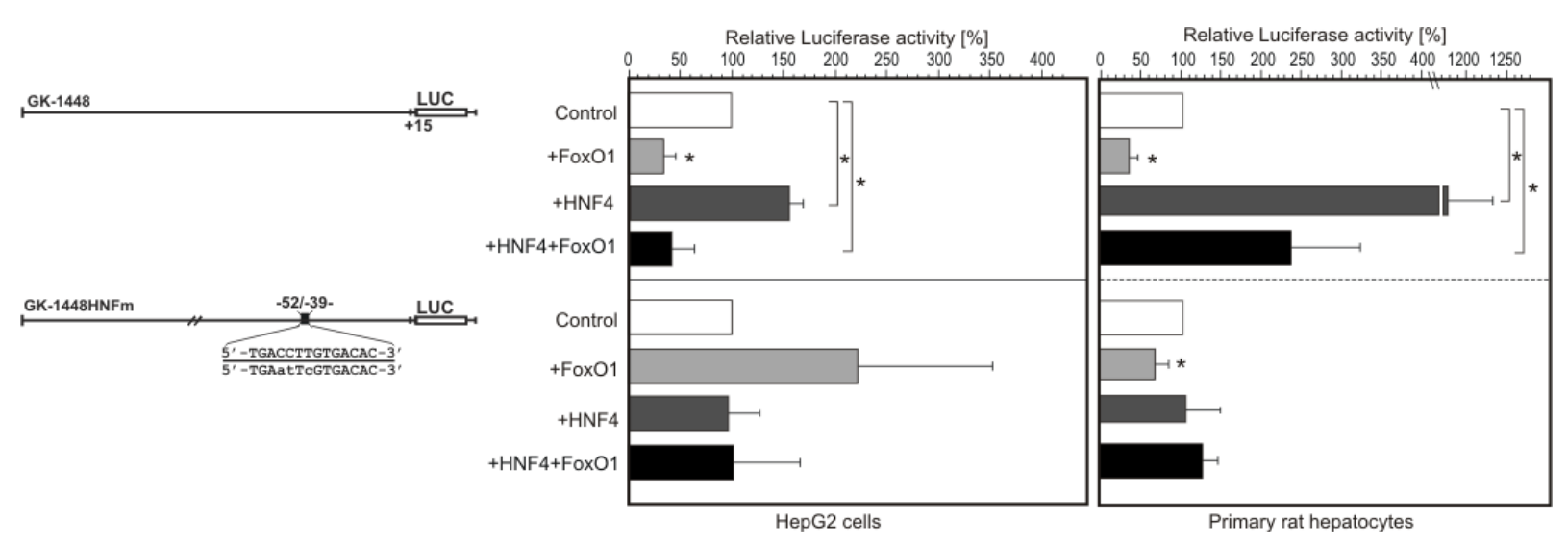

Figure 20. Mutation of the HNF4 binding element leads to loss of FoxO-1-mediated repression of GK promoter Luc constructs Primary rat hepatocytes and HepG2 cells were transiently cotransfected with the FoxO1 and/or HNF4 expression vectors and either a GK-1448 wild type construct or a 1448bp construct mutated at the HNF4 site (GK-1448 HNF4m). After $5 \mathrm{~h}$ of transfection the medium was changed and the cells were cultured for 48 hours. In each experiment the percentage of Luc activity was determined to the GK-1448 wild type and HNF4m LUC control constructs, which were set equal to $100 \%$. The values represent means \pm S.E. of three independent experiments. Statistics, Student's t test for paired values: * significant differences control versus FoxO1 or versus HNF4a, or versus FoxO1+HNF4a; $p \leq 0.05$. 


\subsubsection{Regulation of glucokinase mRNA levels by insulin, glucagon and cAMP}

Insulin and glucagon act antagonistically on many genes involved in glucose metabolism. GK mRNA levels were induced in primary rat hepatocytes treated with $100 \mathrm{nM}$ insulin for $5 \mathrm{~h}$, and repressed when hepatocytes were treated with $10 \mathrm{nM}$ glucagon and $100 \mu \mathrm{M}$ cAMP for $5 \mathrm{~h}$. In contrast, the mRNA of the gluconeogenic gene PEPCK was induced by glucagon and CAMP and inhibited by insulin (Fig $21 \mathrm{~A}$ ).

During fasting stages glucagon levels are high and inhibit many of the genes involved in glycolysis and induce the genes involved in gluconeogenesis to maintain normal blood glucose levels. When Male Wistar rats were fasted for $48 \mathrm{~h}$ the protein levels of glucokinase were completely undetectable, however, the GK protein levels become, again visible after a refeeding period of $2 \mathrm{~h}$ (Fig $21 \mathrm{~B}$ ) since during refed stages insulin levels are high and regulate the blood glucose levels by inducing genes involved in the glucose metabolism such as glucokinase. Glucagon signaling is known to activate FoxO gene transcription by inhibiting the PKB pathway, which will regulate the target genes (Kuiperij et al., 2005). In normal fed rats the protein levels of FoxO1 were less in comparison to the $48 \mathrm{~h}$ fasted rat and $48 \mathrm{~h}$ fasted and $2 \mathrm{~h}$ refed rat. These results explain that, FoxO1 could be a downstream target of glucagon signaling. FoxO1 suppresses the glycolytic gene glucokinase and activates gluconeogenic genes like PEPCK during fasting to maintain glucose homeostasis (Fig 21). In conclusion FoxO factors could be one of the key players in carbohydrate metabolism.

A)

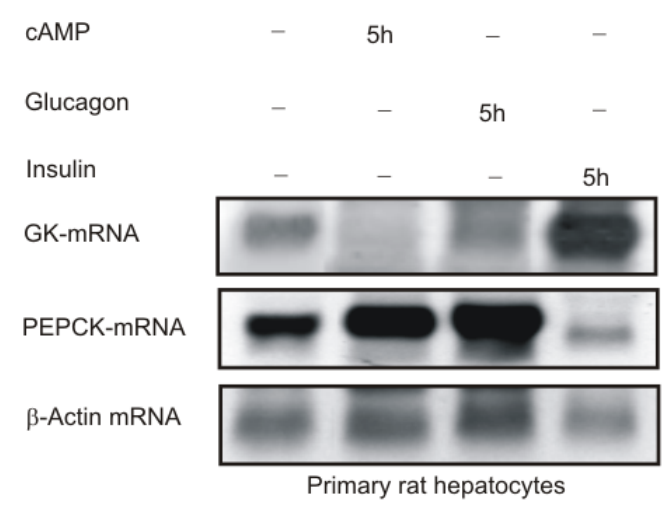

B)

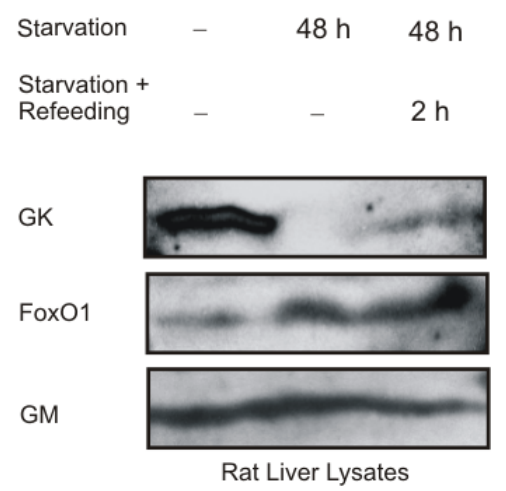

Figure 21. Insulin and glucagon/CAMP act antagonistic on GK and PEPCK transcription and regulation of GK during fasting and refeeding A) Freshly isolated primary rat hepatocytes were cultured for $5 \mathrm{~h}$ in basal medium M199 containing $0.5 \mathrm{nM}$ insulin, $100 \mathrm{nM}$ dexamethasone and $4 \%$ fetal calf serum (FCS). After $5 \mathrm{~h}$ cells were cultured for $19 \mathrm{~h}$ without insulin and FCS. After $19 \mathrm{~h}$ the cells were incubated with $100 \mathrm{nM}$ insulin, $10 \mathrm{nM}$ glucagon and $100 \mu \mathrm{M}$ cAMP for $5 \mathrm{~h}$. After $5 \mathrm{~h}$ of treatment, total RNA was isolated and $20 \mu \mathrm{g}$ of RNA subjected to Northern analysis with respective digoxigenin-labeled anitsense RNA probes. Autoradiographic signals were obtained by chemiluminescence. B) Male Wistar rats housed in controlled environmental conditions were used for fasting and refeeding experiment. Protein isolated from the frozen liver was used to examine the liver glucokinase and FoxO1 protein levels. Golgi membrane (GM) antibody was used as loading control. 


\subsubsection{Modulation of rat liver glucokinase promoter by resveratrol}

Resveratrol is a phytoalexin abundantly present in a plant Polygonum capsidatum and skin of red grapes. It is supposed that resveratrol has a number of beneficial health effects against cancer, aging, inflammation and diabetes. Resveratrol is known to increase the activity of the enzyme SIRT1 (sirtuins) which deacetylates the endogenous inactive FoxO to active FoxO. Since the previous results indicated that the glucokinase promoter is suppressed by overexpressed FoxO1 we wanted to prove the effect of endogenous FoxO on the glucokinase promoter by stimulating hepatocytes with resveratrol. Primary rat hepatocytes were transfected with the GK wild type and the constructs carrying mutations in the FoxO binding sites and the HNF4 binding site and treated with $50 \mu \mathrm{M}$ resveratrol for $24 \mathrm{~h}$ before measuring Luc activity. Wild type GK promoter activity was reduced by 3-fold and the construct pGI3GK-1448mFBEa carrying a mutation in the FBEa site was suppressed by 2-fold when treated with resveratrol. The hepatocytes transfected with the construct pGI3GK-1448mFBEb carrying a mutation in the FBEb site or the construct pGI3GK-1448HNF4m a carrying mutation in the HNF4 binding site or the construct pGI3GK-1448mFBEab carrying mutations in both FoxO binding sites showed no reduction in Luc activity when treated with $50 \mu \mathrm{M}$ resveratrol (Fig 22). These results indicate that mutations in the FoxO binding sites or in the HNF4 binding site leads to a loss of resveratrol activated FoxO1-mediated repression of liver GK. 

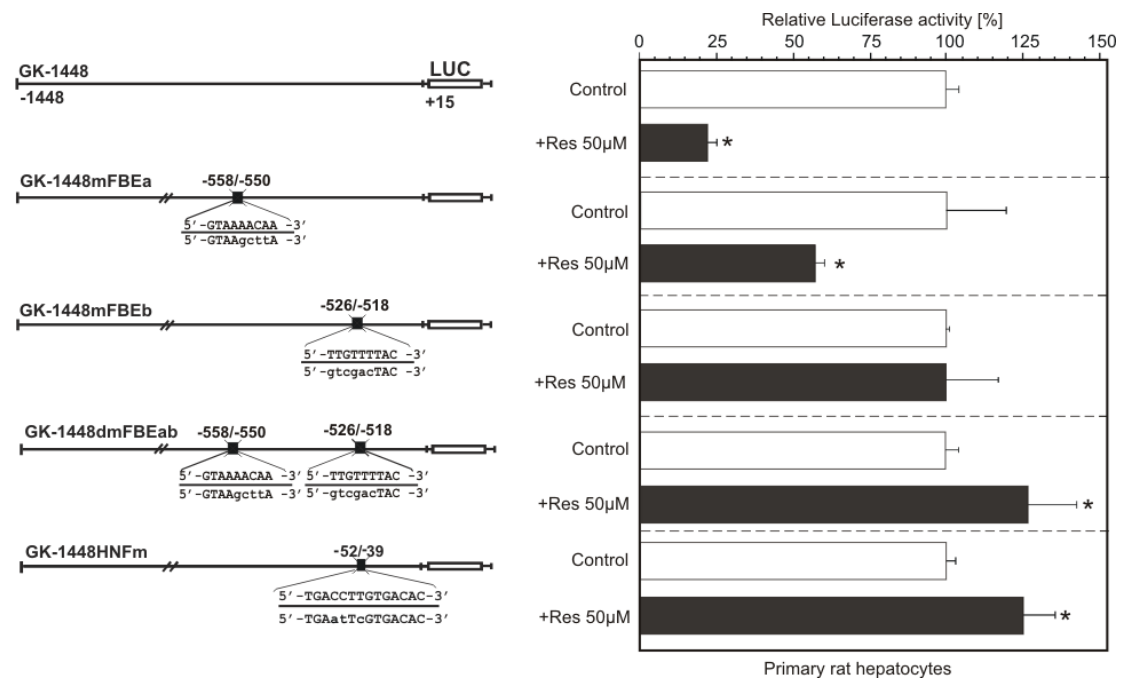

Figure 22. Mutations in the FoxO binding elements lead to loss of resveratrol mediated repression of GK promoter Luc constructs Primary rat hepatocytes were transiently transfected with either a GK1448 wild type construct or a 1448bp construct mutated at the FBEa (GK-1448 mFBEa), the FBEb (GK$1448 \mathrm{mFBEb}$ ), and the FBEa and b (GK-1448 dm FBEab) sites a 1448bp construct mutated at the HNF4 site (GK-1448 mHNF4). After $5 \mathrm{~h}$ of transfection the medium was changed and the cells were cultured for $24 \mathrm{~h}$ and the medium was changed again and stimulated the hepatocytes with $50 \mu \mathrm{M}$ resveratrol for $24 \mathrm{~h}$. In each experiment the percentage of Luc activity was determined to the respective GK-LUC control constructs, which were set equal to $100 \%$. The values represent means \pm S.E. of three independent experiments. Statistics, Student's $\mathrm{t}$ test for paired values: * significant differences control versus resveratrol $50 \mu \mathrm{M} ; \mathrm{p} \leq 0.05$.

\subsubsection{In-vivo binding of FoxO1 with HNF4 in HEK293T cells}

Since HNF4-mediated glucokinase promoter activity was repressed by FoxO1 in luciferase assays, we intended to determine the physical interaction of FoxO1 with HNF4 by coimmunoprecipitation. HEK293T cells were transiently transfected with Flag-tagged FoxO1 expression vector along with HNF4 expression vectors. Approximately $200 \mu \mathrm{g}$ of cell lysate was immunoprecipitated with anti-HNF4 antibody and the immune complexes were resolved by SDSPAGE, followed by Western blotting with antibodies against FoxO1 and HNF4. The HNF4precipitated complexes include FoxO1 (Fig 23), demonstrating the in vivo interaction between FoxO1 and HNF4. Foxo1 and HNF4 over expressed lysates were used as positive controls and were immunoblotted using anti-FoxO1 antibody and anti-HNF4 antibody, anti-Golgi membrane antibody was used as loading control (Fig 23). 


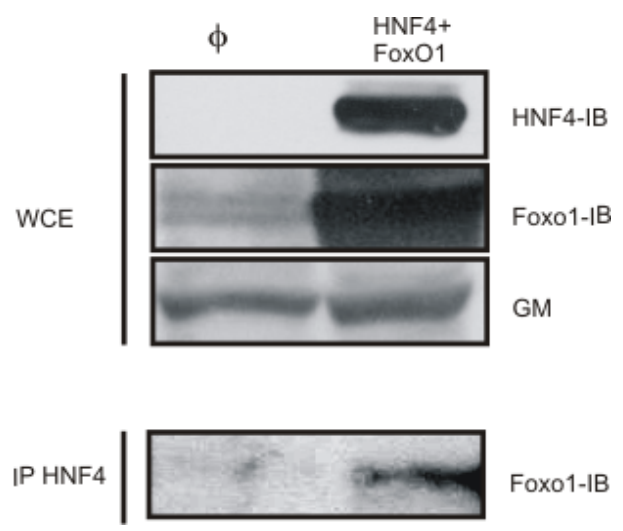

Figure 23. Interaction of FoxO1 with HNF4 in HEK293T cells HEK 293T whole cell extracts that expressed Flag-tagged FoxO1 along with full length HNF4 were used for in vivo binding. FoxO1 was immunoprecipitated using anti-HNF4 antibody. Whole cell extracts (WCE) and immunoprecipitated complexes were resolved on SDS-PAGE and immunoblotted with anti-FoxO1 antibody HNF-4 and GM antibodies.

\subsubsection{Modulation of FoxO1-mediated repression of the GK promoter by insulin}

Insulin signalling via the PI3K/PKB pathway induces glucokinase gene expression and has a dynamic effect on FoxO factors due to phosphorylation of FoxOs by PKB. This prompted us to investigate the effects of insulin on the repressive activity of FoxO1 on the GK promoter. Hepatocytes transfected with the wild type GK promoter construct (pGI3GK-1448) were induced by about 2-fold when stimulated with $100 \mathrm{nM}$ insulin alone (Fig 24). The GK promoter activity was reduced by 2-fold when FoxO1 was cotransfected, however, the repressive activity of FoxO1 was completely abolished in the presence of insulin and the GK promoter activity regained an induction of 2-fold as with insulin alone (Fig 24). These results demonstrate that insulin signalling dominates and inactivates FoxO1, which leads to a loss of GK repression. Besides inactivating FoxO1, insulin stimulates the GK promoter activity. 


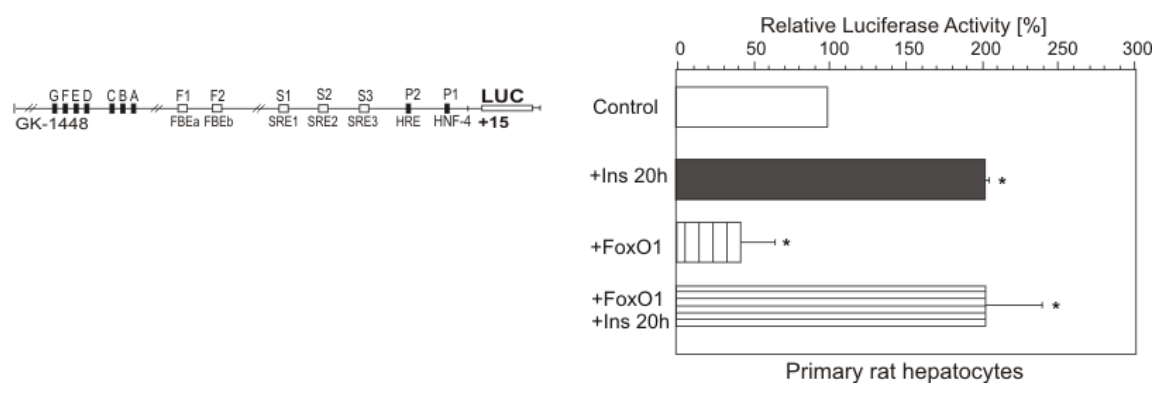

Figure 24. Insulin abolished the FoxO1-mediated repression of GK promoter Luc constructs Primary rat hepatocytes were transiently cotransfected with FoxO1 along with GK-1448 wild type construct. After $5 \mathrm{~h}$ of transfection the medium was changed and the cells were cultured for $24 \mathrm{~h}$. After 24 $\mathrm{h}$ the medium was changed again and stimulated with $100 \mathrm{nM}$ insulin for further $20 \mathrm{~h}$. In each experiment the percentage of Luc activity was determined to the respective GK- LUC control construct, which was set equal to $100 \%$. The values represent means \pm S.E. of three independent experiments. Statistics, Student's t test for paired values: * significant differences control versus insulin $20 \mathrm{~h}$, or versus FoxO1, or versus FoxO1+insulin $20 \mathrm{~h} ; \mathrm{p} \leq 0.05$.

\subsubsection{Resveratrol inhibits insulin-induced glucokinase mRNA and protein levels}

Since resveratrol repressed the glucokinase promoter we investigated the effects of resveratrol also on GK mRNA and protein levels. Resveratrol is known to activate the deacetylating enzyme SIRT1 which in turn activates FoxO factors by deacetylation (Daitoku et al., 2004). Primary rat hepatocytes were treated with $10 \mu \mathrm{M}$ and $50 \mu \mathrm{M}$ resveratrol for $2 \mathrm{~h}$ and challenged with $100 \mathrm{nM}$ of insulin for another $16 \mathrm{~h}$. While resveratrol at $10 \mu \mathrm{M}$ initiated a minor reduction of GK mRNA, resveratrol at $50 \mu \mathrm{M}$ reduced GK mRNA expression below basal. In hepatocytes treated with 10 $\mu \mathrm{M}$ resveratrol for $2 \mathrm{~h}$ and then challenged with $100 \mathrm{nM}$ insulin, the inhibitory effect of resveratrol on GK mRNA was lost and insulin induced GK expression, showing that insulin signalling dominated the resveratrol mediated repression. Treatment of hepatocytes with insulin and 50 $\mu \mathrm{M}$ resveratrol did not show a derepression of GK mRNA (Fig $25 \mathrm{~A}$ ). In contrast to GK expression, resveratrol alone induced PEPCK mRNA levels. Further, the inhibitory effect of insulin on PEPCK gene expression was reversed by resveratrol at $50 \mu \mathrm{M}$ but not at $10 \mu \mathrm{M}$ (Fig $25 \mathrm{~A})$.

The effect of resveratrol on insulin induced glucokinase gene regulation was also examined at the protein level. In order to visualize the GK protein on Western analysis the hepatocytes were stimulated with $250 \mathrm{nM}$ of insulin. Hepatocytes treated with $10 \mu \mathrm{M}$ resveratrol did not show any inhibitory effect on GK protein when compared to control (Fig 25 B). However, resveratrol alone at $50 \mu \mathrm{M}$ or even in the presence of insulin reduced GK protein levels below the detection limit, showing that resveratrol inhibits insulin-mediated effects and represses the GK protein. Insulin alone induced GK protein levels when compared to control cells (Fig 25 B). These results 
conclude that resveratrol acts against to insulin signalling and blocks the insulin mediated effects on glucokinase both at mRNA and protein levels. Resveratrol mediated repression on GK gene expression could be via activating the FoxO transcription factors by deacetylation.

A)

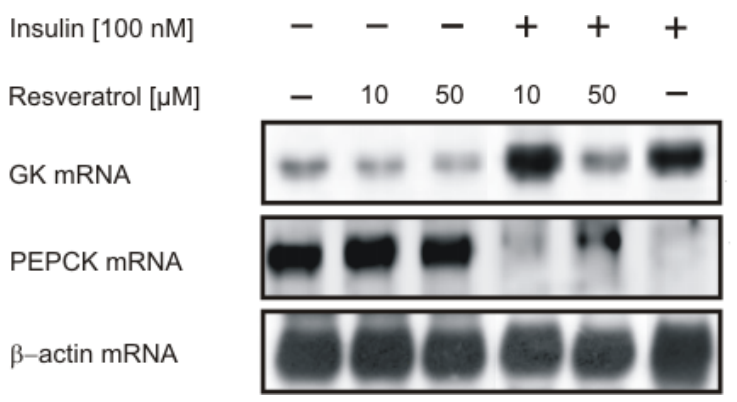

B)

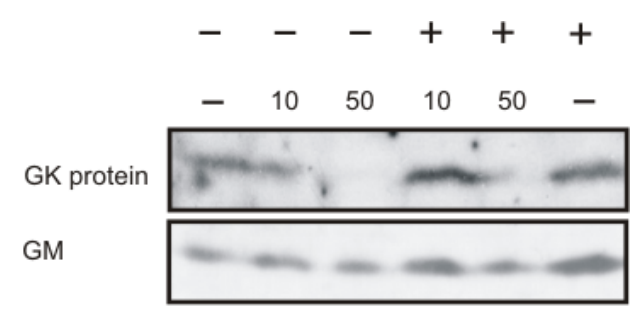

Figure 25. Regulation of GK and PEPCK gene expression by insulin and resveratrol in primary rat hepatocytes

Freshly isolated hepatocytes were cultured $24 \mathrm{~h}$ under standard conditions. A $24 \mathrm{~h}$ the medium was changed and cells were treated with $100 \mathrm{nM}$ insulin and $10 \mu \mathrm{M}$ and $50 \mu \mathrm{M}$ resveratrol respectively and cultured for further $16 \mathrm{~h}$. A) Northern blot, $20 \mu \mathrm{g}$ of total RNA prepared form the cultured hepatocytes were hybridized to digoxigenin labeled GK, PEPCK and $\beta$-actin antisense RNA probes. Autoradiographic signals were detected by chemiluminescence. B) Western blot, hepatocytes were cultured for $24 \mathrm{~h}$ and at $24 \mathrm{~h}$ the medium was changed and cells were stimulated with insulin and resveratrol. A total of $100 \mathrm{~g}$ of protein from the hepatocytes were subjected to Western analyses with an antibody against glucokinase, (GK) or Golgi membrane (GM). Autoradiographic signals were obtained by chemiluminescence.

\subsubsection{Down regulation of glucokinase gene expression by FoxO1 and SIRT1 overexpression}

Our previous results on GK promoter down regulation by FoxO1 and resveratrol prompted us to prove the effects of FoxO1 and its upstream deacetylase SIRT1 on glucokinase mRNA levels. In hepatocytes transfected with an expression vector coding for FoxO1, the GK mRNA levels were reduced when compared to control cells (Fig 26 A). Likewise, hepatocytes transfected with the SIRT1 expression vector showed down regulation of GK mRNA as in the FoxO1 transfected cells (Fig 26 A). These results suggest that FoxO1 can be a downstream target of SIRT1 and is involved in the down regulation of glucokinase gene expression. In order to check the overexpression of FoxO1 and Myc-tagged SIRT1, HEK293T cell lysates were analysed by Western Blot to detect FoxO1 by anti-FoxO1 or SIRT1 by anti-Myc tag antibody, the Golgi membrane antibody was used as loading control (Fig 26 B). 
A)

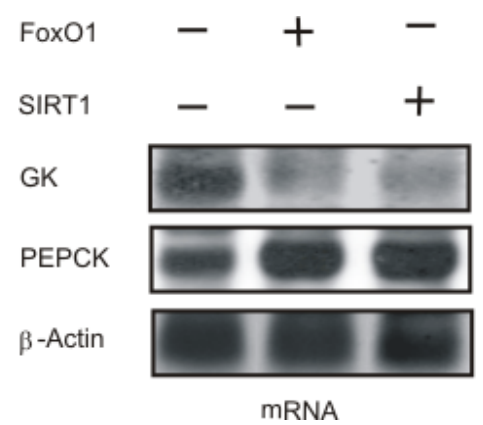

B)

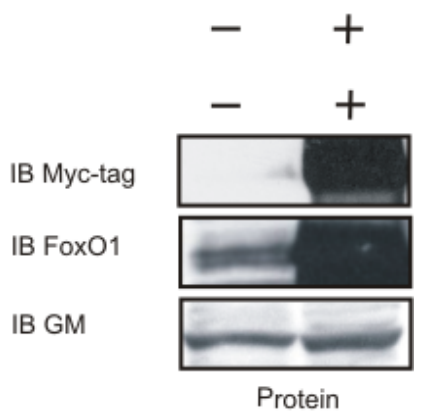

Figure 26. Regulation of GK and PEPCK gene expression by FoxO1 and SIRT1 in primary rat hepatocytes

Freshly hepatocytes were transfected with FoxO1 and SIRT1 expression vectors and after $5 \mathrm{~h}$ of transfection the medium was changed and cultured for $24 \mathrm{~h}$. After $24 \mathrm{~h}$ the medium was changed again and cultured for further $24 \mathrm{~h}$. A) Northern blot, $20 \mu \mathrm{g}$ of total RNA prepared form the cultured hepatocytes were hybridized to digoxigenin labeled GK, PEPCK and $\beta$-actin antisense RNA probes. Autoradiographic signals were detected by chemiluminescence. B) Western blot, cells were transfected with FoxO1 and Myc tagged SIRT1 expression vectors and cultured for $24 \mathrm{~h}$. Total cell extracts were isolated from the cells and used to detect the expression levels of FoxO1 and SIRT1. A total of $100 \mu \mathrm{g}$ of protein was subjected to Western analyses with an antibody against Myc-tag or FoxO1 or Golgi membrane. Autoradiographic signals were obtained by chemiluminescence.

\subsubsection{Resveratrol deacetylated p300-dependent acetylated FoxO1}

Resveratrol is known to activate SIRT1 which possess deacetylating activity. Since resveratrol showed repression GK expression we examined whether resveratrol can mediate deacetylation of FoxO1. To study the effects of resveratrol on deacetylation of FoxO1 we have used p300 possessing acetylating activity. The transcriptional co-activator p300 possesses histone acetyltransferase activity and plays an important role in activation of gene expression. Thus, p300 binds and acetylates FoxO1 at K242, K245, and K262 which leads to attenuation of FoxO1 as a transcription factor (Fukuoka et al., 2003). Therefore, we cotransfected HEK293T cells with Flag-tagged FoxO1 and p300 expression vectors and treated the samples with resveratrol. To identify the acetylation status of FoxO1 we have used an antibody which specifically detects the K242 and K245 residues of FoxO1. Cells transfected with FoxO1 alone did not show any acetylation, whereas cells transfected with FoxO1 together with p300 showed acetylation of FoxO1, which indicates that FoxO1 is acetylated by p300. However, p300 acetylated FoxO1 was deacetylated by $50 \mu \mathrm{M}$ resveratrol in $6 \mathrm{~h}$ (Fig 27). These results support our previous results that inactive FoxO1 is activated by resveratrol by deacetylation which in turn represses the glucokinase gene expression. 


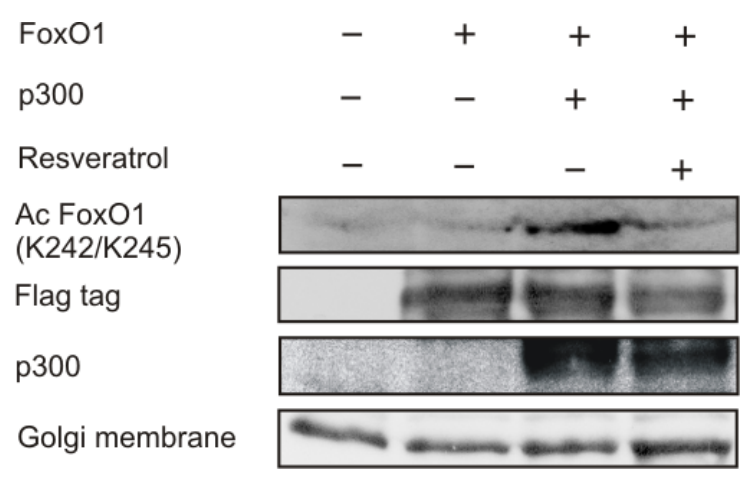

Figure 27. Resveratrol deacetylates p300 acetylated FoxO1

HEK293T cells transfected with expression vectors of Flag-tagged FoxO1 and p300 were cultured for 24 h. One sample was treated with $50 \mu \mathrm{M}$ resveratrol for $6 \mathrm{~h}$ as indicated. $150 \mu \mathrm{g}$ of whole cell extracts from the HEK293T cells were resolved by SDS-PAGE. The anti-acetylated FoxO1 (K242/245) antibody specifically recognizing the acetylated K242 and K245 residues in Foxo1 was used to detect acetylated FoxO1. The p300 was detected using anti-p300 antibody and Flag-tagged FoxO1 was detected with antiFlag antibody. Golgi membrane antibody was used as loading control. Autoradiographic signals were obtained by chemiluminescence.

\subsubsection{Repression of glucokinase enzyme activity by resveratrol and FoxO1 in primary rat hepatocytes}

The previous results showed down regulation of glucokinase gene expression by resveratrol and this could be reversed by insulin at both mRNA and protein levels. To support the previous data, we aimed to study the effect of resveratrol on GK enzyme activity which was measured in primary rat hepatocytes. Whole cell extracts were used for qualitative analysis of the glucokinase enzyme activity by Michaelis-Menten and Lineweaver-Burk methods. The rate of the reaction and the Vmax was calculated by Michaelis-Menten method and linearization of MichaelisMenten curves will give the Lineweaver-Burk plot which explains the $\mathrm{Km}$ and glucokinase $\mathrm{Km}$ falls between $8-16 \mathrm{mM}$. Hepatocytes were treated with different concentrations of resveratrol alone and some samples treated with resveratrol were challenged with $250 \mathrm{nM}$ insulin. The GK enzyme activity was measured in the presence of different glucose concentrations and it was found that it was not affected by resveratrol alone at $10 \mu \mathrm{M}$. However, when $10 \mu \mathrm{M}$ resveratrol treated cells were challenged with $250 \mathrm{nM}$ insulin, the Vmax of the GK enzyme activity was reduced compared to the insulin treated control although it was induced compared to the untreated control GK (Fig $25 \& 28 \mathrm{C}$ ). By contrast, the enzyme activity was suppressed by 50 $\mu \mathrm{M}$ resveratrol alone and this was not reversed by insulin. Insulin alone induced the rate of the reaction and Vmax of GK enzyme activity, as observed at mRNA and protein levels (Fig 25 \& 28 $A$ and $C$ ). Linearization of the Michaelis-Menten curves gives the Lineweaver-Burk plots of GK enzyme activity for different treatments. The intercept of lines on the negative $\mathrm{X}$-axis gives the $\mathrm{Km}$, treatments with resveratrol and insulin did not change the $\mathrm{Km}$ of glucokinase which falls 
between -0.06 to -0.1 i.e $10-15 \mathrm{mM}$ of glucose (Fig $28 \mathrm{C}$ ). This explains that the velocity of the glucokinase enzyme activity was due to the reduced amount of the enzyme.

Hepatocytes were then transfected with a constitutively active FoxO1 to prove that FoxO1mediated suppression of glucokinase is visible also at the enzyme activity. Hepatocytes transfected with constitutively active FoxO1 displayed significantly reduced $\mathrm{Vmax}$ of glucokinase (Fig $28 \mathrm{~F}$ ). The $\mathrm{Km}$ values for control and FoxO1 were between -0.06 to -0.1 which is equal to 10-15 mM glucose (Fig $28 \mathrm{E}$ ). These results indicate that FoxO1 is a major modulator for the down regulation of glucokinase gene expression. 
A)

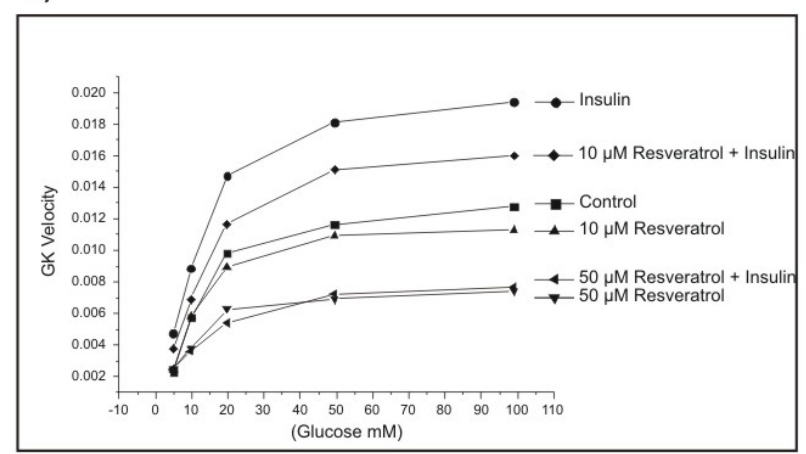

B)

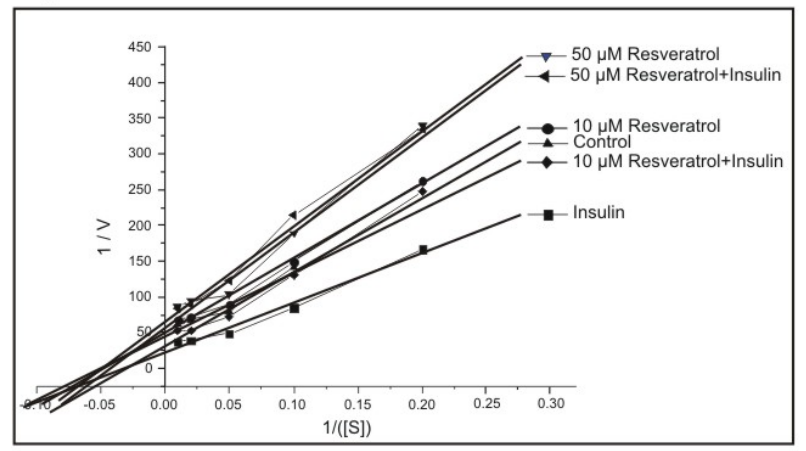

C)

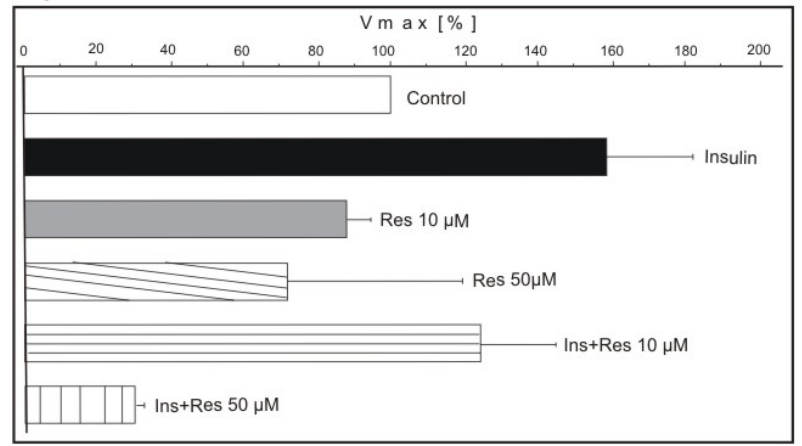

D)

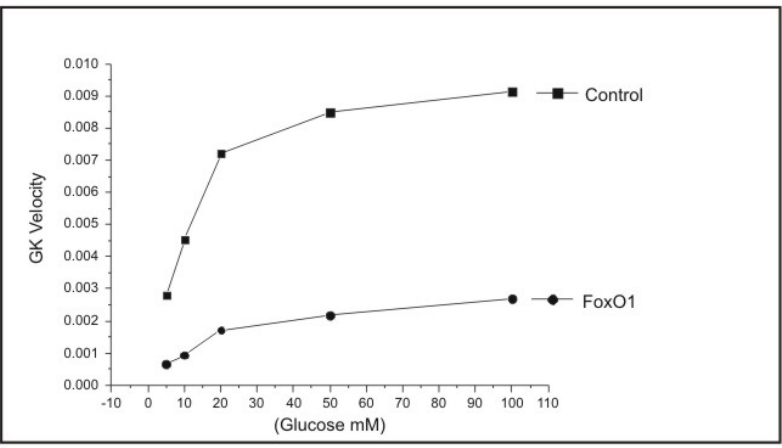

E)

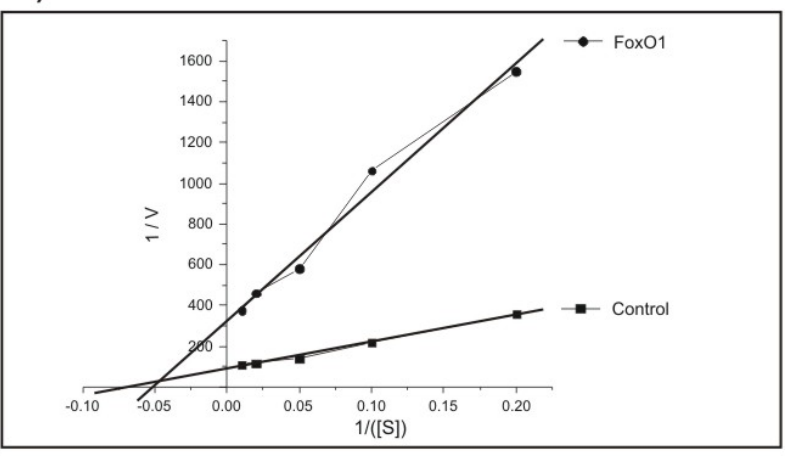

F)

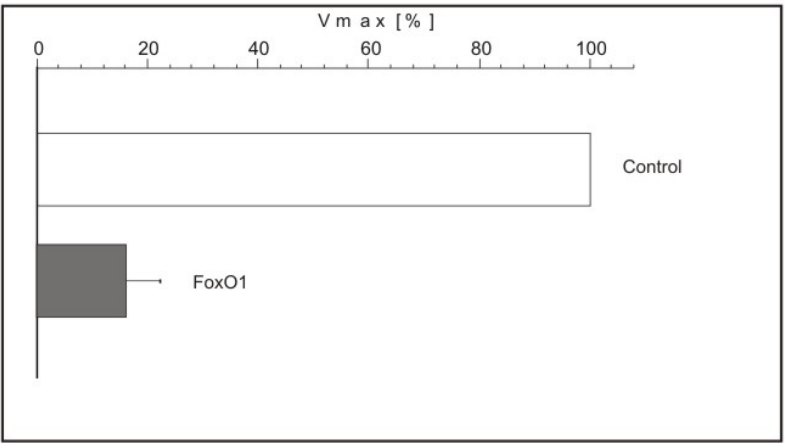

Figure 28. Regulation of glucokinase enzyme activity by resveratrol and FoxO1 in primary rat hepatocytes Freshly isolated hepatocytes were cultured $24 \mathrm{~h}$ under standard conditions. After $24 \mathrm{~h}$ the cells were given fresh medium and stimulated with Resveratrol and insulin $(250 \mathrm{nM})$ for further $20 \mathrm{~h}$ as indicated in the panels A, B and C. Hepatocytes were transfected with constitutively active FoxO1 to measure the GK enzyme activity as showed in the panels D, E, and F. Panel A, B, D and E are the qualitative analysis of glucokinase enzyme activity measured by Michelis-Menten and Lineweaver-Burk plots and are made from the average of three independent experiments. Panel $C$ and $F$ depicts the Vmax of the glucokinase enzyme activity calculated from three independent experiments. In each experiment the percentage of Vmax was determined to the control, which was set equal to $100 \%$. The $\mathrm{R}^{2}$ values for the Lineweaver-Burk plots were $R^{2}=0.99$. 


\section{Discussion}

Glucose is the major nutrient carbohydrate which can be utilized in mammals by all cells to produce energy in the form of adenosine triphosphate (ATP). Once glucose enters into the cells through specific glucose transporters (GLUTs) the first step of glucose utilization is phosphorylation of glucose to glucose 6-phosphate. This can be done by four different hexokinases I - IV from which hexokinase IV is termed glucokinase (GK). Glucokinase acts as a glucose sensor in pancreatic $\beta$-cells and in hepatocytes to maintain glucose homeostasis. Mutations in the GK gene cause Maturity Onset Diabetes of the Young Type II (MODY II). GK is encoded by a single gene consisting of 10 exons; it has two widely separated and functionally distinct cell-type specific promoters. The upstream promoter is operating in pancreatic $\beta$-cells whereas the downstream promoter is responsible for hepatic GK gene transcription. In the liver, GK expression is regulated in response to fasting and refeeding (lynedjian et al., 1989) with insulin and glucagon acting as the major regulators. Hepatic GK gene expression is mainly stimulated by insulin in the less aerobic perivenous zone of the liver by both HIF-1 and HNF-4 (Roth et al., 2004a). In addition to HIF-1 and HNF4, insulin regulates several other transcription factors including forkhead transcription factors (FOXO), activator protein-1 (AP-1) and sterol regulator element binding protein (SREBP). Insulin and glucose have been well known to stimulate lipogenesis through induction of SREBP-1 expression, which is highly nutritionally regulated in the liver and adipose tissues (Matsuzaka et al., 2004) and SREBP-2 involved in regulating genes involved in cholesterol synthesis. SREBP-1 was shown to be important as a dominant negative form of SREBP-1 inhibited the insulin-dependent GK gene expression (Foretz et al., 1999b) and transfection of SREBP-1a enhanced GK promoter activity (Roth et al., 2004a). Even though SREBP-1 activates GK gene expression, there are discrepancies in the understanding the effects of insulin-mediated SREBP-1 regulation of GK expression. FoxO transcription factors belong to the fork head family of transcription factors which can also participate in the regulation of genes involved in glycolysis and gluconeogenesis. FoxO factors are dynamically regulated by insulin signaling, since phosphorylation of FoxO factors by PKB leads to nuclear exclusion. Glucagon stimulates the FoxO gene expression to induce the genes involved in gluconeogenesis. Recent reports on transgenic mice expressing constitutively active FoxO1 in the liver showed negative regulation of glucokinase gene expression (Zhang et al., 2006). However, molecular details of this negative regulation of FoxO1 on glucokinase gene expression are still not known to the last detail. The present study has shown that both insulin and SREBP-1 induced GK gene expression individually in primary rat hepatocytes. Insulin signaling activated SREBP-1 gene transcription within $16 \mathrm{~h}$ which could in turn activate the GK 
gene expression in a cooperative manner. A GK promoter characterization with transfection assays revealed that putative SREBP binding elements 2 and 3 of the GK promoter appear to be important for the SREBP-1 effect. In addition it was found that deletion or mutations in the foot print region $B$ lead to loss of promoter regulation by SREBP-1 even though the nucleotide sequence of the site does not resemble a classical SREBP binding site. So far, the factor binding to the foot print $B$ site is unknown.

Investigation of the negative GK expression by FoxO1 revealed that FoxO1 could mediate its effect via the putative FoxO1 binding sites present in the GK promoter or via interacting with HNF-4. During fasting stages glucagon signaling might activate FoxO1 at the gene level or it could be deacetylated by SIRT1 proteins. This would promote the nuclear localization of FoxO which then can induce the gluconeogenic genes such as PEPCK and repress the genes involved in glycolysis like glucokinase.

\subsection{Regulation of glucokinase expression by insulin and SREBP-1a}

\subsubsection{Transcriptional regulation of glucokinase and SREBP-1 by insulin}

The pancreatic hormone insulin acts on primary target tissues including muscle, adipose tissue, and liver. Insulin is known to regulate many genes involved in many processes including energy metabolism. Insulin induces transcription of genes encoding glycolytic enzymes and down regulates genes encoding gluconeogenic enzymes by modulating several transcription factors such as SREBP-1. A key liver enzyme that is transcriptionally induced by insulin in hepatocytes is glucokinase and the insulin-dependent maintenance of glucokinase activity is essential for the liver to maintain glucose homeostasis when carbohydrate supply is high. SREBP-1 is known to activate genes involved in glycolytic and lipogenic pathways which lead to the synthesis of fatty acyl-CoA from glucose carbon atoms for lipid storage. Previous evidence suggests that the insulin-dependent induction of liver GK transcription could be mediated by SREBP-1, which itself is induced at the transcriptional level by insulin in the liver (Foretz et al., 1999a). In this study, treatment of hepatocytes with insulin for $1 \mathrm{~h}$ induced SREBP-1 mRNA to values which were 2fold higher than the GK mRNA levels. Treatment of insulin for $16 \mathrm{~h}$ induced SREBP-1 mRNA 10 fold more than GK mRNA. Treatment of hepatocytes with the LXR ligand (TO-901317) at $10 \mu \mathrm{M}$ for $16 \mathrm{~h}$ showed tremendous enhancement of SREBP-1 mRNA. However, the effect of TO901317 on the GK was similar to the effect of insulin after $1 \mathrm{~h}$. LXR ligand stimulated hepatocytes did not show any additive effect on the transcription of both genes. Transfection of 
hepatocytes with SREBP-1 showed a similar effect as insulin on GK mRNA expression (Fig 18). These results could explain that during a high carbohydrate diet, insulin induces GK gene expression as an early response to store the increased glucose as glycogen. However, long term regulation could be via insulin induced SREBP-1 since the excess glucose can then be stored as fat by activating the lipogenic pathway.

\subsection{Regulation of glucokinase promoter activity by SREBP-1a}

\subsubsection{The B site in the GK promoter is important for the SREBP-1a-mediated induction}

Previous studies showed that SREBP-1a induced the GK promoter (Roth et al., 2004a); however the molecular details were not known about the SREBP-1a-dependent regulation of the GK promoter. In the present study we have used a -1448 bp fragment of the liver specific rat GK promoter to understand its regulation by SREBP-1a. Computational analysis of -1448 bp fragment predicted three putative SREBP binding elements. DNaseI footprint analysis of the GK promoter detected seven elements A-G (in 3' to 5' direction) specifically interacting with liver enriched factors. The 3' end of the promoter contains additional footprints P1 and P2. The P1 element was shown to be involved in binding of HNF-4 (Roth et al., 2002). The element $P 2$ has been shown to be bound by USF-1, USF-2 (Iynedjian, 1998) as well as HIF-1 (Roth et al., 2004b). A deletion analysis showed that P1 and P2, although P2 contains an E-box sequence which can theoretically be bound by SREBP, are not involved in the SREBP effect (Roth et al., 2004a). However, the importance of the footprints A-G in SREBP-1a mediated regulation was not studied yet. The present study showed that a serial deletion of the GK promoter up to -781 which excludes the footprints from $C$ to $G$ did not affect the SREBP-1a-mediated induction. In line, sequence analysis of the Footprint $C$ of the GK promoter predicted a typical E-box (CANNTG) which could be bound by SREBP1. Mutation of this E-box element did not abolish the SREBP-1a-mediated GK promoter activity. Interestingly, deletion of the GK promoter further to -748 which omits the footprint $B$ abolished the SREBP-1a-mediated activation even though three other putative SREBP binding sites not located in footprinted areas remained intact. The deletion studies showed for the first time that footprint B appears to be important for the SREBP1a mediated regulation of the GK promoter. Since the B site can be divided in two parts we aimed next to understand the contribution of each part of the B site for the SREBP-1-dependent induction. Therefore we generated the constructs GK-1448mFPB1 and GK-1448mFPB2, respectively. Site-directed mutation of the footprint B1 completely abolished the GK promoter 
activity by SREBP-1a in primary hepatocytes and HepG2 cells. Interestingly, sequence analysis of the footprint B1 and B2 revealed that this site does not match to any known SREBP binding site. Thus, it could be the so far unknown liver enriched factor which could be important for the SREBP-1-mediated induction of the GK promoter in the liver.

\subsubsection{The SRE2 and SRE3 elements are important for the SREBP-1a-mediated induction of the GK promoter}

In the current investigation, the wild type GK promoter (GK-1448) was induced when cotransfected with SREBP-1a in both primary rat hepatocytes and HepG2 cells. Site-directed mutagenesis of the computer predicted putative SREBP binding elements SRE2 and SRE3, revealed that SREBP-1a-dependent induction was unchanged when the SRE3 element was mutated whereas loss of SRE2 abolished induction in HepG2 cells (Fig 14). Transient transfection assays showed that both SRE2 and SRE3 were necessary for the transactivation of GK promoter by SREBP-1a in primary hepatocytes. The differential regulation of GK promoter by SREBP-1 in different cell types could be utilization of SRE2 and SRE3 elements in a different manner or it could be some other factors involved. Previous investigations suggested that the binding of SREBP-1 to SRE2 or SRE3 was not mutually exclusive since SRE2 showed stronger affinity to SREBP-1 than SRE3, in contrast transient transfection in Alexander cells showed that both SRE2 and SRE3 were necessary for the transactivation of GK by SREBP-1c. In parallel, Chip analysis of high carbohydrate diet induced SREBP-1 showed binding with the liver GK promoter (Kim et al., 2004). With the current knowledge it is difficult to explain the relationship between SRE2 and SRE3 by insulin-dependent SREBP-1-mediated activation of liver GK.

\subsubsection{Co-operativity of HNF-4 and SREBP-1a is important for the regulation of the GK promoter}

The hepatocyte nuclear factor-4 $\alpha$ (HNF-4) and SREBP-1 have been shown to be important for many genes involved in glucose metabolism (Yamamoto et al., 2004). Previous studies showed that HIF-1 $\alpha$, HNF-4 and p300 function co-operatively to enhance the activity of the liver-specific GK promoter (Roth et al., 2004a). The present investigation showed that mutations in the HNF-4 binding site of the GK promoter attenuated the SREBP-1a-dependent activation of the promoter in primary rat hepatocytes (Fig 16) whereas mutations in the HRE site were unable to abolish the SREBP-1a effect. This was at the first glance unexpected but a possible explanation could be that all these factors are co-operatively involved in the regulation of GK expression. This 
appears to be possible since insulin does not only activate SREBP expression but also phosphorylation of the coactivator p300 via PKB signaling. This coactivatior was shown to interact with both SREBP (Giandomenico et al., 2003) and HNF4 (Roth et al., 2004a). Thus, mutation of the HNF4 site may then abolish the interaction of HNF4 and p300 together with SREBP. However, under hypoxic conditions the SREBP may be replaced by HIF-1. This would allow the cell to have a redundant system which can adapt to different environmental conditions.

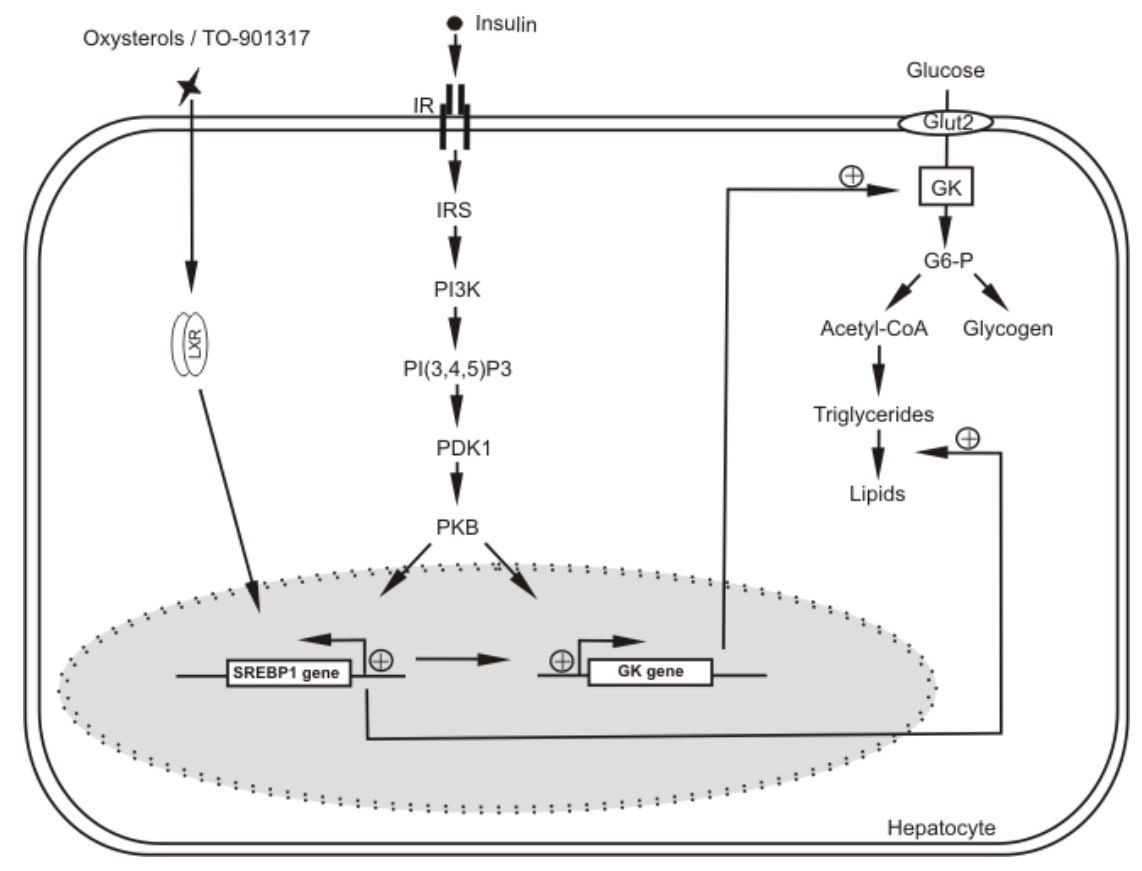

Figure 29. Insulin-dependent SREBP-1a-mediated regulation of glucokinase gene expression Insulin activates both SREBP-1 and glucokinase gene expression via the PI3K/PKB pathway. GK gene expression could be activated by both insulin signaling as well as by insulin activated SREBP-1. The nuclear receptors $\mathrm{LXR} \alpha$ are known to be activated by oxysterols or synthetic nonsteroidal LXR agonist TO-901317. Thus activated LXR $\alpha$ induce the SREBP-1 gene expression which is involved in the regulation of several genes involved in the lipogenesis besides glucose metabolism. When hepatocytes are stimulated with the insulin, SREBP-1 gene expression becomes activated which in turn activate GK gene expression in an insulin independent manner. Thus activated GK would convert glucose to glucose 6-phosphate which could augment the glycogen levels and in the presence of excess glucose, it could be shuttled to the lipogenic pathway.

Insulin receptor substrates (IRS); phosphoinositide 3-kinase (PI3K); phosphatidylinositol phosphatedependent kinase-1 (PDK-1); protein kinase B (PKB); Glucose transporter 2 (Glut2); Liver x receptor (LXR); Glucose 6-phosphate (G6-P); Glucokinase (GK); 


\subsection{Down regulation of glucokinase gene expression by the transcription factor FoxO1}

In this investigation, we found that the GK gene expression was suppressed by FoxO1. This appeared to be due to the direct action of FoxO1 alone and via its interaction with HNF-4 $\alpha$ in both primary rat hepatocytes as well as in HepG2 cells. To our knowledge these studies provide first time evidence that liver specific GK gene expression is down regulated by FoxO1 by these two mechanisms.

It is well known that liver-specific GK promoter activity can be induced by HNF-4 $\alpha$ (Roth et al., 2004a). FoxO1 is a major transcription factor involved in the activation of genes involved in the production of glucose. Recent reports on FoxO1 showed that they are involved in the down regulation of genes regulating the induction of glucose output (Zhang et al., 2006). In this study we have shown that the wild type GK promoter was significantly suppressed when cotransfected with FoxO1. In addition, when FoxO was cotransfected with HNF-4, the HNF-4 $\alpha$-mediated induction of the GK promoter was also brought down by FoxO1. Mutations in the putative FoxO1 binding site FBEb led to the loss of FoxO1 influenced repression; however, mutation in the FBEa did not affect the suppression by FoxO1. Interestingly, mutations in both FBEa and FBEb did not abolish the reduction of the HNF-4-induced activity of the GK promoter (Fig 19). However, the FoxO1 modulated repression of the GK promoter was lost when the HNF-4 binding element was mutated. Since FoxO1 is able to reduce the HNF-4 induction on GK promoter, we expected that FoxO1 might physically interact with HNF4 and influence the GK promoter activity. To support the idea, we have shown the in vivo interaction of both HNF-4 and FoxO1 by protein pull down assays (Fig 23). This clearly explains that FoxO1 interacts with $\mathrm{HNF}-4 \alpha$ and down regulates the GK gene expression in a HNF-4 dependent manner. These data indicate that the FoxO1 effects on GK gene expression could be exerted via binding at the FoxO1 binding elements and via physical interaction with HNF-4.

\subsubsection{Expression of glucokinase during fasting and refeeding}

The hormone insulin will be secreted by $\beta$-cells of the pancreas when the blood glucose levels are high in order to maintain the glucose homeostasis and further metabolism of glucose. Insulin regulates several genes involved in glucose metabolism in a positive and negative manner. Mainly the genes involved in glucose catabolism are up-regulated and the genes involved in glucose generation are down regulated by insulin via PI3K/PKB. In contrast, glucagon which is 
secreted by pancreatic $\alpha$-cells during fasting stages acts antagonistic to insulin. Glucagon is known to up-regulate the genes involved in glucose production and reduces the expression of genes involved in glucose utilization. Any discrepancies in this balance lead to excess blood glucose levels. This severe metabolic malfunction is known as Diabetes. The first step in glucose catabolism is phosphorylation of glucose to glucose 6-phosphate which is done by glucokinase in the liver. Glucokinase mRNA was induced by several folds when hepatocytes were treated with insulin and suppressed by glucagon and CAMP which is a second messenger of glucagon signaling (Fig $21 \mathrm{~A}$ ). In contrast, the expression of the gluconeogenic gene PEPCK was enhanced by glucagon and CAMP whereas insulin completely abolished it (Fig 21 A). Many investigations on insulin-mediated GK gene regulation suggested that the GK gene is induced via PI3K/PKB. However, the molecular details of the GK suppression during fasting were limited. When rats were fasted for $48 \mathrm{~h}$ the levels of GK protein were completely undetectable, whereas $48 \mathrm{~h}$ fasted rats which were refed for $2 \mathrm{~h}$ displayed an induction of the GK protein levels. FoxO factors are known to respond to the stimuli of several nutritional and hormonal factors and it was shown that fasting and refeeding significantly regulate the gene expression of FoxO factors. Imposed fasting for $48 \mathrm{~h}$ especially induced FoxO1 to significant levels and refeeding for $3 \mathrm{~h}$ inhibited the FoxO1 expression to control levels (Imae et al., 2003). Thus regulated FoxO transcription factors act on target genes required to maintain the nutritional homeostasis As we have observed that GK protein levels were undetectable during $48 \mathrm{~h}$ fasting this could be due to the effect of up-regulated FoxO1 (Fig 21 B).

In response to insulin FoxO proteins are known to be phosphorylated by PKB leading to their nuclear exclusion. The GK-1448 wild type promoter was induced by $100 \mathrm{nM}$ insulin and suppressed by FoxO1 in hepatocytes. The suppression by FoxO1 was completely abolished when FoxO1 cotransfected cells were stimulated with $100 \mathrm{nM}$ insulin (Fig 24). During fasting stages glucagon activated FoxO1 could suppress the glycolytic genes such as GK and during refeeding insulin signaling leads to nuclear exclusion of FoxO1, which in turn would reactivate the GK gene transcription.

\subsubsection{Effects of resveratrol on glucokinase gene expression}

Resveratrol is an active ingredient of a medicinal plant known as Polygonum capsidatum and it has been demonstrated to activate $\mathrm{NAD}^{+}$-dependent SIRT1 deacetylases which activate FoxO proteins by deacetylation (Frescas et al., 2005). In this investigation we have shown that GK wild 
type promoter (GK-1448) activity was reduced when hepatocytes were stimulated with $50 \mu \mathrm{M}$ resveratrol. By contrast, hepatocytes transfected with GK promoter constructs carrying mutations in the putative FoxO1 binding sites or the HNF-4 binding site, failed to show the FoxO1 effect when stimulated with resveratrol. This data suggest that FoxO1 is activated by resveratrol and acts on the GK promoter.

Resveratrol was shown to possess anti-insulin effects on both glycolytic GK and gluconeogenic PEPCK expression. Indeed, the present study shows that increasing concentrations of resveratrol down regulate the GK gene expression in a dose dependent manner. Insulin effects were almost unchanged when challenged with $10 \mu \mathrm{M}$ resveratrol, whereas resveratrol at $50 \mu \mathrm{M}$ was able to block the insulin effects and to keep the GK gene expression low while PEPCK mRNA levels were reinduced (Fig $25 \mathrm{~A}$ ). This was also visible at the level of the GK protein.

To elucidate the repression by FoxO1 and SIRT1 on GK gene expression, hepatocytes were transfected with the FoxO1 and SIRT1 expression vectors. FoxO1 suppressed the GK mRNA and induced PEPCK mRNA levels significantly. Similar effects were observed on GK and PEPCK mRNA levels in the SIRT1 transfected hepatocytes. This explains that FoxO1 might be the downstream target of SIRT1 and its transcriptional activity would be induced by deacetylation (Fig $26 \mathrm{~A}$ ).

\subsubsection{Deacetylation of FoxO1 by resveratrol}

The FoxO1 protein was shown to be acetylated by the transcriptional coactivator cAMPresponse element-binding protein (CBP) and p300 which leads to the transcriptional attenuation. The three major acetylation residues in the FoxO1 include K242, K245 and K262 and are shown to be deacetylated by silent information regulator (Sir2) which enhanced the FoxO1-mediated transcription (Daitoku et al., 2004). Acetylation of FoxO1 at the three positively charged lysines in the FoxO1 DNA-binding domain diminishes the ability to interact with a target gene DNA and it promotes the phosphorylation of FoxO1 which excludes FoxO1 from nucleus (Matsuzaki et al., 2005). Resveratrol was shown to bind SIRT1, the mammalian ortholog of Sir2; causing the conformational changes in the enzyme which permit binding to other proteins which are to be deacetylated (Borra et al., 2005). In this investigation we have shown that p300 acetylated FoxO1 at Lys 242 and Lys 245 whereas resveratrol deacetylated it (Fig 27). This supports our previous results showing that down regulation of GK promoter by resveratrol may be due to FoxO1 (Fig 22). Based on this, we propose that resveratrol activated SIRT1 deacetylates FoxO1 
which in turn leads to the repression of GK gene expression. Glucose and pyruvate levels are known to fluctuate during fasting, which regulate the ratio between $N A D^{+} / N A D H$. Previous investigations identified that increasing concentrations of pyruvate markedly increased the SIRT1 protein levels in the liver and these changes in protein levels were shown to be regulated at the post-translational levels as SIRT1 mRNA levels were unchanged (Rodgers et al., 2005). In addition, this supports that SIRT1 plays a major role in the activation of FoxO1 via NAD+dependent deacetylation in response to the nutritional status.

\subsubsection{Modulation of glucokinase enzyme activity by resveratrol and FoxO1}

The present study showed that treatment of hepatocytes with insulin induced the glucokinase enzyme activity. Increasing concentrations of resveratrol markedly inhibited the glucokinase enzyme activity. When hepatocytes stimulated with insulin were challenged with resveratrol, resveratrol blocked the insulin-mediated induction of glucokinase enzyme activity. The treatments with insulin or resveratrol did not alter the sigmoidal kinetics of the glucokinase enzyme and followed Michaelis-Menten curves. Linearization of the Michaelis-Menten curves gave Lineweaver-Burk plots which predicted a Km of glucokinase of 10-15 mM (Fig 28 A, B \& C). Similarly, FoxO1 transfected hepatocytes showed also a reduction in the maximal velocity of enzyme activity and did not alter the Michaelis-Menten sigmoidal curves Fig 28 D, E \& F). This shows that the enzyme by itself appears not to be activated by resveratrol or FoxO1. The reduced Vmax of the enzyme is rather due to the low amount of enzyme which was synthesized due to inhibition of GK expression by resveratrol and FoxO1. Thus, these enzymatic assays strongly support the down regulation of GK mRNA and protein by resveratrol and FoxO1.

In conclusion, for the first time we have shown that the liver-specific glucokinase gene expression is down regulated by FoxO1. During fasting stages the $\mathrm{NAD}^{+}$/ $\mathrm{NADH}$ ration will be high which will activate the $\mathrm{NAD}^{+}$-dependent SIRT1 which in turn binds and deacetylates FoxO1 transcription factors. This leads to the activation of FoxO1 proteins which will be translocated into the nucleus and act on its target genes like GK and PEPCK. Thus, in addition to several effects of FoxO1 on cell proliferation and apoptosis they are also important for appropriate regulation of glucose metabolism. 


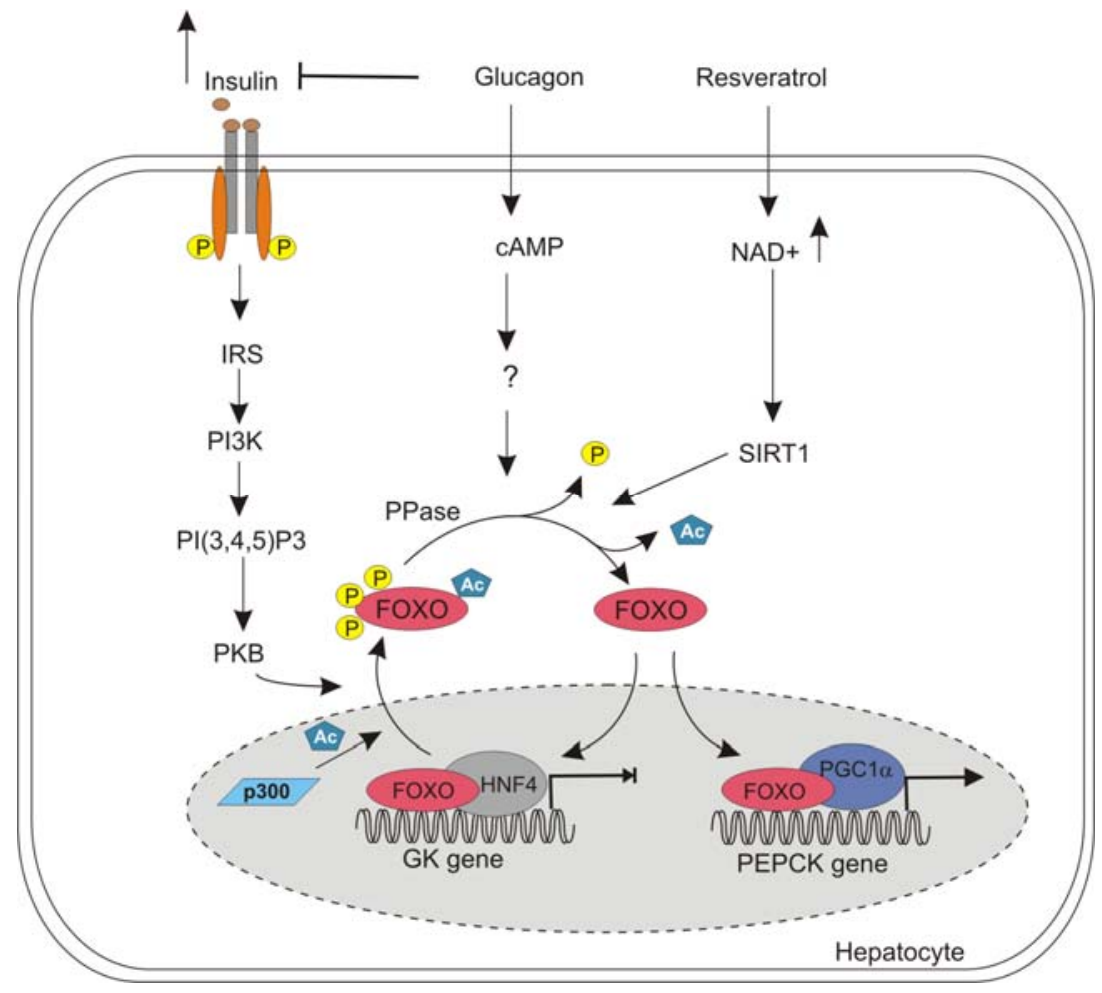

Figure 30. Regulation of glucokinase and PEPCK gene expression by FoxO1 FoxO1 transcription factors are predominantly nuclear and are presumed to be active. Besides acetylation of FoxO1 by a transcriptional coactivator $\mathrm{p300}$, insulin via PKB mediates phosphorylation of FoxOs on three conserved residues in the nucleus, which initiates their export to the cytoplasm. This would lead to the derepression of GK gene expression. Treatment with resveratrol increases NAD ${ }^{+}$-dependent SIRT1 deacetylases, which are known to interact and deacetylate cytoplasmic inactive acetylated FoxO1 into active. Activation of FoxO1 by glucagon via cAMP leads to nuclear import and activates the PEPCK gene expression and represses the GK gene expression.

Insulin receptor substrates (IRS); phosphoinositide 3-kinase (PI3K); protein kinase B (PKB); phosphatidylinositol 3,4,5-triphosphate (PI[3,4,5]P3); pyrophosphatase (PPase); cyclic adenosine monophosphate (cAMP); Silent information regulator 1 (SIRT1); Glucokinase (GK); Phosphoenolpyruvate carboxy kinase (PEPCK). 


\section{Reference List}

Aiston,S., Trinh,K.Y., Lange,A.J., Newgard,C.B., and Agius,L. (1999). Glucose-6-phosphatase overexpression lowers glucose 6-phosphate and inhibits glycogen synthesis and glycolysis in hepatocytes without affecting glucokinase translocation. Evidence against feedback inhibition of glucokinase. J Biol Chem 274, 24559-24566.

Arden,K.C. and Biggs,W.H., III (2002). Regulation of the FoxO family of transcription factors by phosphatidylinositol-3 kinase-activated signaling. Arch. Biochem. Biophys. 403, 292-298.

Bali,D., Svetlanov,A., Lee,H.W., Fusco-DeMane,D., Leiser,M., Li,B., Barzilai,N., Surana,M., Hou,H., Fleischer,N., and . (1995). Animal model for maturity-onset diabetes of the young generated by disruption of the mouse glucokinase gene. J Biol Chem 270, 21464-21467.

Baltrusch,S., Lenzen,S., Okar,D.A., Lange,A.J., and Tiedge,M. (2001). Characterization of glucokinase-binding protein epitopes by a phage-displayed peptide library. Identification of 6phosphofructo-2-kinase/fructose-2,6-bisphosphatase as a novel interaction partner. J Biol Chem 276, 43915-43923.

Bogan,A.A., Dallas-Yang,Q., Ruse,M.D.J., Maeda,Y., Jiang,G., Nepomuceno,L., Scanlan,T.S., Cohen,F.E., and Sladek,F.M. (2000). Analysis of protein dimerization and ligand binding of orphan receptor HNF4alpha. J Mol Biol 302, 831-851.

Borra,M.T., Smith,B.C., and Denu,J.M. (2005). Mechanism of human SIRT1 activation by resveratrol. J. Biol. Chem. 280, 17187-17195.

Brunet,A., Park,J., Tran,H., Hu,L.S., Hemmings,B.A., and Greenberg,M.E. (2001). Protein kinase SGK mediates survival signals by phosphorylating the forkhead transcription factor FKHRL1 (FOXO3a). Mol. Cell Biol. 21, 952-965.

Brunet,A., Sweeney,L.B., Sturgill,J.F., Chua,K.F., Greer,P.L., Lin,Y., Tran,H., Ross,S.E., Mostoslavsky,R., Cohen,H.Y., Hu,L.S., Cheng,H.L., Jedrychowski,M.P., Gygi,S.P., Sinclair,D.A., Alt,F.W., and Greenberg,M.E. (2004). Stress-dependent regulation of FOXO transcription factors by the SIRT1 deacetylase. Science 303, 2011-2015.

Chen,C. and Okayama,H. (1987). High-efficiency transformation of mammalian cells by plasmid DNA. Mol. Cell Biol. 7, 2745-2752. 
Chen,C.A. and Okayama,H. (1988). Calcium phosphate-mediated gene transfer: a highly efficient transfection system for stably transforming cells with plasmid DNA. Biotechniques 6 , $632-638$.

Chomczynski,P. and Sacchi,N. (1987). Single-step method of RNA isolation by acid guanidinium thiocyanate-phenol-chloroform extraction. Anal. Biochem. 162, 156-159.

Daitoku,H., Hatta,M., Matsuzaki,H., Aratani,S., Ohshima,T., Miyagishi,M., Nakajima,T., and Fukamizu,A. (2004). Silent information regulator 2 potentiates Foxo1-mediated transcription through its deacetylase activity. Proc. Natl. Acad. Sci. U. S. A 101, 10042-10047.

Dhe-Paganon,S., Duda,K., Iwamoto,M., Chi,Y.I., and Shoelson,S.E. (2002). Crystal structure of the HNF4 alpha ligand binding domain in complex with endogenous fatty acid ligand. J. Biol. Chem. 277, 37973-37976.

Foretz,M., Guichard,C., Ferre,P., and Foufelle,F. (1999a). Sterol regulatory element binding protein-1c is a major mediator of insulin action on the hepatic expression of glucokinase and lipogenesis-related genes. Proc. Natl. Acad. Sci. U. S. A. 96, 12737-12742.

Foretz,M., Pacot,C., Dugail,I., Lemarchand,P., Guichard,C., Le,L.X., Berthelier,L.C., Spiegelman,B., Kim,J.B., Ferre,P., and Foufelle,F. (1999b). ADD1/SREBP-1c is required in the activation of hepatic lipogenic gene expression by glucose. Mol. Cell Biol. 19, 3760-3768.

Frescas,D., Valenti,L., and Accili,D. (2005). Nuclear trapping of the forkhead transcription factor FoxO1 via Sirt-dependent deacetylation promotes expression of glucogenetic genes. J. Biol. Chem. 280, 20589-20595.

Fukuoka,M., Daitoku,H., Hatta,M., Matsuzaki,H., Umemura,S., and Fukamizu,A. (2003). Negative regulation of forkhead transcription factor AFX (Foxo4) by CBP-induced acetylation. Int. J. Mol. Med. 12, 503-508.

Garfinkel,D., Garfinkel,L., Meglasson,M.D., and Matschinsky,F.M. (1984). Computer modeling identifies glucokinase as glucose sensor of pancreatic beta-cells. Am. J Physiol 247, R527R536.

Giandomenico,V., Simonsson,M., Gronroos,E., and Ericsson,J. (2003). Coactivator-dependent acetylation stabilizes members of the SREBP family of transcription factors. Mol. Cell Biol. 23, 2587-2599. 
Gilon,P., Ravier,M.A., Jonas,J.C., and Henquin,J.C. (2002). Control mechanisms of the oscillations of insulin secretion in vitro and in vivo. Diabetes 51 Suppl 1, S144-S151.

Ginot,F., Decaux,J.F., Cognet,M., Berbar,T., Levrat,F., Kahn,A., and Weber,A. (1989). Transfection of hepatic genes into adult rat hepatocytes in primary culture and their tissuespecific expression. Eur. J. Biochem. 180, 289-294.

Graham,F.L. and van der Eb,A.J. (1973). A new technique for the assay of infectivity of human adenovirus 5 DNA. Virology 52, 456-467.

Grossbard,L. and Schimke,R.T. (1966). Multiple hexokinases of rat tissues. Purification and comparison of soluble forms. J. Biol. Chem. 241, 3546-3560.

Guo,S., Rena,G., Cichy,S., He,X., Cohen,P., and Unterman,T. (1999). Phosphorylation of serine 256 by protein kinase $B$ disrupts transactivation by FKHR and mediates effects of insulin on insulin-like growth factor-binding protein-1 promoter activity through a conserved insulin response sequence. J. Biol. Chem. 274, 17184-17192.

Hanahan,D. (1983). Studies on transformation of Escherichia coli with plasmids. J. Mol. Biol. $166,557-580$.

Hariharan,N., Farrelly,D., Hagan,D., Hillyer,D., Arbeeny,C., Sabrah,T., Treloar,A., Brown,K., Kalinowski,S., and Mookhtiar,K. (1997). Expression of human hepatic glucokinase in transgenic mice liver results in decreased glucose levels and reduced body weight. Diabetes 46, 11-16.

Hirota,K., Daitoku,H., Matsuzaki,H., Araya,N., Yamagata,K., Asada,S., Sugaya,T., and Fukamizu,A. (2003). Hepatocyte nuclear factor-4 is a novel downstream target of insulin via FKHR as a signal-regulated transcriptional inhibitor. J. Biol. Chem. 278, 13056-13060.

Imae,M., Fu,Z., Yoshida,A., Noguchi,T., and Kato,H. (2003). Nutritional and hormonal factors control the gene expression of FoxOs, the mammalian homologues of DAF-16. J. Mol. Endocrinol. 30, 253-262.

Iynedjian,P.B., Jotterand,D., Nouspikel,T., Asfari,M., and Pilot,P.R. (1989). Transcriptional induction of glucokinase gene by insulin in cultured liver cells and its repression by the glucagoncAMP system. J. Biol. Chem. 264, 21824-21829. 
Iynedjian,P.B. (1998a). Identification of upstream stimulatory factor as transcriptional activator of the liver promoter of the glucokinase gene. Biochem. J. 333, 705-712.

Iynedjian,P.B. (1998b). Identification of upstream stimulatory factor as transcriptional activator of the liver promoter of the glucokinase gene. Biochem. J 333, 705-712.

Iynedjian,P.B., Jotterand,D., Nouspikel,T., Asfari,M., and Pilot,P.R. (1989). Transcriptional induction of glucokinase gene by insulin in cultured liver cells and its repression by the glucagoncAMP system. J. Biol. Chem. 264, 21824-21829.

Iynedjian,P.B., Marie,S., Wang,H., Gjinovci,A., and Nazaryan,K. (1996). Liver-specific enhancer of the glucokinase gene. J. Biol. Chem. 271, 29113-29120.

Iynedjian,P.B., Roth,R.A., Fleischmann,M., and Gjinovci,A. (2000). Activation of protein kinase $B / c A k t$ in hepatocytes is sufficient for the induction of expression of the gene encoding glucokinase. Biochem. J 351, 621-627.

Jetton,T.L., Liang,Y., Pettepher,C.C., Zimmerman,E.C., Cox,F.G., Horvath,K., Matschinsky,F.M., and Magnuson,M.A. (1994). Analysis of upstream glucokinase promoter activity in transgenic mice and identification of glucokinase in rare neuroendocrine cells in the brain and gut. $\mathrm{J}$ Biol. Chem. 269, 3641-3654.

Kamata,K., Mitsuya,M., Nishimura,T., Eiki,J., and Nagata,Y. (2004). Structural basis for allosteric regulation of the monomeric allosteric enzyme human glucokinase. Structure. 12, 429-438.

Kim,S.Y., Kim,H.I., Kim,T.H., Im,S.S., Park,S.K., Lee,I.K., Kim,K.S., and Ahn,Y.H. (2004). SREBP-1C mediates the insulin-dependent hepatic glucokinase expression. J Biol Chem 279, 30823-30829.

Kitamura,Y.I., Kitamura,T., Kruse,J.P., Raum,J.C., Stein,R., Gu,W., and Accili,D. (2005). FoxO1 protects against pancreatic beta cell failure through NeuroD and MafA induction. Cell Metab 2, 153-163.

Kotzka,J., Lehr,S., Roth,G., Avci,H., Knebel,B., and Muller-Wieland,D. (2004). Insulin-activated Erk-mitogen-activated protein kinases phosphorylate sterol regulatory element-binding Protein-2 at serine residues 432 and 455 in vivo. J. Biol. Chem. 279, 22404-22411. 
Krones,A., Kietzmann,T., and Jungermann,K. (2000). Perivenous localization of insulin receptor protein in rat liver, and regulation of its expression by glucose and oxygen in hepatocyte cultures. Biochem. J. 348 Pt 2, 433-438.

Kuiperij,H.B., van der,H.A., Raaijmakers,J., Weijzen,S., Medema,R.H., Bos,J.L., Burgering,B.M., and Zwartkruis,F.J. (2005). Activation of FoxO transcription factors contributes to the antiproliferative effect of cAMP. Oncogene 24, 2087-2095.

Ladias,J.A., Hadzopoulou,C.M., Kardassis,D., Cardot,P., Cheng,J., Zannis,V., and Cladaras,C. (1992). Transcriptional regulation of human apolipoprotein genes ApoB, ApoCIII, and ApoAll by members of the steroid hormone receptor superfamily HNF-4, ARP-1, EAR-2, and EAR-3. J. Biol. Chem. 267, 15849-15860.

Lannoy,V.J., Decaux,J.F., Pierreux,C.E., Lemaigre,F.P., and Rousseau,G.G. (2002). Liver glucokinase gene expression is controlled by the onecut transcription factor hepatocyte nuclear factor-6. Diabetologia 45, 1136-1141.

Lenzen,S., Tiedge,M., and Panten,U. (1987). Glucokinase in pancreatic B-cells and its inhibition by alloxan. Acta Endocrinol. (Copenh) 115, 21-29.

Li,J., Ning,G., and Duncan,S.A. (2000). Mammalian hepatocyte differentiation requires the transcription factor HNF-4alpha. Genes Dev. 14, 464-474.

Liang,Y., Jetton,T.L., Zimmerman,E.C., Najafi,H., Matschinsky,F.M., and Magnuson,M.A. (1991). Effects of alternate RNA splicing on glucokinase isoform activities in the pancreatic islet, liver, and pituitary. J. Biol. Chem. 266, 6999-7007.

Matschinsky,F.M., Kauffman,F.C., and Ellerman,J.E. (1968). Effect of hyperglycemia on the hexose monophosphate shunt in islets of Langerhans. Diabetes 17, 475-480.

Matsuzaka,T., Shimano,H., Yahagi,N., Amemiya-Kudo,M., Okazaki,H., Tamura,Y., lizuka,Y., Ohashi,K., Tomita,S., Sekiya,M., Hasty,A., Nakagawa,Y., Sone,H., Toyoshima,H., Ishibashi,S., Osuga,J., and Yamada,N. (2004). Insulin-independent induction of sterol regulatory elementbinding protein-1c expression in the livers of streptozotocin-treated mice. Diabetes 53, 560-569.

Matsuzaki,H., Daitoku,H., Hatta,M., Aoyama,H., Yoshimochi,K., and Fukamizu,A. (2005). Acetylation of Foxo1 alters its DNA-binding ability and sensitivity to phosphorylation. Proc. Natl. Acad. Sci. U. S. A 102, 11278-11283. 
Mullis,K.B. and Faloona,F.A. (1987). Specific synthesis of DNA in vitro via a polymerasecatalyzed chain reaction. Methods Enzymol. 155, 335-350.

O'Doherty,R.M., Lehman,D.L., Seoane,J., Gomez-Foix,A.M., Guinovart,J.J., and Newgard,C.B. (1996). Differential metabolic effects of adenovirus-mediated glucokinase and hexokinase I overexpression in rat primary hepatocytes. J Biol Chem 271, 20524-20530.

Ogg,S., Paradis,S., Gottlieb,S., Patterson,G.I., Lee,L., Tissenbaum,H.A., and Ruvkun,G. (1997). The Fork head transcription factor DAF-16 transduces insulin-like metabolic and longevity signals in C. elegans. Nature 389, 994-999.

Parker,B.A. and Stark,G.R. (1979). Regulation of simian virus 40 transcription: sensitive analysis of the RNA species present early in infections by virus or viral DNA. J. Virol. 31, 360-369.

Pasco,D.S. and Fagan,J.B. (1989). Efficient DNA-mediated gene transfer into primary cultures of adult rat hepatocytes. DNA 8, 535-541.

Parraga,A., Bellsolell,L., Ferre-D'Amare,A.R., and Burley,S.K. (1998). Co-crystal structure of sterol regulatory element binding protein $1 \mathrm{a}$ at 2.3 A resolution. Structure. 6, 661-672.

Postic,C., Niswender,K.D., Decaux,J.F., Parsa,R., Shelton,K.D., Gouhot,B., Pettepher,C.C., Granner,D.K., Girard,J., and Magnuson,M.A. (1995). Cloning and characterization of the mouse glucokinase gene locus and identification of distal liver-specific DNase I hypersensitive sites. Genomics 29, 740-750.

Rippe,R.A., Brenner,D.A., and Leffert,H.L. (1990). DNA-mediated gene transfer into adult rat hepatocytes in primary culture. Mol. Cell Biol. 10, 689-695.

Rodgers,J.T., Lerin,C., Haas,W., Gygi,S.P., Spiegelman,B.M., and Puigserver,P. (2005). Nutrient control of glucose homeostasis through a complex of PGC-1alpha and SIRT1. Nature 434, 113-118.

Roth,U., Curth,K., Unterman,T.G., and Kietzmann,T. (2004a). The transcription factors HIF-1 and HNF-4 and the coactivator p300 are involved in insulin-regulated glucokinase gene expression via the phosphatidylinositol 3-kinase/protein kinase B pathway. J Biol Chem 279, 2623-2631.

Roth,U., Jungermann,K., and Kietzmann,T. (2002). Activation of glucokinase gene expression by hepatic nuclear factor 4alpha in primary hepatocytes. Biochem. J 365, 223-228. 
Roth,U., Jungermann,K., and Kietzmann,T. (2004b). Modulation of glucokinase expression by hypoxia-inducible factor 1 and upstream stimulatory factor 2 in primary rat hepatocytes. Biol Chem 385, 239-247.

Sanger,F., Nicklen,S., and Coulson,A.R. (1992). DNA sequencing with chain-terminating inhibitors. 1977. Biotechnology 24, 104-108.

Shankar,S., Singh,G., and Srivastava,R.K. (2007). Chemoprevention by resveratrol: molecular mechanisms and therapeutic potential. Front Biosci. 12, 4839-4854.

Shiota,C., Coffey,J., Grimsby,J., Grippo,J.F., and Magnuson,M.A. (1999). Nuclear import of hepatic glucokinase depends upon glucokinase regulatory protein, whereas export is due to a nuclear export signal sequence in glucokinase. J. Biol. Chem. 274, 37125-37130.

Unterman,T.G., Fareeduddin,A., Harris,M.A., Goswami,R.G., Porcella,A., Costa,R.H., and Lacson,R.G. (1994). Hepatocyte nuclear factor-3 (HNF-3) binds to the insulin response sequence in the IGF binding protein-1 (IGFBP-1) promoter and enhances promoter function. Biochem. Biophys. Res. Commun. 203, 1835-1841.

Vandercammen,A. and Van,S.E. (1990). The mechanism by which rat liver glucokinase is inhibited by the regulatory protein. Eur. J. Biochem. 191, 483-489.

Veiga-da-Cunha,M. and van Schaftingen,E. (2002). Identification of fructose 6-phosphate- and fructose 1-phosphate-binding residues in the regulatory protein of glucokinase. J Biol Chem 277 , 8466-8473.

Yamamoto,T., Shimano,H., Nakagawa,Y., Ide,T., Yahagi,N., Matsuzaka,T., Nakakuki,M., Takahashi,A., Suzuki,H., Sone,H., Toyoshima,H., Sato,R., and Yamada,N. (2004). SREBP-1 interacts with hepatocyte nuclear factor-4 alpha and interferes with PGC-1 recruitment to suppress hepatic gluconeogenic genes. J. Biol. Chem. 279, 12027-12035.

Zhang,W., Patil,S., Chauhan,B., Guo,S., Powell,D.R., Le,J., Klotsas,A., Matika,R., Xiao,X., Franks,R., Heidenreich,K.A., Sajan,M.P., Farese,R.V., Stolz,D.B., Tso,P., Koo,S.H., Montminy,M., and Unterman,T.G. (2006). FoxO1 regulates multiple metabolic pathways in the liver: effects on gluconeogenic, glycolytic, and lipogenic gene expression. J. Biol. Chem. 281, 10105-10117. 


\section{Acknowledgements}

I would like to take this opportunity to express my deepest sense of gratitude and admiration to my supervisor, Prof. Dr. Thomas Kietzmann. I have been fortunate to have been able to work with him and have learnt a lot from him. Above all, I value his thinking; his sharp sense of observation and sound judgment, in scientific as well as non-scientific matters. I am also thankful to him for giving me the respect and freedom to shape the work that I have done.

I would like to thank my co-supervisor PD.Dr. J.-G. Scharf for his constant encouragement and all his support during these years.

Heartfelt thanks to Prof. Dr. G. Burckhardt, the speaker of GRK 335 for invaluable support and maintaining an open and scientifically alive environment. It has been a pleasure to be a part of this $\mathrm{PhD}$ program.

I would like to thank Frau Fischer the secretary of the GRK 335 and all the instructors of the Postgraduate program (GRK 335), for all the knowledge they have imparted during the first two years of my stay here. I have learnt much about many diverse fields during this course.

The people I work with know me, just as I know them, as few others do, for all our virtues and importantly, our faults. I am therefore extremely glad to thank all my lab members, past and present, for making the lab a pleasant and friendly place to be in. Among the erstwhile members, I would like to especially thank Dr.Tolja who taught me how to isolate the rat primary hepatocytes which is bread and butter for all my work and special regards to my Poland friend Dr.Jacek. I may not forget the priceless time with Dr.Elitsa who is like suitable buffer to the lab and helped me in several aspects of my science. I am grateful to know Dr. Dani who is specialist in several aspects of science and for providing me gaseous vitamins when I don't have. It was interesting to have Doreen in our lab and arranged all the consumables for my work in time.

Among the recent set of people, I would like to thank Mirza for his cool attitude and helping me for arranging the $\mathrm{N}_{2}$ bottles. I would like to give my best wishes to Zukaa and enthusiastic diploma students Tina, Jenny, Jule, and Julja, they are like Charles angels.

I feel most lucky to have many of my old and new friends from Germany who made my life most memorable and colorful in Germany.

I wish to thank the professors R. Hardeland and D. Doenecke for being my thesis referee and co-referee.

I am grateful to the office staff for their efficient and timely help whenever required.

I would like to dedicate this work to my mother Sri. Janaki Devi and my sister Seshu kumari, without them I may not reach to this stage today. None of this would have been possible without their unconditional love and support. 


\section{Publications}

1. Kietzmann,T. and Ganjam,G.K. (2005). Glucokinase: old enzyme, new target. Expert Opinion on Therapeutic Patents 15, 705-713.

2. Bahadur,U., Ganjam,G.K., Vasudevan,N., and Kondaiah,P. (2005). Estrogen regulation of chicken riboflavin carrier protein gene is mediated by ERE half sites without direct binding of estrogen receptor. Mol. Cell Endocrinol. 231, 1-11.

\section{Conferences}

\begin{tabular}{ccccc}
\hline Conference & Organization & Location & Date & Contribution \\
\hline $\begin{array}{c}\text { Cell Signalling } \\
\text { world }\end{array}$ & $\begin{array}{c}\text { Receherches } \\
\text { Scientifiques } \\
\text { Luxembourg } \\
(\mathrm{RSL})\end{array}$ & Luxembourg & $\begin{array}{c}\text { January } \\
25-28,2006\end{array}$ & - \\
\hline GASL & $\begin{array}{c}\text { German } \\
\text { Association for } \\
\text { the Study of the } \\
\text { Liver }\end{array}$ & Goettingen & January & Poster \\
& & & $26-27,2007$ & presentation \\
\hline
\end{tabular}




\section{Biography}

Name:

Date of birth:

Place of birth:

Nationality:

$1993-1994:$

$1994-1996:$

$1997-2000$ :

$2000-2002:$

$2002-2004:$
Goutham Kumar Ganjam

12.02.1979

Uppugundur, Andhra Pradesh (A.P), India

Indian

Board of Secondary Education, Z. P. High School, Uppugundur, A.P, India

Board of Intermediate Education (Science stream), Ongole, A.P, India

Bachelor of Science (Botany, Genetics, Chemistry), Nagarjuna University,

Guntur, A.P, India

Master of Science (Life Science), Devi Ahilya Vishwavidyalaya, Indore, Madhya Pradesh, India

M.Sc Dissertation: "Isolation of TGF- $\beta 3$ isoform cDNA from Xenopous leavis by RT-PCR strategy". Molecular Reproduction, Development and Genetics department, Indian Institute of Science, Bangalore, India.

Junior Research Fellow, Molecular Reproduction, Development and Genetics department, Indian Institute of Science, Bangalore, India.

Research work: "Role of Estrogen Response Element Half Sites in Estrogen mediated Gene Regulation; Insights from Chicken Riboflavin Carrier Protein Promoter Characterization"

April 2004-Sep 2007: PhD at the DFG-funded Graduate College 335, "Clinical, Cellular and Molecular biology of the internal organs" Georg-August-University, Goettingen, Germany. Postgraduate student Thesis title: "Regulation of rat liver glucokinase gene expression by sterol regulatory element binding protein-1a and forkhead box class 01 transcription factors". 